\title{
Isolation and Structural Elucidation of \\ Secondary Metabolites from New Zealand \\ Marine Sponge Aaptos confertus
}

by

Charlotte Josephine Page

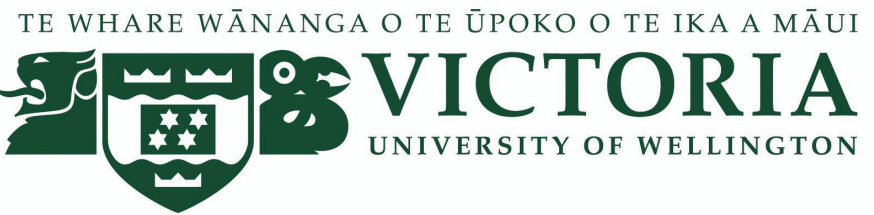

A thesis

submitted to the Victoria University of Wellington

in partial fulfilment of the

requirements for the degree of

Master of Drug Discovery and Development

Victoria University of Wellington

2017 


\section{Abstract}

This study reports on the spectroscopy-guided isolation and structural elucidation of secondary metabolites from the New Zealand marine sponge Aaptos confertus. An extraction of the sponge material, followed by several purification steps, led to the isolation of potential new compounds CJP02_20A, CJP02_20C and CJP02_04CB, a known 2,5-diketopiperzine cyclo(L-Phe-L-Pro), and a previously reported 3-((13-methylhexadecyl)oxy)propane-1,2diol. Corrections to the ${ }^{1} \mathrm{H}$ NMR data reported for 3-((13-methylhexadecyl)oxy)propane1,2-diol were also recorded.

The relationship between the oceanic climate where a marine organism habituates and its production of secondary metabolites is discussed. The isolation of a diverse range of compounds, either novel or new to the genus, suggests that organisms originating in temperate climates are similar in value to those from tropical climates, where higher rates of predation (and therefore, selective pressure) are thought to produce superior diversity in their secondary metabolic distribution. In addition to the new compounds isolated, the diketopiperazine described is the first reported molecule of that class from the genus Aaptos.

The significance of the isolated compounds is discussed, in the context of drug discovery and development. The potential of the branched-chain mono-glycerol ether 3-((13methylhexadecyl)oxy)propane-1,2-diol as a lipid biomarker for the genus Aaptos was examined, as this compound has only been reported from species of that genera. In addition, it's potential as an immunomodulatory drug is discussed, including the significance of the ether linkage in contrast to the more common ester linkage. The isolation of the 2,5diketopiperazine cyclo(L-Phe-L-Pro) new to the genus was shown to support the potential in diversity of climate and geographical distribution. This class of molecule is generated through the shikimate biosynthetic pathway; a metabolic route used by bacteria, fungi and algae. A proposed symbiotic relationship between the sponge Aaptos confertus and a proximal bacteria, fungi or algae exemplifies the value of New Zealand's diverse and unique marine organisms. 
<smiles>O=C1N[C@H](Cc2ccccc2)C(=O)N2CCC[C@H]12</smiles>

(42)<smiles>CCCC(C)CCCCCCCCCCCCOCC(O)CO</smiles>

(43) 


\section{Acknowledgments}

Firstly, I would like to thank my supervisor Dr. Rob Keyzers for his support, guidance, wisdom and perpetual enthusiasm throughout the past year. You have made this a truly enjoyable and rewarding experience, for which I will be forever thankful. I feel extremely privileged to have been part of your research group. Thank you for being a continuous positive force, no matter how negative the situation was. Each conversation with you continued to raise my confidence and lift my spirits.

I wish to thank Assoc. Prof. Peter Northcote. Your awe-inspiring knowledge has been an inspiration and your humour a delight. Thank you for sharing your ideas and providing enjoyable and exciting conversations about NMR data; I never imagined I could feel such passion for natural products chemistry.

My thesis would not be complete without the assistance of Dr. Simon Hinkley. Thank you immensely for running my samples when our NMR was down. The generosity you have shown will always be appreciated.

My experience would be nowhere near as fulfilling without the assistance of my fellow lab mates. Thank you to Sarah Andreassend and Joe Bracegirdle for teaching me how to use our instruments, and showing me existing protocols. Your patience and willingness to help has been much appreciated. In addition to your technical help, I wish to thank you for your company. I feel privileged to have worked with such great people who have shown such admirable work ethic.

To our extended research group; Helen Woolner, Taitusi Taufa, Sa Weon Hong, Chloe Harland, Naomi Lagarde, Rose McLellan, Wem Turupadang and Nurul Noh. Thank you for your company and input. Particular thanks to Helen; your guidance and help with the mass spectrometer has been greatly appreciated. I also wish to extend my thanks to Ethan Woolly, Ashton Asbury and Sami Aljohani who have been present in the lab throughout various time points in the past year. Thank you also to Jan Vorster for your technical help with NMR and MS, and Teresa Gen for welcoming us into your lab when we were without.

Finally, I owe special thanks to my friends and family. Firstly to my parents Jacqui and Howard Page. Your love and support have been paramount to my wellbeing and success. Thank you Mum for all the beautiful cooked dinners when I have visited home, and always looking out for me. Thank you Dad for your reliability and never hesitating to offer help when needed. Thank you to Lindsay Morris, Rosario Delgado Oro Ojeda and Karina Clavijo Saldias for being wonderful friends and flatmates. You have helped keep me sane over the past year, and I consider myself extremely lucky to be in your company. 


\title{
Glossary
}

\author{
Abbreviation Definition \\ $\delta \quad$ Chemical shift (ppm). \\ ${ }^{1}$ H NMR Proton nuclear magnetic resonance. \\ ${ }^{13}$ C NMR Carbon nuclear magnetic resonance. \\ Ac Acetyl $\left(\mathrm{CH}_{3} \mathrm{C}(\mathrm{O})-\right)$. \\ ADC Antibody Drug Conjugate. \\ ADMET Absorption, Distribution, Metabolism, Excretion, and Toxicity. \\ BCE Before Christian Era. \\ br broad. \\ $\mathbf{C}_{\mathbf{1 8}} \quad$ Octadecyl derived silica gel. \\ $\mathrm{CD}_{3} \mathrm{OD} \quad$ Deuterated methanol. \\ $\mathrm{CDCl}_{3} \quad$ Deuterated chloroform. \\ cDNA Complimentary DNA. \\ CDP CycloDiPeptide Synthase. \\ CE Current Era. \\ CGMP Current Good Manufacturing Practice. \\ $\mathbf{C H}_{2} \mathbf{C l}_{2} \quad$ Dichloromethane. \\ COSY COrrelation SpectroscopY $\left({ }^{1} \mathrm{H}\right.$ to ${ }^{1} \mathrm{H}$ correlations $)$. \\ d Doublet. \\ DBE Double Bond Equivelant. \\ dd Doublet of doublets. \\ DIOL 2,3-Dihydroxy-1-propoxypropyl derivatised silica gel. \\ DKP Diketopiperazine. \\ DMSO Dimethyl sulfoxide. \\ DNA Deoxyribonucleic acid. \\ EMA European Medicines Agency. \\ ERI Eisai Research Institute. \\ EtOAc Ethyl acetate. \\ EU European Union. \\ FDA Food and Drug Administration. \\ GEL Glycerol Ether Lipid. \\ GNPS Global Natural Product Social Molecular Networking. \\ $\mathrm{H}_{2} \mathrm{O} \quad$ Water. \\ HIV Human Immunodeficiency Virus. \\ HMBC Heteronuclear Multiple Bond Correlation (long range ${ }^{1} \mathrm{H}$ to ${ }^{13} \mathrm{C}$ correlations). \\ HP-20 PSDVB stationary support. \\ HPLC High Performance (Pressure) Liquid Chromatography. \\ HRESIMS High Resolution Electro-Spray Ionisation Mass Spectrometry. \\ HSQC Heteronuclear Single Quantum Coherence.
}




\begin{tabular}{|c|c|}
\hline HTS & High-Throughput Screening. \\
\hline $\mathrm{IC}_{50}$ & Concentration at which $50 \%$ of test subjects are inhibited. \\
\hline Ig & Immunoglobulin. \\
\hline$J$ & Scalar coupling constant. \\
\hline $\mathbf{L L P}$ & Liquid-liquid partitioning. \\
\hline m & multiplet. \\
\hline MAb & Monoclonal antibody. \\
\hline MAGE & MonoAlkyl Glyerol Ether. \\
\hline MALDI-TOF & Matrix-Assisted Laser Desorption Ionisation-Time Of Flight. \\
\hline $\mathrm{Me}_{2} \mathrm{CO}$ & Acetone. \\
\hline $\mathrm{MeCN}$ & Acetonitrile. \\
\hline $\mathrm{MeOH}$ & Methanol. \\
\hline MIC & Minimum inhibitory concnentration. \\
\hline MMAE & MonoMethyl Auristatin E. \\
\hline MNP & Marine Natural Product. \\
\hline MOA & Mechanism Of Action. \\
\hline MS & Mass spectrometry. \\
\hline$m / z$ & Mass-to-charge ratio. \\
\hline NCE & New Chemical Entity. \\
\hline NDA & New Drug Application. \\
\hline NET & NorEpinpehrine Transporter. \\
\hline NIH & National Institutes of Health. \\
\hline NIWA & National Institute of Water and Atmospheric research. \\
\hline NMR & Nuclear Magnetic Resonance. \\
\hline NOESY & Nuclear Overhauser Effect Spectroscopy. \\
\hline NRPS & Non-Ribosomal Peptide Synthetase. \\
\hline ppm & Parts per million. \\
\hline PSDVB & Poly(styrene-divinylbenzene). \\
\hline RNA & RiboNucleic Acid. \\
\hline $\mathbf{S}$ & singlet. \\
\hline SAR & Structure-Activity Relationship. \\
\hline SCUBA & Self-Contained Underwater Breathing Apparatus. \\
\hline STS & Soft Tissue Sarcoma. \\
\hline $\mathbf{t}$ & Triplet. \\
\hline TCM & Traditional Chinese Medicine. \\
\hline TDM & Trehalose-6-6'-DiMycolate. \\
\hline TJM & Traditional Japanese Medicine. \\
\hline TLC & Thin-Layer Chromatography. \\
\hline TME & Tumour MicroEnvironment. \\
\hline USPTO & United States Patent and Trademark Office. \\
\hline VUW & Victoria University of Wellington. \\
\hline
\end{tabular}




\section{Contents}

Abstract

Acknowledgements iii

Glossary iv

$\begin{array}{ll}\text { List of Figures } & \text { ix }\end{array}$

List of Tables $\quad$ xii

List of Schemes $\quad$ xiii

1 Introduction 1

1.1 The History of Natural Products in Drug Discovery . . . . . . . . . . . . 1

1.2 Modern Drug Discovery $\ldots \ldots \ldots$. . . . . . . . . . . . 5

1.3 The Evolutionary History of Secondary Metabolites . . . . . . . . . . . . . 12

1.4 Marine Natural Products . . . . . . . . . . . . . . . . . . . . 16

1.4.1 Approved Marine-Derived Drugs _. . . . . . . . . . . 18

1.4.2 Marine-Derived Compounds in Clinical Trials . . . . . . . . . . . 22

1.5 New Zealand Marine Natural Products . . . . . . . . . . . . . . . . . . . . 26

1.6 Natural Products and Intellectual Property . . . . . . . . . . . . . . . 27

1.7 Methods of Screening for Natural Products . . . . . . . . . . . . . . . 29

1.8 Marine Natural Products Amongst the -omics . . . . . . . . . . . . . . . 31

1.9 Isolated Compounds From Aaptos sp. . . . . . . . . . . . . . . 33

1.10 Research Aims . . . . . . . . . . . . . . . . . . . 34 
2.1 Dictyodendrilla dendyi . . . . . . . . . . . . . . 36

2.2 Phorbas areolata .......................... 36

2.3 Aaptos confertus . . . . . . . . . . . . . . . 37

3 Results $\quad 38$

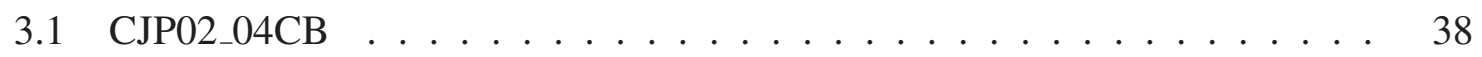

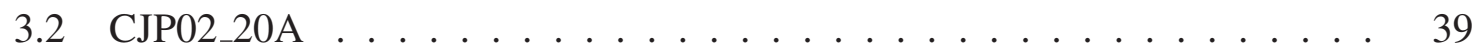

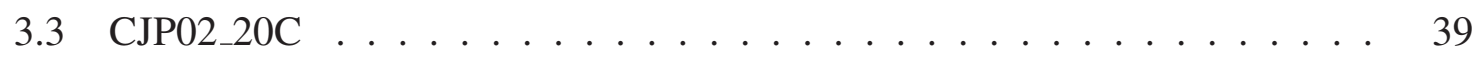

3.4 2,5-Diketopiperazine Cyclo(L-Phe-L-Pro) $\ldots \ldots \ldots \ldots$

3.5 Branched-Chain Mono-Glycerol Ether . . . . . . . . . . . . . . . . . . 42

4 Experimental $\quad 49$

4.1 General Experimental . . . . . . . . . . . . . . . . . . . . . 49

4.2 Sponge Screening . . . . . . . . . . . . . . . . . 50

4.2.1 Screen of Phorbas areolata . . . . . . . . . . . . . . 50

4.2.2 Screen of Dictyodenrilla dendyi . . . . . . . . . . . . . 50

4.2.3 Screen of Aaptos confertus . . . . . . . . . . . . . . . 51

4.3 Isolation of CJP01_93B . . . . . . . . . . . . . . 51

4.3.1 Large-scale extraction of Aaptos confertus . . . . . . . . . . . . . 51

4.4 Isolation of CJP02_20A . . . . . . . . . . . . 53

4.5 Further Purification of the $30 \%$ HP-20 Fraction $\ldots \ldots$. . . . . . . . . . 54

$4.600 \mathrm{~F}$ - Isolation of CJP02_04CB . . . . . . . . . . . . 55

4.7 00G - Isolation of Cyclo(L-Phe-L-Pro $\ldots \ldots \ldots 5$

$4.800 \mathrm{G}$ - Isolation of CJP02_20C $\ldots \ldots \ldots \ldots$

4.9 Incomplete/Discarded Purifications . . . . . . . . . . . . . . 56

4.9 .1 Further purification of $\mathrm{OOK} \ldots \ldots \ldots 56$

4.9 .2 Further purification of OOJ . . . . . . . . . . 56

4.9 .3 Further purification of $\mathrm{OOH} \ldots \ldots \ldots 57$

4.9 .4 Further purification of OOD . . . . . . . . . . 57

4.9 .5 Further purification of $\mathrm{OOC} \ldots \ldots \ldots 57$ 
5 Conclusions

5.1 Diversity of Secondary Metabolites in a Temperate Climate . . . . . . . . 59

$5.2 \quad 2,5$-Diketopiperazine cyclo(L-Phe-L-Pro) $\ldots \ldots \ldots$

5.3 Branched-Chain Mono-Glycerol Ether . . . . . . . . . . . . . 61

A Screening Protocol $\quad 65$

A.1 Existing Marine Chemistry Screening Protocol _. . . . . . . . . . 65

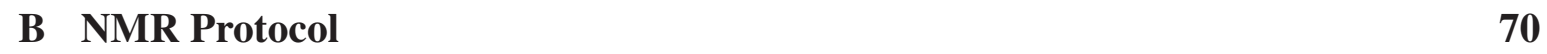

C Routine Experimental Protocols $\quad 71$

C.1 Cyclic Loading . . . . . . . . . . . . . . . . . . . . . . 71

C.1.1 Background .................... 71

C.1.2 Procedure ...................... 72

C.2 DIOL Dry-Loading . . . . . . . . . . . . . . 73

C.2.1 Procedure ....................... 74

D Spectra of Sponge Screens $\quad 75$

$\begin{array}{llr}\text { E Spectra of Known Compounds } & 83\end{array}$

$\begin{array}{lll}\text { F Spectra of Unkown Compounds } & 94\end{array}$ 


\section{List of Figures}

1.1 Well-known NPs that disobey Lipinski's Rule of Five. . . . . . . . . . . . 7

1.2 Recently-approved anticancer and antitumour agents. . . . . . . . . . 8

1.3 Natural product antibacterial and antifungal agents $\ldots \ldots . \ldots$

1.4 Macrolide antibacterial agents. . . . . . . . . . . . . . 10

1.5 Antifungal and antiparasitic agents. . . . . . . . . . . . 11

1.6 Ziconotide, the synthetic form of $\omega$-conotoxin MVIIA. . . . . . . . . 13

3.1 Structure of the isolated 2,5-diketopiperazine cyclo(L-Phe-L-Pro) (42) . . . 40

3.2 Assignments for the isolated 2,5-DKP cyclo(L-Phe-L-Pro) . . . . . . . . . 42

3.3 Observed COSY and HMBC correlations for the isolated 2,5-DKP cyclo(LPhe-L-Pro $\ldots \ldots \ldots \ldots \ldots$. . . . . . . . . . . . . . . . . . . .

3.4 Structure of 3-((13-methylhexadecyl)oxy)propane-1,2-diol . . . . . . . . 42

3.5 Observed COSY and HMBC correlations for 3-((13-methylhexadecyl)oxy)propane-

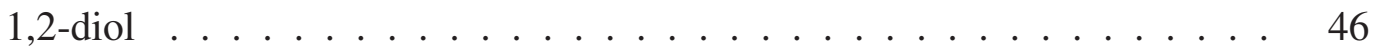

3.6 Assignments for 3-((13-methylhexadecyl)oxy)propane-1,2-diol . . . . . . . 46

C.1 Cyclic-Loading Procedure. . . . . . . . . . . . . . . 72

D.1 ${ }^{1} \mathrm{H}$ spectrum of $75 \% \mathrm{HP}-20$ fraction from Dictyodendrilla dendyi $(600 \mathrm{MHz}$,

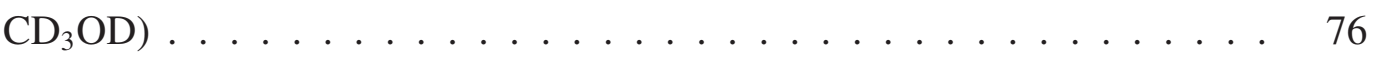

D.2 COSY spectrum of 75\% HP-20 fraction from Dictyodendrilla dendyi (600

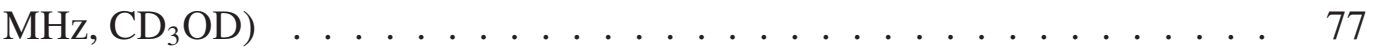

D.3 Multiplicity-Edited HSQC spectrum of 75\% HP-20 fraction from Dictyodendrilla dendyi $\left(600 \mathrm{MHz}, \mathrm{CD}_{3} \mathrm{OD}\right) \ldots \ldots \ldots \ldots$ 
D.4 ${ }^{1} \mathrm{H}$ spectrum of $75 \% \mathrm{HP}-20$ fraction from Phorbas areolata $(600 \mathrm{MHz}$,

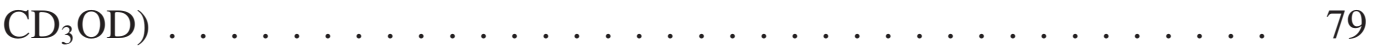

D.5 ${ }^{1} \mathrm{H}$ spectrum of $75 \% \mathrm{HP}-20$ fraction from Aaptos confertus $\left(600 \mathrm{MHz}, \mathrm{CD}_{3} \mathrm{OD}\right) 80$

D.6 COSY spectrum of 75\% HP-20 fraction from Aaptos confertus $(600 \mathrm{MHz}$,

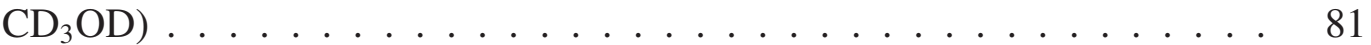

D.7 Multiplicity-Edited HSQC spectrum of 75\% HP-20 fraction from Aaptos confertus showing methylenes in blue and methyls and methines in red (600

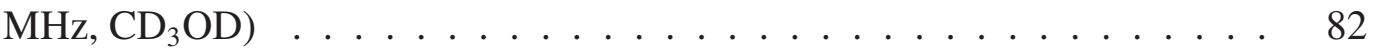

E.1 ${ }^{1} \mathrm{H}$ spectrum of Cyclo(L-Phe-L-Pro) $\left(500 \mathrm{MHz}, \mathrm{CD}_{3} \mathrm{OD}\right) \ldots \ldots$

E.2 ${ }^{13} \mathrm{C}$ spectrum of Cyclo(L-Phe-L-Pro) $\left(125 \mathrm{MHz}, \mathrm{CD}_{3} \mathrm{OD}\right) \ldots \ldots$

E.3 COSY spectrum of Cyclo(L-Phe-L-Pro) $\left(500 \mathrm{MHz}, \mathrm{CD}_{3} \mathrm{OD}\right) \ldots \ldots 6$

E.4 Multiplicity-Edited HSQC spectrum of Cyclo(L-Phe-L-Pro) showing methylenes in blue and methyls and methines in red $\left(500 \mathrm{MHz}, \mathrm{CD}_{3} \mathrm{OD}\right) \ldots . . . . .87$

E.5 HMBC spectrum of Cyclo(L-Phe-L-Pro) $\left(600 \mathrm{MHz}, \mathrm{CD}_{3} \mathrm{OD}\right) \ldots \ldots 8$

E.6 ${ }^{1} \mathrm{H}$ spectrum of 3-((13-methylhexadecyl)oxy)propane-1,2-diol (600 MHz,

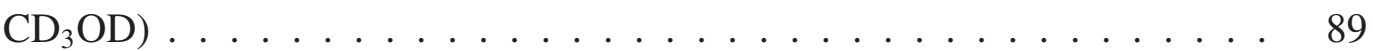

E.7 ${ }^{13} \mathrm{C}$ spectrum of 3-((13-methylhexadecyl)oxy)propane-1,2-diol (150 MHz,

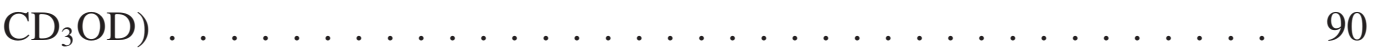

E.8 COSY spectrum of 3-((13-methylhexadecyl)oxy)propane-1,2-diol (600 MHz,

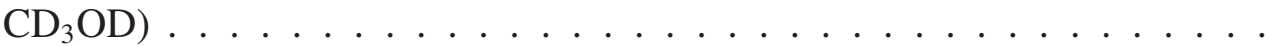

E.9 Multiplicity-Edited HSQC spectrum of 3-((13-methylhexadecyl)oxy)propane1,2-diol showing methylenes in blue and methyls and methines in red (600

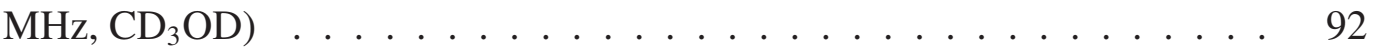

E.10 HMBC spectrum of 3-((13-methylhexadecyl)oxy)propane-1,2-diol (600 MHz,

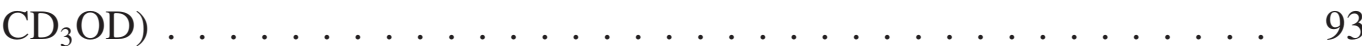

F.1 ${ }^{1} \mathrm{H}$ spectrum of CJP02_04CB $\left(600 \mathrm{MHz}, \mathrm{CD}_{3} \mathrm{OD}\right) \ldots \ldots . \ldots$

F.2 ${ }^{13} \mathrm{C}$ spectrum of CJP02_04CB $\left(150 \mathrm{MHz}, \mathrm{CD}_{3} \mathrm{OD}\right) \ldots \ldots$

F.3 COSY spectrum of CJP02_04CB $\left(600 \mathrm{MHz}, \mathrm{CD}_{3} \mathrm{OD}\right) \ldots \ldots$. . . . . . . 97

F.4 Multiplicity-Edited HSQC spectrum of CJP02_04CB showing methylenes in blue and methyls and methines in red $\left(500 \mathrm{MHz}, \mathrm{CD}_{3} \mathrm{OD}\right) \ldots \ldots 8$ 
F.5 HMBC spectrum of CJP02_04CB $\left(600 \mathrm{MHz}, \mathrm{CD}_{3} \mathrm{OD}\right) \ldots . \ldots 99$

F.6 ${ }^{1} \mathrm{H}$ spectrum of CJP02_20A $\left(600 \mathrm{MHz}, \mathrm{CD}_{3} \mathrm{OD}\right) \ldots \ldots \ldots$

F.7 ${ }^{13} \mathrm{C}$ spectrum of CJP02_20A $\left(150 \mathrm{MHz}, \mathrm{CD}_{3} \mathrm{OD}\right) \ldots \ldots \ldots 1$

F.8 COSY spectrum of CJP02_20A $\left(600 \mathrm{MHz}, \mathrm{CD}_{3} \mathrm{OD}\right) \ldots \ldots \ldots$

F.9 Multiplicity-Edited HSQC spectrum of CJP02_20A showing methylenes in blue and methyls and methines in red $\left(600 \mathrm{MHz}, \mathrm{CD}_{3} \mathrm{OD}\right) \ldots \ldots$

F.10 HMBC spectrum of CJP02_20A $\left(600 \mathrm{MHz}, \mathrm{CD}_{3} \mathrm{OD}\right) \ldots \ldots$

F.11 ${ }^{1} \mathrm{H}$ spectrum of CJP02_20C $\left(600 \mathrm{MHz}, \mathrm{CD}_{3} \mathrm{OD}\right) \ldots \ldots \ldots$

F.12 ${ }^{13} \mathrm{C}$ spectrum of CJP02_20C $\left(150 \mathrm{MHz}, \mathrm{CD}_{3} \mathrm{OD}\right) \ldots \ldots \ldots$

F.13 COSY spectrum of CJP02_20C $\left(600 \mathrm{MHz}, \mathrm{CD}_{3} \mathrm{OD}\right) \ldots \ldots$

F.14 Multiplicity-Edited HSQC spectrum of CJP02_20C showing methylenes in blue and methyls and methines in red $\left(600 \mathrm{MHz}, \mathrm{CD}_{3} \mathrm{OD}\right) \ldots \ldots$ 


\section{List of Tables}

$3.1{ }^{1} \mathrm{H}(500 \mathrm{MHz})$ and ${ }^{13} \mathrm{C}(150 \mathrm{MHz})$ NMR data for 2,5-DKP cyclo(L-Phe-LPro) $*=$ signal not observed. $* *=$ not determinable . . . . . . . . . . . 44

$3.2{ }^{1} \mathrm{H}(600 \mathrm{MHz})$ and ${ }^{13} \mathrm{C}(150 \mathrm{MHz}) \mathrm{NMR}$ data for 3-((13-methylhexadecyl)oxy)propane-

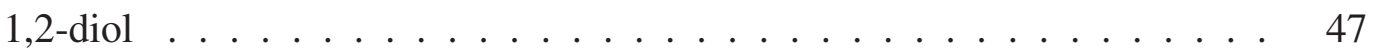




\section{List of Schemes}

3.1 Isolation scheme of 2,5-DKP cyclo(L-Phe-L-Pro) $\ldots . \ldots$. . . . . . . . . 43

3.2 Isolation scheme of 3-((13-methylhexadecyl)oxy)propane-1,2-diol $\ldots . . . \quad 48$ 


\section{Chapter 1}

\section{Introduction}

\subsection{The History of Natural Products in Drug Discovery}

Natural products have shaped the course of drug discovery since the beginning of "medicine". ${ }^{1-3}$ The underlying principle of natural products is that organisms, plant or otherwise, contain active compounds that can be introduced to human systems and exert some beneficial biological effect, such as pain relief, in a therapeutic manner. Historically, natural products from plants and animals have formed the basis of most medicines. ${ }^{4}$ The earliest recorded evidence of natural sources being used for healing purposes began with the ancient Egyptian civilisation (c. $1500 \mathrm{BC}$ ) where many plants, including foods, were used to cure maladies and their preparations were described in detail with recipes for ointments and pills. ${ }^{5}$ Fast-forward to the present time and natural products are still being used, and to inspire the development of, drugs. In fact, 40\% of newly approved pharmaceuticals between 1981 and 2010 consist of either synthetic molecules with natural product pharmacophores, synthetic natural product mimics, pure natural products or were derived from natural products (semi-synthetic). ${ }^{3}$ In order to understand the value of natural products, it is necessary to understand their origin and historical context.

Evidence of medicine predates any literary text or historical event. ${ }^{6}$ El Sidron is a wellstudied archaeological site in northwest Spain, which has provided detailed insight into the prehistoric use of natural products as medicine. The fossilised bones and teeth of the Neanderthals (Homo neanderthalensis) have been analysed using pyrolysis gas chromatography and mass spectrometry, to reveal that more than 50,000 years ago stone-age, cave-dwelling 
humans crushed and infused herbs for their curative properties. In the hardened plaque layer they found remains of plants, wood smoke and cooked starch plants. Included in such plants were yarrow and chamomile; considered to be quite bitter. Since these plants have little nutritional value, and an unappealing taste, it has been proposed that they were used for their medicinal properties. Yarrow, a tonic and astringent, is another example and chamomile is known for its relaxing and anti-inflammitory properties. ${ }^{7}$ Long before ancient Egyptian medicine, there existed the Mesopotamian tablets of the Fertile Crescent. These tablets, made from clay, listed conditions, remedies and prognoses. The worlds oldest medical record, a Sumerian clay tablet (c. $2150 \mathrm{BCE})$, records that wounds were washed in beer and hot water, poultices were made from materials such as pounded pine, prunes, wine dregs and lizard dung. There was also evidence of the use of distillation to make an essence of cedar and other volatile oils. ${ }^{8}$

The use of material from living organisms for medicinal purposes dates back to pre-historical and pre-recorded times, but was largely documented in ancient Egyptian culture. The ancient Egyptians were responsible for the birth of medicine, characterised and recorded on Egyptian papyri. Their medicinal use of natural products date back to before the first century, and are detailed in the Edwin Smith Papyrus (c. 1570 BC) and the Ebers papyrus (c. 1550 BC). ${ }^{9}$ The Edwin Smith papyrus is named after the person who purchased the papyrus in Luxor in $1862 .{ }^{7}$ It is thought it may have been copied from an older document, possibly written by Imhotep, a famous historical figure made deity, the god of warfare and healing. The Edwin Smith papyrus focuses more on the 'rational' treatment of disease. It includes instructions of preparing formulations (such as measurements, and modifications like crushing, cooking and mixing of ingredients). Beer, wine, water and honey were the most common vehicles for ingesting the preparations, and both papyri include further details on administration and formulations. They describe when to take the medicine, and what time and temperature it should be taken at. For example, brewer's yeast was recommended for the treatment of intestinal infections and skin diseases. We know now that it contains vitamin B12 (1) and possesses antibiotic properties against Staphylococcii. ${ }^{10}$

Plants were a source of laxatives, including the fruit of the sycamore, colocynth, figs and aloe. Some were also used as diuretics including juniper berries, brym and spring squill. ${ }^{10}$ 


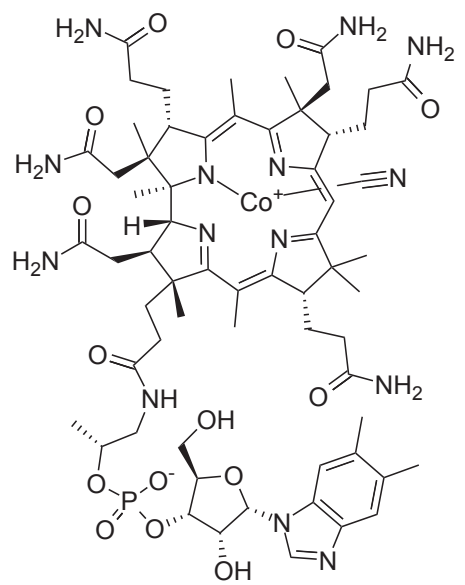

(1)

Honey was mentioned for its soothing, antibacterial and antifungal properties. They also calmed pain by using a plant called shepen, believed to be the opium poppy. ${ }^{10}$ The Ebers papyrus was brought by German writer and Egyptologist Georg Ebers. It contains hundreds of spells, charms and incantations to expel evil and disease, including many herbal and mineral remedies. ${ }^{7}$ Twelve medical papyri have been found to date, and are assumed to be part of a larger original corpus. Papyri are written documents made from the pith of the wild papyrus plant ${ }^{11}$ and are considered (collectively as the Egyptian pharmacopoeia) to be the source of modern pharmaceutics, literally and etymologically. ${ }^{10}$ Effectively, they are doctors handbooks. Egyptian medical practice also utilised both rational and irrational treatment; those being scientific methods and spiritual procedures, respectively. From what information is available, their medical practice was a "combination of clinical observation intertwined with the rich mysticism and religion of Egypt". ${ }^{11}$ Illness that could be visualised was treated rationally, whereas hidden illness was treated spiritually. Evidence of this is derived from many sources including art, archaeology, human remains and most relevant, the papyri.

Another pillar of medicine is rooted in traditional Chinese and Japanese medicine (often referred to as TCM and TJM, respecitively), whose excuberant use of herbal remedies trumps that of any other culture. Traditional Eastern medicine follows the concepts of qi, yin and yang, the Five Phases wuxing (fire, earth, metal, water, wood) ${ }^{7}$ and the concept of dao (The Way) which are infused in specific ingredients and preparations. ${ }^{9}$ Food-derived medicine in Eastern culture originated in the Zhou dynasty (1122-256 BCE), where there was an extensive list of food cures for specific symptoms. This evidence is based on archaeological exca- 
vations, proposing that people inhabited the Chinese mainland close to a million years ago. For example, fossil remains of the Peking man, found in a cave at Zhoukoudian, southwest of Beijing, date back to the prehistoric era. ${ }^{12}$ As the ancient Egyptian use of natural products were scribed upon papyri, TCM was notated in the Huang-di NeiJing, (translation: the Yellow Emporer's Inner Canon) believed to be produced between 400 and 260 BCE, which recounts discussions between the Yellow (or Golden) Emperor, Huang-di, and his associates and advisors including First Minister Ch'i Po. ${ }^{11}$ Another prolific text is the Nei Ching (c. 479-300 BCE) which deals almost exclusively with acupuncture but also makes mention of natural remedies. For example, Chinese physicians used 'moxibustion' which is a cone of moxa (powdered leaves of the mugwort plant). This was placed on particular acupuncture points and set alight. The warmth (and resulting blister) supposedly increased yang. ${ }^{8}$ The Chinese also had an extensive list of remedies (up to 16,000 - not all herbal) which were given to patients. For example, remedies included pulverised seahorses for goitre, or octopus ink mixed with vinegar for heart disease. ${ }^{8}$ Despite these well-known historical texts, there was a shift away from the Huang-di Nei' Jing during the Han dynasty. The primary physician was Zhang Zhongjing who authored Shanghan Han Za Bing Lun. This describes more than 100 herb-based remedies. ${ }^{7}$ One section, Jin-Kui Yao Lue, lists more than 250 recipes using preparations from plants. ${ }^{7}$ One of the few surgeons mentioned was Hua T'o (c. 143-208 BC). He was said to have invented an all-purpose anaesthetic called mafeisan, based on wine with additions of cannabis, opium poppies, datura (a type of nightshade), mandrake and various mixtures of these. ${ }^{7}$

Following the path of written medical knowledge comes the Hippocratic Corpus (400-500 $\mathrm{CE}$ ), which defined Greek medicine, and many modern practices in medicine. Although largely associated with methods of general practice, it also enthusiastically mentions the use of many natural remedies. ${ }^{7}$ One prominent text, De Materia Medica, covers the use of 600 plants used in medicine; many of these are drugs are known to be effective. The text was written between 50 and $70 \mathrm{CE}$ by Pedanius Dioscordies, a Greek physician. ${ }^{9}$ Greek medicine is strongly associated with Hippocrates, deemed the father of Western medicine. While TCM and TJM coined the concept of the four elements - earth, air, fire and water ${ }^{7}$ the ancient Greeks had humorism, the idea that the body contained four fluids - blood, yellow 
bile, black bile and phlegm. ${ }^{7}$ Hippocrates wrote the Hippocratic Corpus, which consists of approximately 60 written documents thought to be added upon by students, disciples and followers up to four or five centuries later. ${ }^{7}$ Many of these show knowledge of herbal remedies which included olive oil, honey and more than 200 vegetables and herbs. These were either to be taken whole or extracted (from figs, garlic, and onion to parsley, poppy, hibiscus, chamomile, cumin and saffron). ${ }^{7}$ Also, it includes use of the humble leek to the fat of the hippopotamus, pomegranate, fried mice and lapis lazuli. ${ }^{6}$

The Middle-ages saw the birth of apothecary. Although some remedies were unconventional, they also made use of therapies such as the opium poppy, juice of hemlock and showed knowledge of processing (heating, etc.) Notable examples include the use of willow bark to reduce fever and inflammation (as aspirin does). Often, the bark was chewed on, containing salicin, which is very similar to acetylsalicylic acid (aspirin). ${ }^{13}$

\subsection{Modern Drug Discovery}

Natural products (NPs) have been the single most productive source of lead compounds for the development of new drugs, even after the advent of HTS (high-throughput screening) and the post-genomic era. Almost half of the drugs approved between 1994 and 2008 were based on natural products. ${ }^{14}$ Natural products have continued to provide key scaffolds and compounds for drug discovery and development. As of 2013, 1453 new chemical entities (NCEs) had been approved by the United States Food and Drug Administration (FDA), of which $c .40 \%$ are natural products (NPs) or NP-inspired (semi-synthetic NP derivatives, synthetic compounds based on NP pharmacophores, or NP mimics). ${ }^{15}$ Natural products also account for $74 \%$ of the anti-tumour NCEs that had been approved. ${ }^{15}$ There are many contributing factors to the success of NPs, including their innate interactions with biological targets and a long history of evolution, which culminates in an arsenal of secondary metabolites for an organism.

A limiting factor to drug design is the popular Lipinski's rule of five. ${ }^{16}$ A review by Rodrigues ${ }^{5}$ highlights the need to depend on natural products for drug design. The authors use a number of examples to illustrate bioactive compounds that fail to adhere to the rule of five 
criteria, and points out that $18 \%$ of the natural products from the Dictionary of Natural Products database violate the rule of five in at least two criteria, $31 \%$ from the TCM database, $15 \%$ of DrugBank and $9 \%$ of the ChEMBL database. Approximately half of approved drugs from natural sources were found to comply with Lipinski's Rule of Five, but the remainder had higher molecular weights, more rotatable bonds and more chiral centres. ${ }^{14}$ The chemical diversity of natural products is a better match to that of successful drugs, than other sources of drugs (i.e purely synthetic or combinatorial methods). In particular, natural products are renowned for producing macrolides that do not adhere to Lipinskis Rule of Five. This is a reminder that natural products are not limited to human imagination or rules, and have proved valuable for being so.

Natural sources have produced many anticancer agents (that also disobey Lipinskis Rule of Five), for example, bleomycin (2), actinomycin D (3), paclitaxel (4), halichondrin B (5), epoxomicin (6), dolastatin 10 (7), calicheamicin (8), and mitomycin. (9) ${ }^{15}$

Antitumour terpenes from plant sources include vincristine (10) and paclitaxel (4). In addition, there exists a semi-synthetic from a plant source called camptothecin (11) (a quinolone alkaloid) as well as its water-soluble semi-synthetic derivative topotecan. ${ }^{15}$ (12) Other recentlyapproved anti-cancer drugs include carfilzomib (13), a semi-synthetic derivative of epoximicin (6) and eribulin (14), a macrocyclic ketone analogue of the natural product halichon$\operatorname{drin} B(\mathbf{5}) .{ }^{15}$

Many natural products are also used as antiinfectives, encompassing antibacterials and antifungals. Microorganisms in particular have provided an abundant source of natural products, developed on a commercial scale for human medicine. ${ }^{15}$ As examples, azithromycin (15) and clarithromycin (16) are semi-synthetic derivatives of the macrolide erythromycin (17), doxycycline (18) is a second generation tetracycline, amoxicillin (19) is a semi-synthetic penicillin derivative and cephalexin (20) is a derivative of cephalosporin (21). These are all commonly used as outpatient treatments of bacterial skin or respiratory infections. ${ }^{15}$ Macrolide antibacterial agents are not uncommon. Other examples are tylosin (22), vancomycin (23), daptomycin (24), liparmycin (fidaxomicin) (25), rifampicin (26), and streptomycin (27). Antifungals and antiparasitic agents include amphotericin B (28), caspofungin (29), monensin (30), and avermectin B1b (31). ${ }^{15}$ 


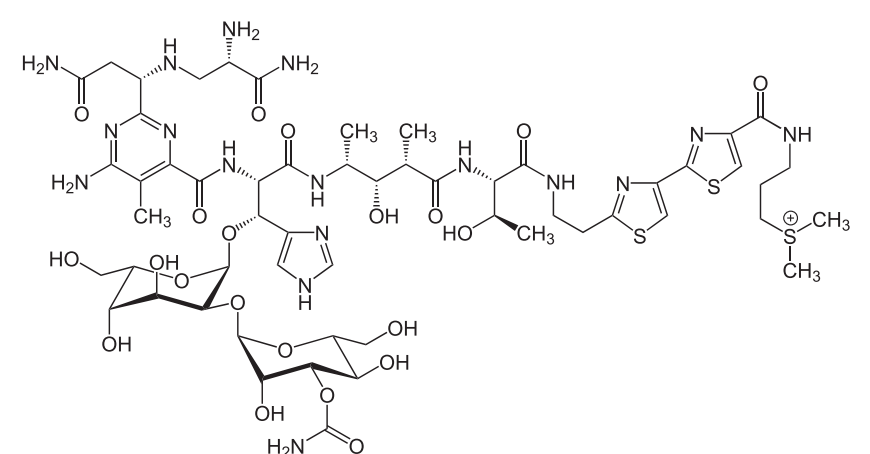

(2)

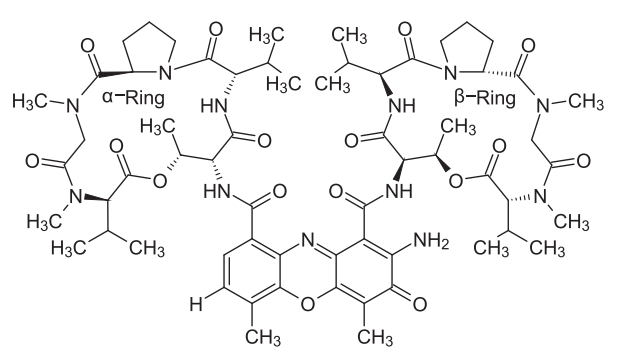

(3)

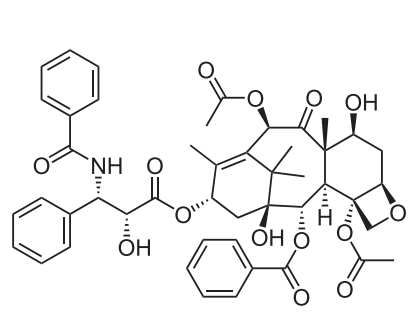

(4)

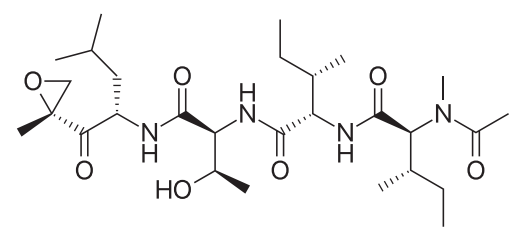

(6)

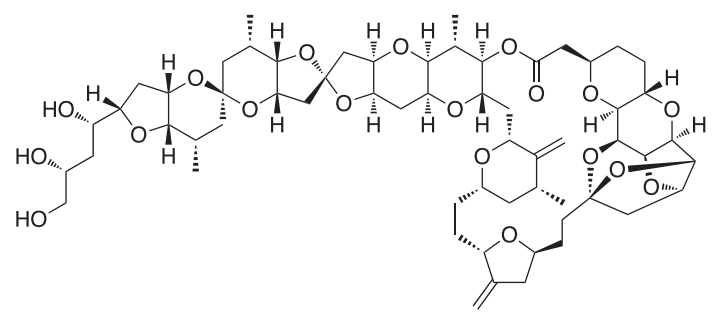

(5)

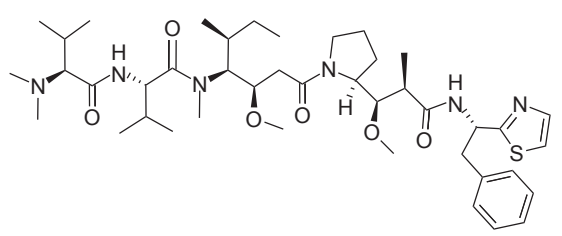

(7)

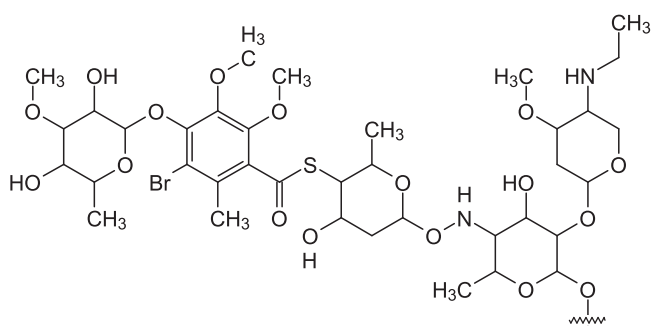

(8)

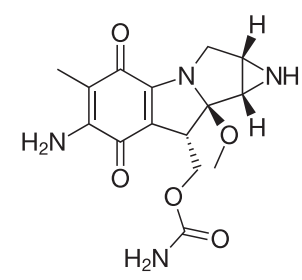

(9)

Figure 1.1: Well-known NPs that disobey Lipinski's Rule of Five. 


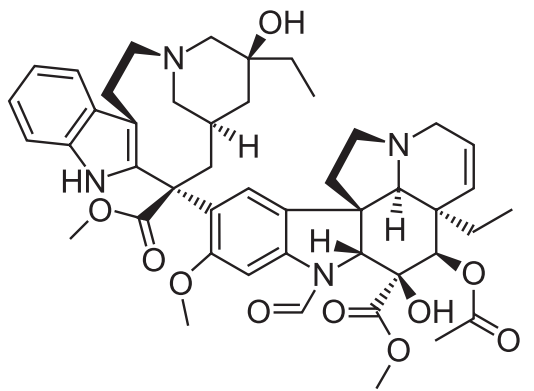

(10)<smiles>CC[C@@]1(O)C(=O)OCc2c1cc1n(c2=O)Cc2cc3ccccc3nc2-1</smiles>

(11)<smiles>CC[C@@]1(O)C(=O)OCc2c1cc1n(c2=O)Cc2cc3c(CN(C)C)c(O)ccc3nc2-1</smiles>

(12)

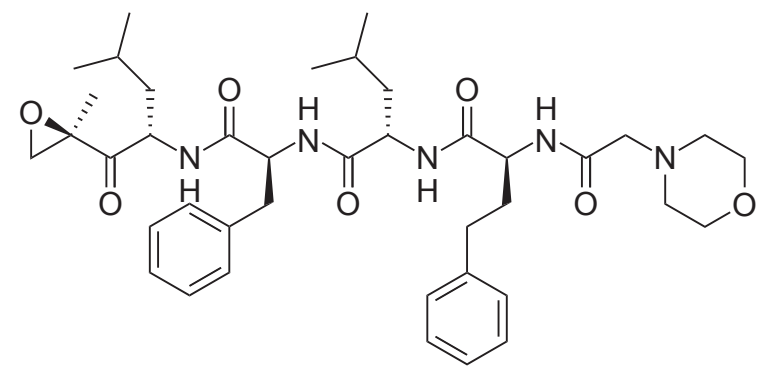

(13)

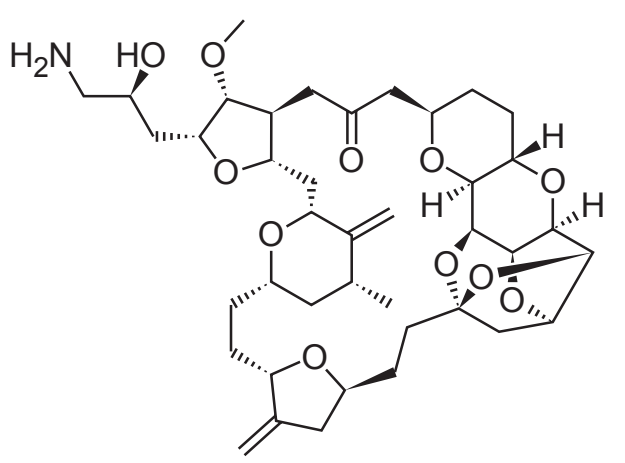

(14)

Figure 1.2: Recently-approved anticancer and antitumour agents. 


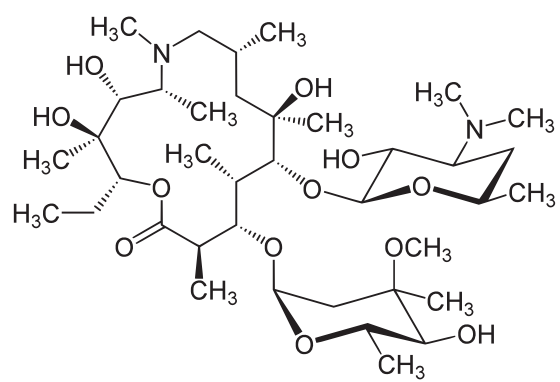

(15)

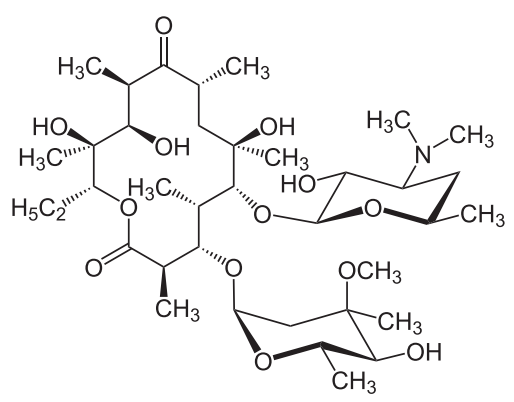

(17)

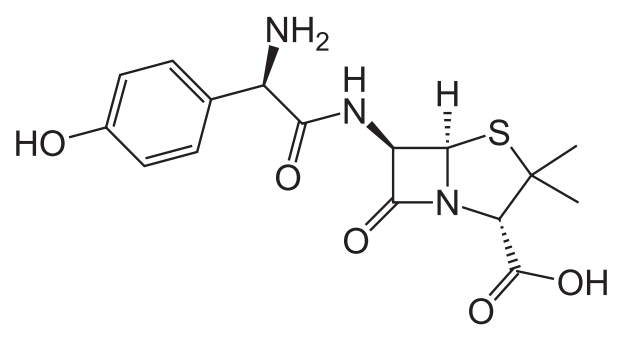

(19)

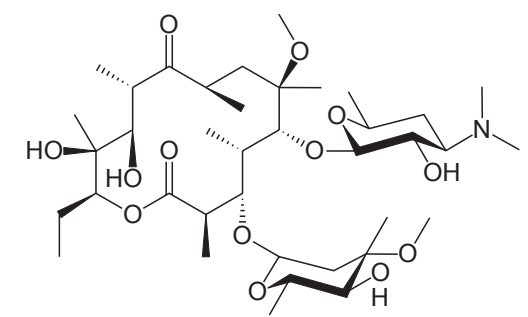

(16)<smiles>C[C@@H]1[C@H]2C(=C(O)[C@]3(O)C(=O)C(C(N)=O)=C(O)[C@H](N(C)C)[C@H]3[C@@H]2O)C(=O)c2c(O)cccc2[C@@H]1C</smiles>

(18)

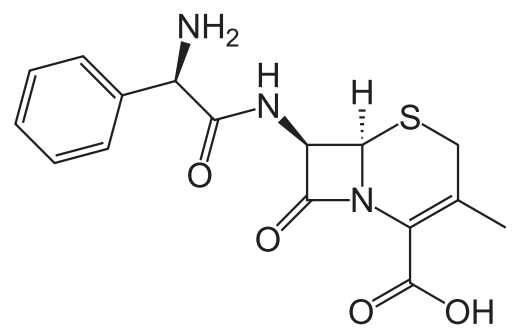

(20)<smiles>[R]C(=O)N[C@@H]1C(=O)N2C(C(=O)O)=C([R])CS[C@H]12</smiles>

(21)

Figure 1.3: Natural product antibacterial and antifungal agents 


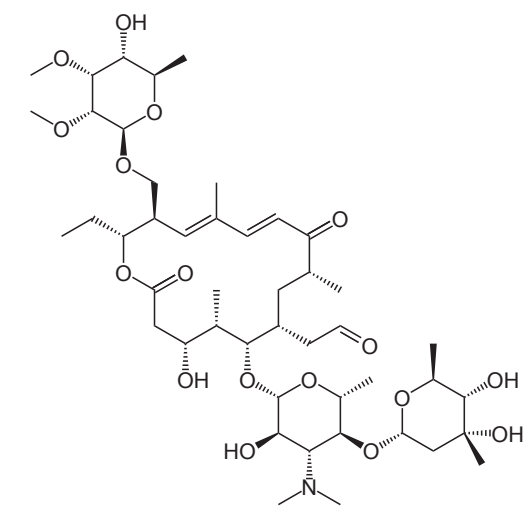

(22)

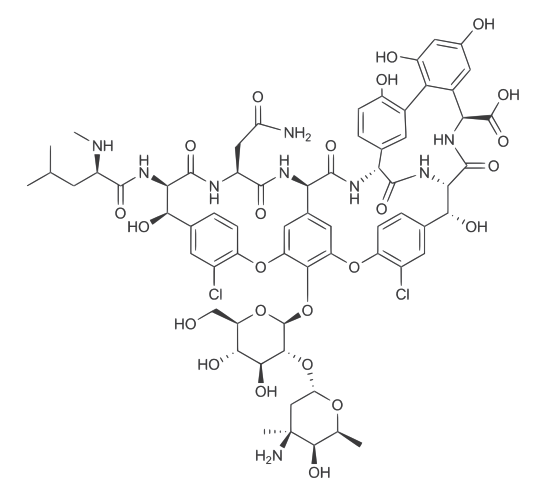

(23)

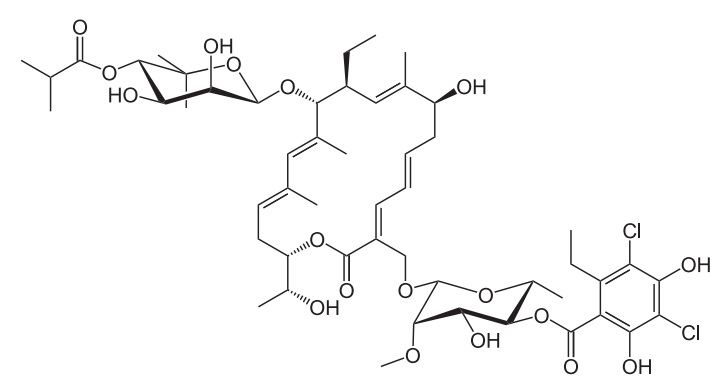

(25)

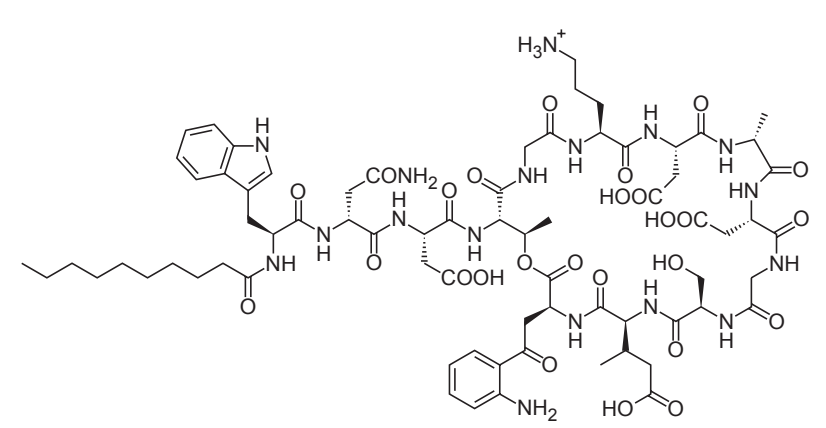

(24)

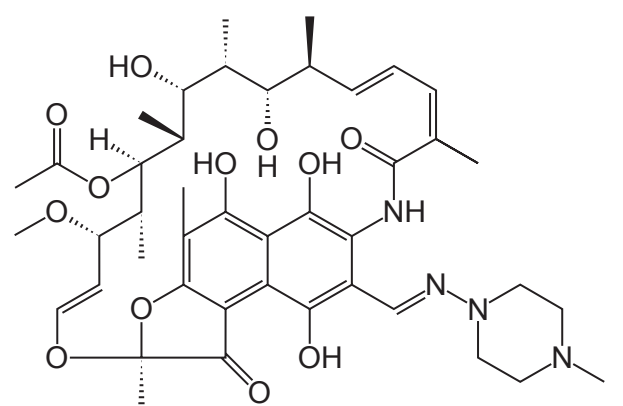

(26)

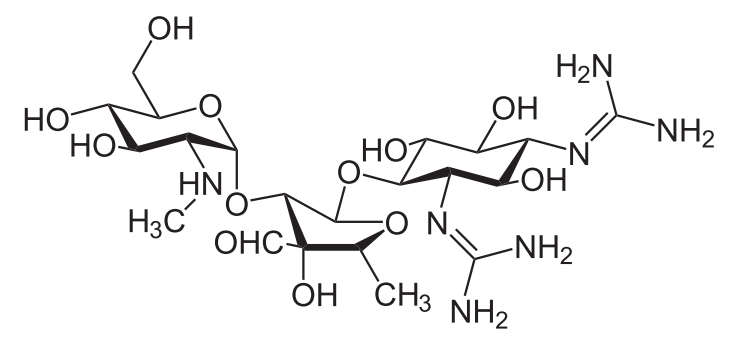

(27)

Figure 1.4: Macrolide antibacterial agents. 


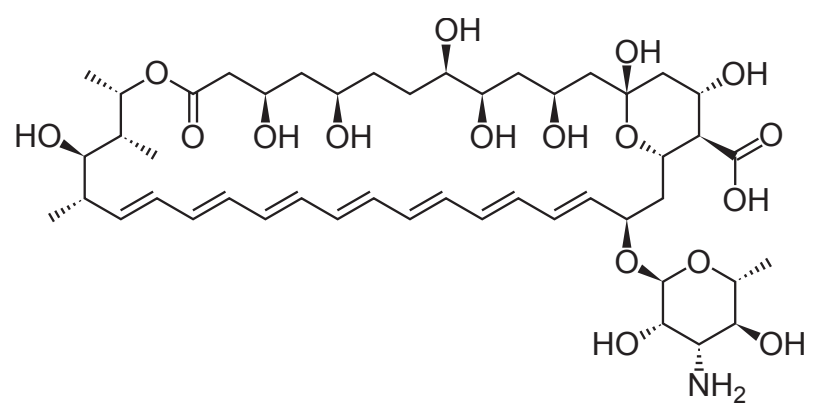

(28)

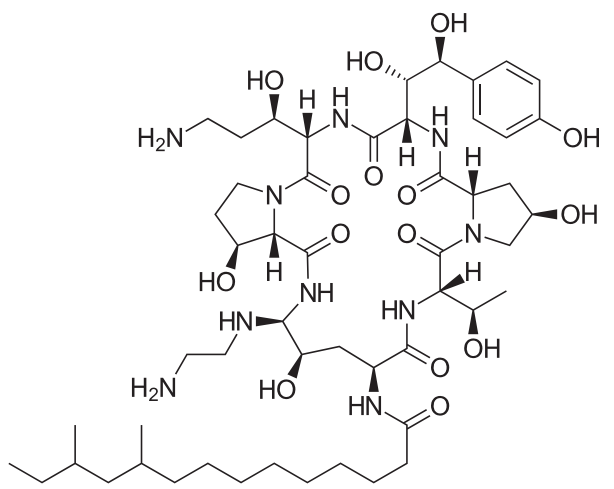

(29)

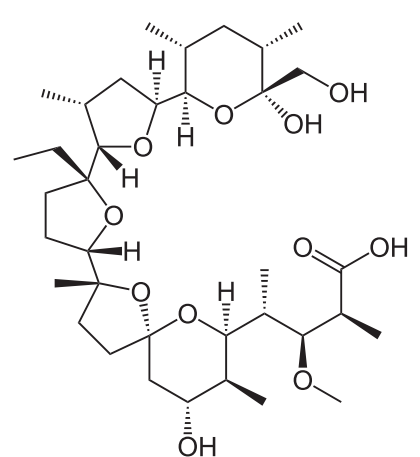

(30)

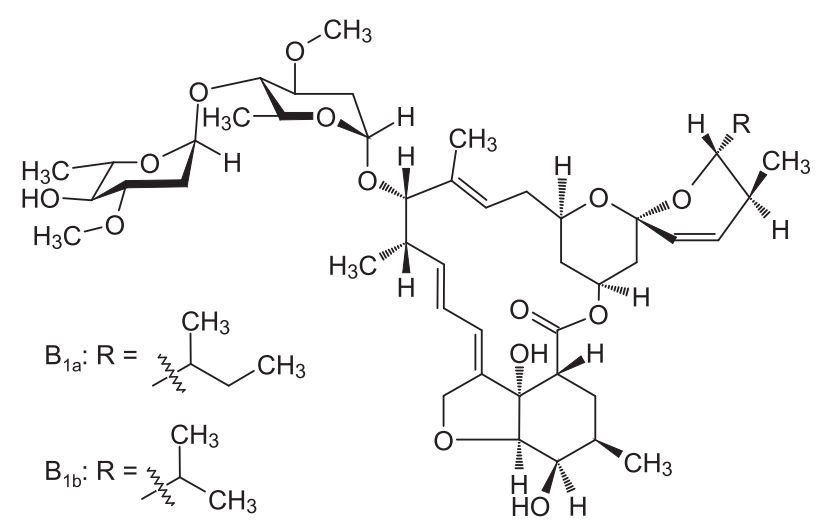

(31)

Figure 1.5: Antifungal and antiparasitic agents. 
In opposition to rationally designed drugs, natural products are not limited by human imagination and display an impressive amount of structural variation. ${ }^{17}$ Principle component analysis of natural products in comparison with synthetic molecules shows that natural products cover a wider range of physical variables ${ }^{18}$ including their range of pharmacophores and degree of stereochemistry. In other words, they occupy greater and more diverse chemical space. Natural product scaffolds have also been referred to as priveleged structures in reference to their success as drugs. Such scaffolds are being used as cores of compound libraries made by combinatorial techniques. ${ }^{14}$

The concept of using natural remedies as medicines has proven its value from historical evidence. As the use of natural products in medicine has been conserved for many thousands of years, the conservation of specific secondary metabolites in living organisms has also played a huge role in the drugs we use today. Although historically, the "active pharmaceutical ingredients may not have been known, advances in qualitative techniques have allowed us to determine the chemical structures of these pharmaceuticals derived from living organisms. Many of the active ingredients can be attributed to what are now known as secondary metabolites of these organisms.

\subsection{The Evolutionary History of Secondary Metabolites}

An understanding of secondary metabolites is also vital to understanding natural product chemistry and its success as a source of human therapeutics. Secondary metabolites are primarily defined as compounds that are not necessary for the survival of an organism, but confer a survival advantage. They are mainly produced where an organism lacks kinetic defences, or lives in a highly-crowded area. ${ }^{19}$ For example, some organisms produce toxins to discourage predators from consuming them. ${ }^{20} \mathrm{~A}$ recent marine example is $\omega$-conotoxin MVIIA (32) produced by the cone snail Conus magnus, which immobilises prey and predators. ${ }^{21}$ Another example is ragwort, which produces the antifeedant pyrrolizidine alkaloids such as senecionine (33), which deters mammalian herbivores. ${ }^{20}$

One view is that secondary metabolites are carefully selected for alongside the evolution of the organism; they are considered biologically validated, as they have been subject to 


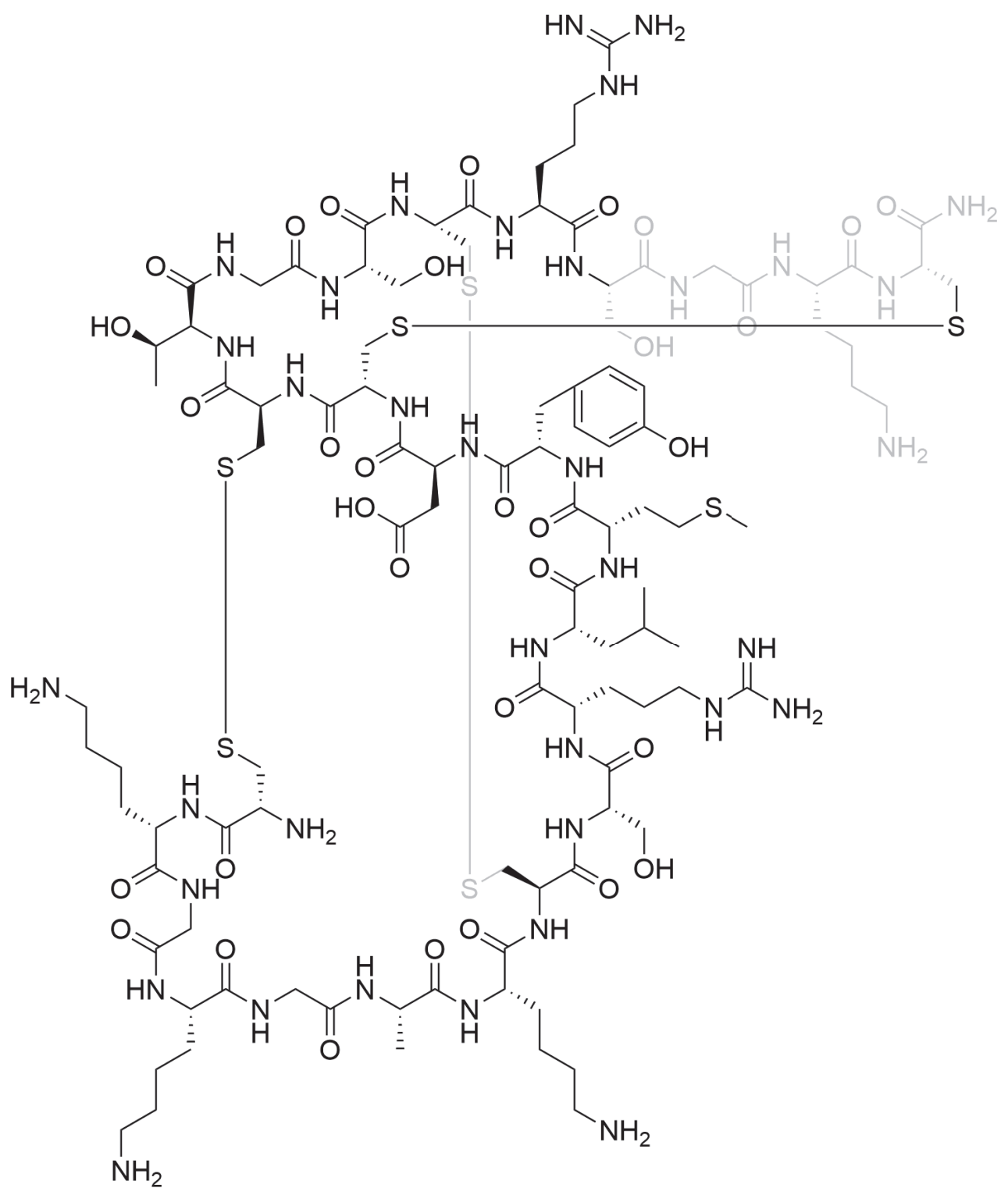

(32)

Figure 1.6: Ziconotide, the synthetic form of $\omega$-conotoxin MVIIA. 


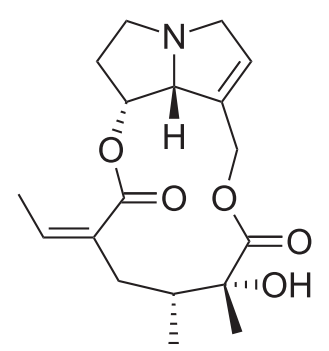

(33)

thousands (or millions) of years of natural selection. The result is a specialised and often potent molecule that improves the survival of the organism. In translating that to their applications in drug discovery and development, they are often specialised and potent towards their mechanism of action, which may be retained in human application despite no encounter with human metabolism. As these molecules are already designed to integrate into biological systems, they have high success in their ability to interact with targets, as opposed to purely synthetically designed compounds. This has been suggested as an explanation for the enormous success that natural products have had as drugs. ${ }^{1,3,22}$

Several theories exist regarding the evolution of secondary metabolites. One theory is that secondary metabolites, such as proteins, have existed since the beginning of biochemical evolution and were present in what's called "primordial soups", formed under natural forces. During Earth's primitive stage, certain molecules may have played roles in prebiotic reactions, involving catalytic RNA (ribonucleic acid). ${ }^{23}$ Traces of supporting evidence can still be seen in a number of antibiotics. A number of antibiotics can inhibit translation (aminoglycosides) by interacting with ribosomes. It is suggested these molecules were one class of RNA-catalysis effectors involved in translation and in other ribozyme-catalysed reactions at the early stage of biochemical evolution. The presence of these secondary metabolites with antibiotic activity play a role allowing certain organisms to flourish in otherwise hostile conditions. Many other organic molecules (outside of commonly-mentioned amino acids - the building blocks for life) are postulated to have other uses in Earth's primitive stage, having pleiotropic effects on cell metabolism. ${ }^{23}$

Over time, evolution works to select organisms that produce the most successful characteristics, which may encompass secondary metabolites; either those that have an adverse effect on a predator or competitor, or those that help a second organism engage in an activity which is advantageous to the producer (e.g. pheromones). The production of these metabo- 
lites must be at minimal cost to the organism. A common way of reducing that burden is to have a highly specific molecular interaction between the molecule and it's target; in other words, be highly potent. Secondary metabolite production can employ coding by tens of kilobases of DNA, and several tens of discrete enzyme-catalysed reactions. This produces very complex secondary metabolites, which come at a relatively high metabolic cost to the organism. One given example is the aglycone core of erythromycin (17). This requires six consecutive cycles of condensation and reduction, believed to involve 28 discrete enzymecatalysed reactions. ${ }^{24}$ Other examples include the vancomycin family of antibiotics, all involved in sophisticated biosynthetic pathways. ${ }^{24}$ Often, secondary metabolites are complex in their structure and the chemical space they occupy. From a biosynthetic perspective, such molecules are energy- and time-consuming and their synthesis would not be resourceful if they were not of value to the organism. It is understood that to be elaborate in structure yet conserved, they are likely to be highly beneficial to the organism. ${ }^{25,26}$

Another theory is that secondary metabolites were produced from universally-present precursors (most often acetyl-CoA, amino acids or shikimate) that may have arisen by the duplication and divergence of genes that account for primary metabolism. ${ }^{19}$ Some of these duplications resulting in divergence are very old, some are more recent. However, they do become conserved for tens of millions of years, equipping the organism with a set of conserved ancestral genes. Davies' idea of secondary metabolite evolution above ${ }^{23}$ can be disputed, however. It fails to explain how the enzymes that make the antibiotics make them now. If they were made prebiotically, there would have been no genetic continuity. It has been suggested that metabolites may been continually beneficial, otherwise they would have been eradicated by means of degenerative mutation. ${ }^{19}$

In general, due to the nature of their lifestyle, microbes are well-equipped at producing antibacterials and antifungals, plants are adept at producing chemical defences for a wide range of uses, and marine organisms are proficient in producing potent cytotoxic metabolites. The main threat of a microbe is another microbe, so they develop chemical defences to use locally against other bacteria or fungi. The mechanism of action of these metabolites often applies to common sructural features of microbes, and can be used effectively against a range of microbial organisms, including those pathogens that affect humans. As well 
as defensive structures to deter predators for feeding on them, plants produce a range of chemical defences as well. While plants are not always renowned for their antimicrobial metabolites, they produce metabolites of an unprecedented range, most notably alkaloids and terpenoids. In general, alkaloids and terpenoids are toxic to herbivores and pathogens and are believed to act as chemical defences. Other possible endogenous uses for alkaloids are to capture excess, or for temporary storage of, nitrogen. ${ }^{23}$

\subsection{Marine Natural Products}

Marine organisms, like plants, are rendered immobile and must produce either structural or chemical defences. They are well-known for producing cytotoxic compounds that inhibit growth, or microtubule-stabilising agents of which many are effective as anticancer agents, as the same mechanism of action is applicable for rapidly-dividing cancerous cells in humans. This makes marine secondary metabolites of interest, as they are also relatively untapped in comparison to microbes and plants. The first investigation of the marine environment as a source of medicine is unknown, however both TCM and TJM incorporate toxic properties of marine-derived products, for example, the use of puffer fish (Fugu) in Japanese cuisine. Additionally, Tryian Purple, a dye from the Mediterranean mollusc, was used in the Roman era and has shown significant activity against some cancers, and was also used in TCM to treat leukaemia. ${ }^{27}$

Marine organisms have generated, and have been the inspiration for, numerous drugs on the market. One of the most well-known examples is ziconotide (under the name Prialt ${ }^{\circledR}$ ); a synthetic form of $\omega$-conotoxin MVIIA (32). ${ }^{27,28}$ Another recent marine drug is Ecteinascidin743 (ET-743) marketed as Yondelis ${ }^{\circledR}(\mathbf{3 5})$. This was the first marine-derived anticancer drug to enter the market. Alongside these examples are halichondrin B (5), also an anticancer agent, didemnin B and alpidine (39). Although didemnin B did not survive clinical trials due to its extreme toxicity, its analogue, alpidine, is currently in Phase II clinical trials. ${ }^{27}$ Other marine-dervied drugs are ara-A and ara-C from the Caribbean sponge Tectitethya crypta.

Marine natural products can originate from a number of sources, most notably sponges, algae, nudibranchs and also bacteria living within these invertebrate and plant sources. Since 
immobile marine sponges have no kinetic means of protecting themselves, they must produce potent chemicals instead to deter predators. ${ }^{29-32}$ A review by Molinksi ${ }^{28}$ reviews drug discovery and development from marine natural products, beginning with a brief history. The author explains how natural products originating from terrestrial life were the traditional source of medicine but drugs from marine natural products, however, were delayed until the advancement of technology, most importantly the advent of SCUBA (Self-Contained Underwater Breathing Apparatus) diving in the 1950s. Phenotypic screening of soil samples for NPs continued in the 1970s and 1980s and was expanded beyond the soils into marine environments with the advent of SCUBA. Samples were able to be collected by divers or sampling devices including bacteria, algae, and invertebrates (tunicates, corals, bryozoans, sea slugs, sponges etc.). ${ }^{15}$

Even with the advent of SCUBA, there is still a profound amount of marine life yet to be investigated. As it stands, less than $5 \%$ of the deep sea has been explored. ${ }^{27}$ With the development of advanced autonomous robotics, exploration of the sea is bound to unravel a staggering amount of new bioactive compounds. ${ }^{17,26}$ Marine organisms are unique in their production of chemical defences, and produce a "dizzying array" 33 of secondary metabolites. These include, but are not limited to, terpenes, steroids, polyketides, peptides, alkaloids, macrolides and porphyrins. Many of these act as trail markers, sexual attractants, antifouling compounds or antifeedants. Marine sponges, for example, are limited in their kinetic abilities. Therefore, their defences against predators come in the form of potent chemicals that can withstand dilution and still exert a heavily toxic effect. ${ }^{23}$ There is an overwhelming amount of diversity encapsulated within the earth's oceans, as compared to the terrestrial environment. This translates to an unprecedented amount of potential for drug discovery from marine sources. While the terrestrial environment accounts for 2 of the 36 animal phyla identified taxonomically, the marine environment accounts for the remaining 34 (half of these are both marine and terrestrial). ${ }^{27}$ 


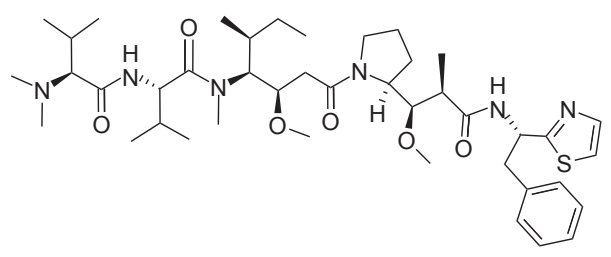

(34)

\subsubsection{Approved Marine-Derived Drugs}

\section{Dolostatin 10 (Adcetris $\left.{ }^{\circledR}\right)$}

The dolostatins are a series of peptides (linear and cyclic) isolated from the sea hare Dolabella auricularia. Although they were isolated from the sea hare, the metabolites are products of the cyanobacterium Caldora penicillate, thought to exist in a symbiotic relationship with the mollusc. ${ }^{27,34}$ The orginial dolostatins were unsuitable as potential drugs and did not progres past Phase II clinical trials due to excessive toxicity. ${ }^{27,34} \mathrm{~A}$ number of analogues were synthesised including auristatin PE (soblidotin, TZT-1027, YHI-201), cematodin and synthadotin (tasidotin, ILX-651) but did not progress beyond Phase I/early Phase II clinical trials. ${ }^{27,34}$ Consequently, two variations of auristatin (MMAE (monoethylauristatin E) and vedotin) were synthesised and were found to be highly bioactive. ${ }^{27,34}$ Seattle Genetics were able to link specific MAbs (monoclonal antibodies) to both of these "war-heads", becoming Adcetris ${ }^{\circledR}$ (34). ${ }^{27,34}$ Specifically, this conjugate consisted of a mouse MAb linked to 8 valine-citruline-MMAE molecules where the MAb was directed against the CD30 epitope expressed in leukaemic cells. ${ }^{27,34}$ During 2011, Adcetris ${ }^{\circledR}$ (also known as cAC10-vcMMAE) was approved as an ADC (antibody-drug conjugate) by the US FDA (United States Food and Drug Administration) for the treatment of all CD30-positive leukaemias (CD30 is also known as TNFRSF8, a cell membrane protein and tumour marker). ${ }^{27,34}$ The drug was approved in the European Union (EU) in 2012, and was launched in the United Kingdom (UK) in early 2013. ${ }^{27,34}$ It is primarily used in the treatment of Hodgkins Lymphoma. ${ }^{27,34}$ Since it's approval, there have been a number of variants for which clinical trials are ongoing. Each variant utilises different antibodies with the intention of becoming applicable to other diseases. ${ }^{27,34}$

Glembatumumab vedotin is currently in Phase II clinical trials. ${ }^{27,34}$ The MMAE is linked to a fully human MAb CR011 (an anti-CG56792) via the valine-citrulline dipeptide linker as in Adcetris ${ }^{2}{ }^{27,34}$ This variation initially targeted patients with unresectable melanomas at 
stage III or IV that had failed one chemotherapy regimen, and was then expanded to include metastatic breast cancer as well. ${ }^{27,34}$ It is also known by the names CDX-011, CR-011 and CR011-vcMMAE. ${ }^{27,34}$

Pintuzumab vedotin, also known as DCDT-2890 S, is currently in Phase II trials. ${ }^{27,34}$ This ADC was created by Genetech, and uses a humanised IgG1 (immunoglobulin G1) antibody directed against CD22 epitopes in leukaemia. CD22 is not present in rodents, therefore, trials were performed on cynomologus monkeys. This variation demonstrated adequate safety and is in trials for the hope of treating non-Hodgkin's lymphoma. ${ }^{27,34}$

Polatuzumab vedotin (DCDS-4501) was developed by Genetech/Roche, and is currently in Phase II clinical trials for the treament of non-Hodgkin's lymphoma and other various lymphomas in dose escalation studies. ${ }^{27,34}$ DCDS-4501 consists of an ADC with MMAE linked to an anti-CD79b MAb. ${ }^{27,34}$

\section{ET743 (Yondelis $^{\circledR}$ )}

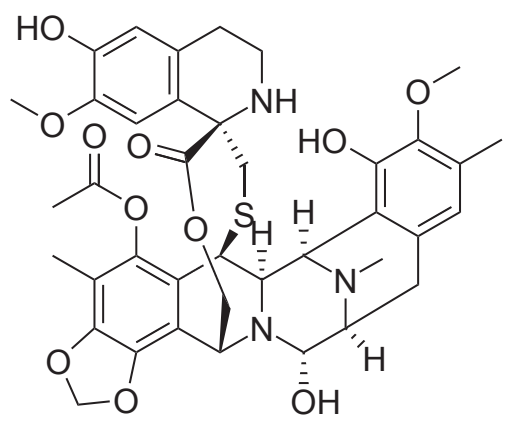

(35)

Yondelis ${ }^{\circledR}(\mathbf{3 5})$ is considered to be the "poster-child" for marine-derived antitumour agents. Fascinatingly, it is identical to the original dimeric isoquinilone alkaloid isolated from the tunicate Ecteinascidia turbinata and is the only complete marine natural product currently approved as an antitumour agent. ${ }^{27,34}$ Yondelis $^{\circledR}$ is approved for the treatment of soft tissue sarcoma (STS) in the EU (approved 2007) and over 70 countries as a monotherapy for treatment of STS. In a number of countries it is also approved for the treatment of recurrent platinum-sensitive ovarian cancer in conjunction with liposomal doxuribicin. ${ }^{27,34}$ The original application for US FDA approval was submitted in 2009 for the treatment of STS, however, it was withdrawn. In February 2015 it was accepted for priority review for STS in the 
USA following the submission of a New Drug Application (NDA) in November 2014. ${ }^{27,34}$ Yondelis works by inhibiting the growth of cancer cells. In addition, it also affects the tumour microenvironment (TME) by limiting the number of macrophages and inhibiting the production of macrophage products that promote tumour growth. ${ }^{27,34}$ Currently, there are a number of ongoing trials listed with the NIH (National Institute of Health) in various phases for the treatment of other cancers ${ }^{27,34}$ Other similar compounds are currently undergoing clinical evaluation such as Lurbectedin (PM01183) in Phases I-III and Zalypsis ${ }^{\circledR}$ (PM-10450) in Phase II, which was isolated from the marine sponge Netropsia sp. ${ }^{27,34}$

\section{Eribulin (Halaven ${ }^{\circledR}$ )}

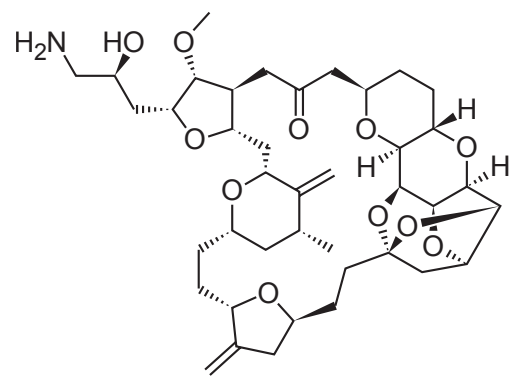

(36)

Eribulin (36), also known as Halaven ${ }^{\circledR}$ or E-7389, is a halichondrin B derivative (5). ${ }^{27,34}$ This is a wholly synthetic molecule that comprises over half of the structure of halichondrin B, an antitubulin compound. ${ }^{27,34}$ Foundational research by the Eisai Research Institute (ERI) determined the active part of molecule resided in the macrolide ring (approximately $600 \mathrm{Da}$ ) and not in the "tail". Work by other research groups synthesised over 200 related molecules. The lead compound was characterised as a modified truncated macrocyclic ketone. ${ }^{27,34}$ As with the parent compound halichondrin B, eribulin interacts with $\alpha$-tubilin, possessing potent nanomolar level activity in in vitro studies. The drug is thought to inhibit microtubular dynamics, resulting in the prolonged arrest of mitosis, thus inducing apoptosis. ${ }^{27,34}$

\section{Ziconotide $\left(\right.$ Prialt $\left.^{\circledR}\right)$}

The story of ziconotide (32) begins with fundamental work by Olivera $^{35}$ on the peptidic neurotoxin from the fish-hunting cone snail Conus magnus, the successful candidate also known as $\omega$-conotoxin MVIIA. ${ }^{27,34}$ It was discovered that these peptidic toxins were specific as to which of the cation-gating channels that they inhibited and/or activated, and they were 
subsequently investigated as potential neurological agents. ${ }^{27,34}$ A small company, Neurex, was established to evaluate the 25-mer cyclic peptide, now known as ziconotide. Close to 200 modifications (of the tricyclic peptide; three CYS-CYS linkages) were synthesised and evaluated for their potential, however, the natural product was the most potent (though made synthetically for trials). ${ }^{27,34}$ Ziconotide (or Prialt ${ }^{\circledR}$ ) became the first intact marinederived product to gain approval as a drug. It was approved by the FDA on 28/12/2004 and was approved by the EMA (European Medicines Agency) two months later. ${ }^{27,34}$ Despite its success, administration of the drug is not desirable as it must be injected intrathecally. However, there are some similar analogues that are currently in development. ${ }^{27,34}$

\section{$X E N-2174$}

XEN-2174 is a product from the company Xenome, and is, as of 2016, in Phase II clinical trials for the treatment of cancer pain and pain from bunion surgery (in Bulgaria). ${ }^{27,34}$ The latter trial was terminated by the FDA, however, although no data has been released. ${ }^{27,34}$ This compound is a slight variation on the naturally occuring $\chi$-conotoxin MrIA, isolated from Conus marmoreus and optimized in a medicinal chemistry programme. ${ }^{27,34}$ Unlike the other conotoxins, this agent is a 13-residue peptide and is a noncompetitive inhibitor of the neuronal norepinephrine transporter (NET). ${ }^{27,34}$

\section{Leconotide ( $\omega$-Conotoxin CVID)}

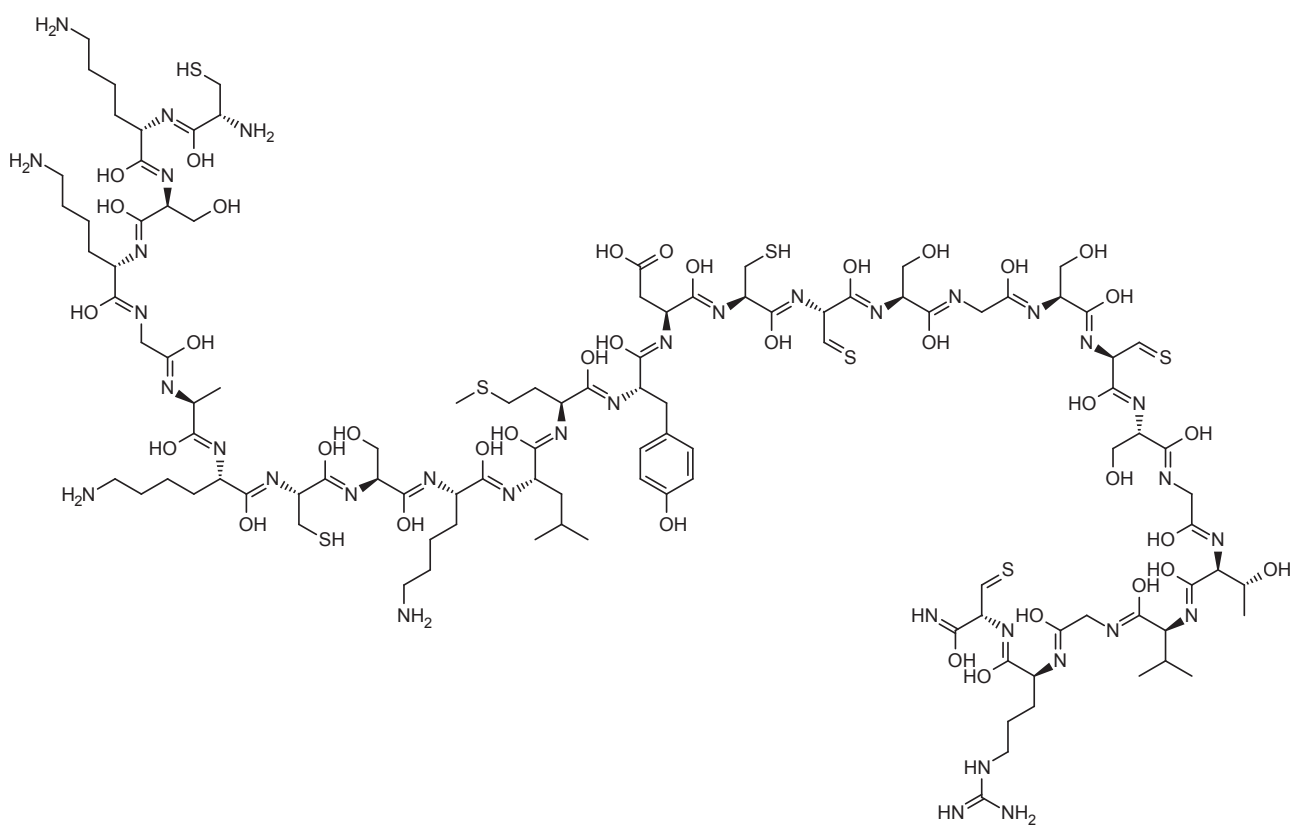


Leconotide (37) is a 27-residue peptide with three internal CYS-CYS bonds, similar to the molecule ziconotide. ${ }^{27,34}$ This variant had reached Phase I trials, sponsored by Relevare Pharmaceuticals (Australia) for the treatment of cancer pain. ${ }^{27,34}$ It is a calcium channel blocker and was originally discovered at the University of Queensland. ${ }^{27,34}$ Although initial experiments administered this drug via the intrathecal route (similar to ziconotide), the clinial trial protocol mentioned systemic administration. ${ }^{27,34}$ The company has now liquidated, however, so its future is unclear. ${ }^{27,34}$ Interestingly, Craik et al. ${ }^{36}$ have demonstrated alteration of peptides (including cone snail toxins) by taking structural cues from plant cyclotides. ${ }^{27,34}$ As a result, the pharmalogical characteristics have changed to producing oral analgesic activity in animal tests, thus giving such moleules potential as oral pain drugs, avoiding the troublesome intrathecal route..$^{27,34}$

Other noteable approved marine drugs not discussed in detail here include ara-A (vidarabine) and ara-C (cytarabine). They were synthesised based on two nucleosides isolated from the Caribbean sponge Tectitethya crypta, These two nucleosides contained D-arabinose opposed to D-ribose. Ara-A was first synthesised in 1960 at the Stanford Research Institute and is approved as an antiviral drug, and is used against herpes simplex and varicella zoster viruses. ${ }^{37}$ Ara-C is a form of chemotherapy, used in the treatment of acute myeloid leukaemia (AML), acute lymphocytic leukaemia (ALL), chronic myelogenous leukaemia (CML) and non-Hodgkin's lymphoma. ${ }^{37}$ It was first synthesised by Walwick et al. in 1959, according to Sneader. ${ }^{37}$ Although currently in clinical trials, another compound, HTI-286 is a synthetic analogue of natural product hemiasterlin ${ }^{38}$ isolated from marine sponge Hemiasterella minor.

\subsubsection{Marine-Derived Compounds in Clinical Trials}

\section{Tetrodotoxin}

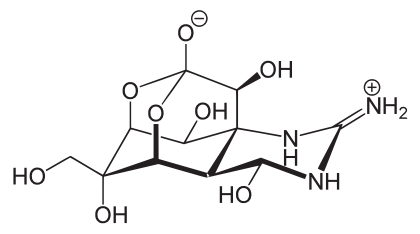

(38)

Tetrodotoxin (38) is a well-known marine toxin, consisting of a highly substituted guanidine 
orthoester. ${ }^{27,34}$ This drug was developed by WEX Pharmaceuticals and is currently in two Phase III trials in the USA, under the name Tectin ${ }^{\circledR} .{ }^{27,34}$ It is under trial for inadequatelycontrolled pain related to cancer. One trial was terminated (under the same company) at Phase II against neuropathic pain from chemotherapy-induced peripheral neuropathy, because the interim results were unsatisfactory to move directly to Phase III trials for the same condition. ${ }^{27}$ It is believed to be produced by a marine microbe, but the exact microbe has been a subject of debate. ${ }^{27,34}$ The synthesis of this compound and other derivatives has been studied in a number of publications, that have been extenisvely reviewed by Nishikawa and Isobe. ${ }^{39}$

\section{Alpidine}

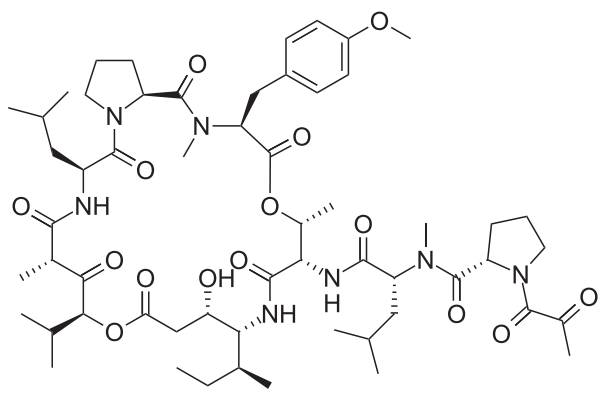

(39)

Alpidine (39) is a close relative of the compound didemnin B (5), formally called dehydrodidemnin B. ${ }^{27,34}$ Didemnin B was the first direct-from-sea antitumour compound. ${ }^{27,34}$ Unfortunately, due to its high toxicity in Phase II trials, it was discontinued as a potential anti-tumour drug. ${ }^{27,34}$ Aplidine was originally isolated from sea squirt Alpidium albicans and first reported in 1989. ${ }^{27,34}$ It was mentioned in a patent application in 1989, and was accepted in a UK patent issued in $1990 .{ }^{27,34}$ The first journal publication mentioning the compound was in Rinheart's 1996 paper covering structure-activity relationship (SAR) of a group of molecules classed as didemnins. ${ }^{27,34}$ It is currently involved in four clinical trials; one at Phase III, two at Phase II and one at Phase I. It is undergoing trials for a number of conditions, including multiple myeloma (with or without dexamethasone) and refractory non-Hodgkin's lymphoma. ${ }^{27,34}$ The mechanism of action for this antitumour compound has not been fully described, but a review by Munoz-Alonso ${ }^{40}$ has revealed some of the cellular interactions, and more have been revealed in subsequent years, involving the immune system. In November 2014, PharmaMar scientists reported that alpidine bound directly to 
eukaryotic elongation factor 1A2 (eEF1A2), a target that is abundantly expressed in multiple myeloma and acute lymphoblastic leukaemia. ${ }^{27,34}$

\section{PM050489/PM060184}

PM050489 is a polyketide, and PM060184 is its chlorinated derivative. Both were isolated from the Madagascan sponge Lithoplocamia lithistoides. ${ }^{27,34}$ The crude extract demonstrated antimitotic activity and the isolated agents demonstrated tubulin-binding activity, with evidence of binding to (or close to) the vinca domain. Further reports of activity include the chlorinated derivative showing activity against P-glycoprotein-epressing tumours. ${ }^{27,34}$ The syntheses were described by the PharmaMar group in 2013, which was necessary due to the low yielding extraction of the two compounds. ${ }^{27,34}$ Currently, PM060184 is listed in one Phase I pharmacokinetc trial under PharmaMar, treating patients with advanced solid tumours. ${ }^{27,34}$

\section{Pipecolidespin, stellatolide A, and irvalec}

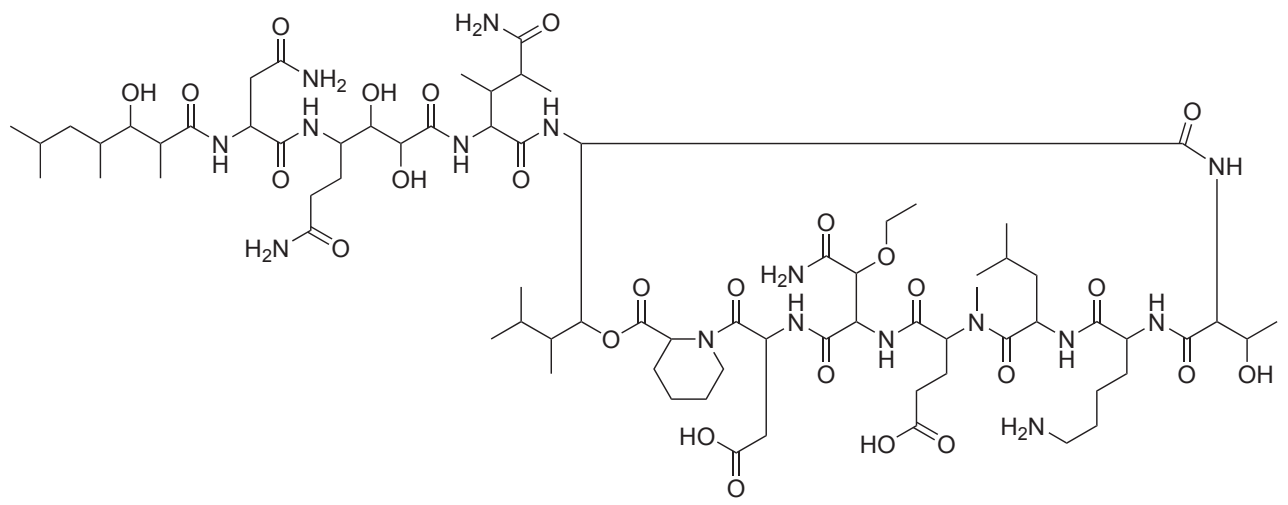

(40)

These three compounds all belong to the company PharmaMar, with all apparently demonstrating some biological activity. ${ }^{27,34}$ Irvalec was pulled from clinical trials at the Phase II level, so they are now reporting solely on the other two leads; pipecolidespin (40) and stellatolide A. ${ }^{27,34}$

\section{Marizomib $^{\circledR}$}

This compound was discovered from the marine actinomycete Salinispora tropica and has been identified as a proteasome inhibitior. ${ }^{27,34}$ It is isolated using a workup to give the cGMP 
(current good manufacturing practice) product. This process is the first marine large-scale fermentation synthesis, employing a wide range of contributors. Nerus Pharmaceuticals, the company formed to develop the compound, and others from the Jensen/Fenical laboratories, liquidated some years ago. As a result, all intellectual property was transferred to Triphase Research and Development Corporation. ${ }^{27,34}$ Currently, the compound is registered in two Phase I trials for the treatment of multiple myeloma. ${ }^{27,34}$

\section{Bryostatin 1}

The bryostatins are a class of 20-membered macrocyclic cytotoxins from the bryozoan Bugula neritina (a fouling filter feeder). ${ }^{27,34}$ Some forms have been also been isolated from sponges and tunicates. ${ }^{41}$ The original molecule was isolated over 30 years ago, and led to a number of analogues being synthesised. Bryostatin 3 was the first discovered, and was reported in 1970, and the isolation and structure of bryostatin 1 reported in $1982 .{ }^{27,34,41}$ All bryostatins possess a " 20 -membered macrolactone ring with three substituted pyran rings linked by a methylene bridge and an $(E)$-disubstituted alkene. All have geminal dimethyls at $\mathrm{C}_{8}$ and $\mathrm{C}_{18}$, and a four carbon side-chain from the $\mathrm{A}$ ring to the lactone oxygen, with another four carbon chain on the other side of the lactone oxygen to the $\mathrm{C}$ ring. Most also have an exocyclic methyl enoate in their $\mathrm{B}$ and $\mathrm{C}$ rings, though bryostatin 3 , in particular, has a butenolide rather than the $\mathrm{C}$ ring methyl enoate, and bryostatins 16 and 17 have glycals in the place of the regular $\mathrm{C}_{19}$ and $\mathrm{C}_{20}$ hydroxyl moieties." ${ }^{27,34,41}$ A number of bryostatins have been isolated from a wide range of geographic locations including from the South China Sea and Atlantic Ocean. ${ }^{27,34,41}$ There are currently 21 naturally occuring bryostatins. ${ }^{27,34,41}$ Four other closely-related bryostatins have been isolated but they are presumed to be artifacts of the isolation techniques used. ${ }^{27,34,41}$

Bryostatin 1 has been the lead compound to enter clinical trials. It was been through over 80 Phase I and Phase II clinical trials as an anticancer drug, but the compound has not progressed. It was also entered in a clinical trial for Alzheimer's disease, but was terminated at Phase II. In June 2015, Aphios Inc. (Massachusetts) announced they had enrolled patients for a Phase I/II study of bryostatin 1 in a trial designed to release the HIV (human immunodeficiency virus) virions from their latent sites in patients. This is a phenomenon of HIV (and 
a number of other viruses), and forms the basis of the anti-HIV treatment known as HAART (highly active antiretroviral therapy). ${ }^{27,34,41}$

\section{Griffithsin}

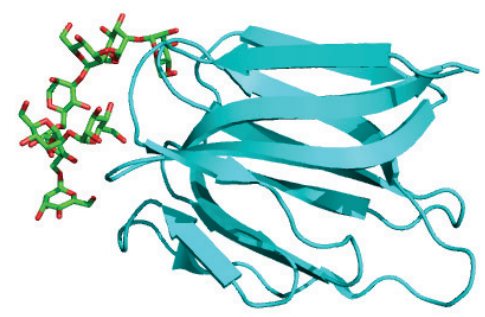

(41)

Griffithsin (41) is a microbial viricide headed for clinial trials. It's structure consists of 121 peptidic residues, and was first reported in 2005 following its isolation from the red alga Griffithsia sp. ${ }^{27,34}$ In order to circumvent a supply issue for the raw natural product, it was synthesised by transferring the DNA sequence corresponding to the peptide via plasmid into (and expressed in) Escherichia coli. ${ }^{27,34}$ Griffithsin was shown to bind to mannose-rich regions of HIV viral proteins. Studies have shown it has the potential to be used as a topical microbicide with potential to also be used as an intravaginal drug to protect against HIV transmission. It is currently being developed for these uses by the "Population Council" (NY, USA). ${ }^{27,34}$

\subsection{New Zealand Marine Natural Products}

Marine organisms originating from the waters of New Zealand have produced a spectacular array of natural products with diverse scaffolds and bioactivities, a result of New Zealand's incredible marine biodiversity. New Zealand's geographic isolation has allowed New Zealand's marine species to evolve their own unique structures and metabolites, allowing for the discovery of many novel compounds. Internationally there is a $0.000001 \%$ chance of discovering a chemically or bioactively useful chemical from a marine organism within an exlusive economic zone. However, New Zealand's success rate is $2 \%$, which is huge by comparison. ${ }^{42}$ Even if the molecule itself does not become a drug, it may enter drug development programmes and generate future drug leads. 
One of the best examples is peloruside A, isolated from sea sponge Mycale henscheli located in the Pelorus Sound. Peloruside A was originally described in 2002 by West, Northcote and Battershill as a potent cytotoxic macrolide. ${ }^{43}$ Since then, copious amounts of work has gone into characterising the compound as a microtubule-stabilizing agent. ${ }^{44-48}$ It has showed profound biological effects at the cellular level ${ }^{45,49-51}$ and on xenografts ${ }^{52}$ and other animal models. ${ }^{53}$ Studies have also been conducted regarding resistance to peloruside, ${ }^{51,54}$ studies of its binding site, ${ }^{45,55}$ and its synthesis and analogues. ${ }^{56}$

Another noteable example is the chemical named pateamine, also isolated from Mycale hentscheli genera located in Thompson Sound. ${ }^{57}$ Pateamine is an exceedingly potent cytotoxin, ${ }^{58}$ which features a thiazole-containing macrolide with a rare dilactone functionality. ${ }^{57}$ Since it's initial discovery, a large number of papers have been published detailing is MOA (mechanism of action) and target ${ }^{59-62}$ (particularly its interactions with eIF4A), ${ }^{63-66}$ its total synthesis, ${ }^{67,68}$ and many analogues. ${ }^{69,70}$

\subsection{Natural Products and Intellectual Property}

The success of a drug, from the perspective of the inventors, depends on its ability to be patented. Once patented, the drug can be approved and the inventors obtain the rights to produce and sell their product, and ultimately, profit. Natural products and their extracts are popular candidates for drugs and supplements. Patents offer exlusive rights to protect such innovations, allowing the inventors to market and sell their product. This is extremely important in the context of TCM and JCM for example, which rely on prepared extracts and compounds from natural materials. It is also relevant for any drug that exists in its natural state (unmodified from the natural product) and drugs that are based upon natural products or use their scaffolds. The United States Patent Office (USPTO) recently revisited the patenting policy guidelines of natural products following three high-profile Supreme Court rulings; Molecular Pathology versus Myriad Genetics, Inc., ${ }^{71}$ and Mayo Collaborative Services versus Prometheus Laboratories, Inc., ${ }^{72}$ and Diamond versus Chakrabarty. ${ }^{73}$ These court cases and guidelines highlight the inconsistancy and change in attitude towards the patenting of natural products. These rulings somewhat strain the prospects of discovering potent drugs of natural origin, and is a challenge that should be acknowledged. 
The most influential ruling involved Association for Molecular Pathology versus Myriad Genetics, Inc. This court ruling invalidated a patent on an isolated DNA molecule from the human cancer-susceptibility gene BRCA. ${ }^{74}$ In 1990, an article was published by Hall et al. ${ }^{75}$ that associated the risk of breast cancer with a certain gene (BRCA1) on the long arm of chromoshome 17. It was noted at the time that testing for the mutations would be an extrememly important tool in the ability to predict one's susceptibility to breast and ovarian cancer. The scientists involved formed Myriad Genetics in 1994, and published the genetic sequence of BRCA1, which they had isolated. ${ }^{76}$ Subsequently, a patent was filed by the University of Utah (from where Myriad Genetics originated), US 5,747,28,2 $2^{77}$ and another patent concerning the isolated and sequenced BRCA2 gene, US 5,837,492, ${ }^{78}$ was filed in 1995 . A series of patents followed with other developments in using these gene sequences as diagnostic tools. The plantiffs, Association for Molecular Pathology et al. acknowledged that if valid, the patents that Myriad was granted would give them exclusivity and the right to isolate an individuals BRCA1 and BRCA2 genes, and give them the right to synthetically create BRCA cDNA (complimentary DNA). ${ }^{71}$ The specific claims that were argued were claims 1 , $2,5,6,7$, and 20 of US 5,747,282; ${ }^{77}$ claims 1,6 , and 7 of U.S. patent $5,837,492 ;{ }^{78}$ claim 1 of U.S. patent $5,693,473 ;{ }^{79}$ claim 1 of U.S. patent $5,709,999 ;{ }^{80}$ claim 1 of US $5,710,001 ;{ }^{81}$ claim 1 of US 5,753,441; ${ }^{82}$ and claims 1 and 2 of US $6,033,857 .{ }^{83}$ The plantiffs claimed that Myriad's patents were invalid under 35 U.S.C. $\$ 101$, as they covered products of nature. The patent act claims that patents may be issued to "[w]hoever invents or discovers any new and useful...composition of matter, $\S 101$, but "laws of nature, natural phenomena, and abstract ideas are basic tools of scientific and technological work that lie beyond the domain of patent protection." ${ }^{71}$ Despite the fact that the molecule was isolated from the human genome by severing chemical bonds between neucleotides, and the isolated DNA molecule is not naturally-occuring, the Supreme Court claimed that the isolation did not constitute an act of invention, and stated it has no "markedly different characteristics from any found in nature" and the claims were sated, such that they were not expressed in terms of chemical composition, only the genetic information in the nucleotide sequence. ${ }^{74}$ It is worth noting, however, the cDNA of the BRCA mutation that had an intron removed was patentable because it was not naturally-occuring (identical cDNA would not be patentable). ${ }^{7471}$ 
In other cases, a recrystallised aspirin and purified form of adrenaline were deemed patentable because the purer forms were therapuetically different from the natural forms. ${ }^{84}$ Similarly, purified vitamin B12 (1) from the fermentation of fungi was granted a patent. ${ }^{85}$ This was similar in the Diamond versus Chakrabarty case, where the Courts deemed a genetically engineered bacterium capable of breaking down crude oil was patentable because, understandably, it was different from any bacterium found in nature. ${ }^{73}$ In the cases above, the Courts took the stance that the isolation or purification had transofmred the natural product, however this was not the case for the isolated BRCA1 and BRCA2 genes, which had also been isolated and purified. In contrast, purified tungsten from tungsten ore and a naturallyoccuring bacterial stain ${ }^{86}$ were held to be unpatentable because the Courts claimed their usefulness was identical in the purified and natural forms. ${ }^{86,87}$ They had discovered "the natural qualities of the pure tungsten" 87 and did not create "a state of inhibition or of non-inhibition in the bacteria". ${ }^{86}$

\subsection{Methods of Screening for Natural Products}

There exists two main current methods of screening and isolating natural products; bioassayguided isolation and spectroscopic-guided isolation. Screening involves anal-ysing bulk fractions of extracts of biological organisms (for example, methanolic or ethanolic extracts of plant material, microbial cultures or marine organisms). Analysis can either be in the form of bioassay to check for biological activity, or by spectroscopy (often ${ }^{1} \mathrm{H}$ (proton), COSY (correlation spectroscopy) or HSQC (heteronuclear single quantum coherence) NMR (nuclear magnetic resonance)) to identify unusual or interesting resonances that indicate novelty or functional groups relevant to potential drugs. Screening often involves a range of biological organisms from similar phyla. For example, one may screen a range of fungi for potential antifungals, or a range of marine sponges for cytotoxic compounds. The result is an order of preference for which organisms will prove most valuable for further isolation and purification.

Bioassay-guided isolation has found a wide range of applications, but comes with its advantages and disadvantages. Bioassay-guided isolation involves the fractionation of bulk, usually alcoholic, extractions followed by biological assays to determine bioactivity of such 
fractions. Fractions (from flash chromatography) ${ }^{88}$ are then pursued for further fractionation, isolation and purification based on their desired biological activity. ${ }^{89}$ This approach guarantees the isolated compounds will be bioactive. However, dereplication is challenging when employing bioassays alone. Dereplication is the process of detection, identification and elimination of previously-known metabolites within the crude biological mixture at the beginning stage of the screening process. ${ }^{89}$ Dereplication often involves the use of separation techniques, analytical techniques and spectroscopic methods and database searching. ${ }^{89}$ Overall, dereplication focuses efforts towards discovering novel bioactive compounds, instead of the pursuit of known compounds. Bioassay-guided screening and isolation does not take into account spectroscopic techniques. Often they can be combined with spectroscopic techniques, but overall the pursuit must be based on bioctivite or spectroscopic properties. Another issue is that bioactivity of a crude mixture is not always representative of the individual compounds. Metabolites present in small amounts that may be potent are overshadowed by common metabolites present in higher amounts. In addition, samples cannot be retrieved after bioassay, which can pose a problem when metabolites are only present in small amounts, such as from marine sponges. A huge advantage of bioassayguided screening is that one can hunt for certain bioactivities. If the goal of the research is to find a novel antibiotic, then a bioassay testing for antibiotic activity can be engingeered and utilised. Rakshith et al. ${ }^{89}$ detail the application of bioassay-guided fractionation coupled with a molecular approach for the dereplication of antimicrobial metabolites.

Spectroscopic-guided isolation relies on spectroscopic techniques to identify possible novel metabolites in a crude mixture, and exclude others, otherwise known as metabolic profiling. ${ }^{88}$ Familiar spectroscopic techniques include ${ }^{1} \mathrm{H}, \mathrm{COSY}$ and HSQC NMR spectroscopy. ${ }^{1} \mathrm{H}$ NMR data is readily available for most compounds (or can be readily predicted), and ${ }^{1} \mathrm{H}$ NMR experiments are usually very quick and easy to obtain, they also provide a large amount of information about the possible chemical structure of the metabolites present. In addition, samples are retrievable and reuseable afterwards, unlike bioassay-guided isolation, which is extremely important when metabolites are of low concentration. Similar in both bioassay and spectroscopic-guided isolation, these methods make use of classic solvent extraction methods, using organic solvent of different polarity. ${ }^{88}$ 
A review by Ciesla textitet al. ${ }^{90}$ details a wider range of screening and isolation techniques, including phytochemical analyses, untrafiltration, bioaffinity chromatography, cellular membrane affinity chromatography, and ligand fishing. The review by Bucar et al. ${ }^{88}$ also details similar methodologies throughout the isolation and purification procedure, include approaches such as ultrasound-assisted extraction, microwave-assisted extraction, accelerated solvent extraction, distillation methods, chromatographic methods, and gas chromatography.

\subsection{Marine Natural Products Amongst the -omics}

Natural products still remain an untapped source, as only a small amount of the world's plant biodiversity has been screened for bioactivity, and similar with microbial cultures and marine environments. ${ }^{14}$ Despite the success of natural products, the area of research is being questioned in terms of its relevance to modern drug discovery and development. While traditional methods of drug discovery from natural products are becoming outdated, new approaches can breathe new life into this valuable area of research. ${ }^{2,4,91}$ In terms of high throughput screening (HTS), crude extracts can be optimised and simplified into fractions that remove molecules with undesirable characteristics or those that are considered promiscuous binders and artefacts. This involves removing highly polar metabolites, salts and carbohydrates, and fats, sterols and other lipids which are often not valuable as potential drugs. A review by Harvey ${ }^{26}$ details the re-emergence of natural products and their potential applications to the -omics. There is considerable potential for marine natural products to be combined with genomics, metabolomics and bioinformatics as whole genome sequencing and whole exome sequencing develop and become more efficient and cost-effective. There is a widely recognised supply issue, particularly with marine natural products whose compounds are only extractable in very small quantities, which this approach may help alleviate. ${ }^{5}$

There exists the perception that natural products are somehow incompatible with modern drug discovery techniques and as such, major pharmaceutical companies have diminished their focus on natural product drug development programmes. ${ }^{26}$

High-throughput screening refers to the screening of a large library of either compounds, extracts, genomes etc. The traditional approach can be easily modified in order to align with 
high-throughput screening. Traditionally, in NP screening, concentrated extract samples were used in bioassays. However, this approach means that some components or compounds are in too low a concentration to present any observable effects. Isolating single compounds in advance of screening is counterproductive to the purpose of bioassay-guided isolation and high-throughput screening, as it would be extremely time-consuming. A review by Harvey ${ }^{26}$ explains that the first step towards simplifying extracts for bioassays is to remove compounds that are likely to cause artefacts, such as polyphenolic tannins found in plant extracts. Or, on the other hand, discarding of early and late fractions that are either highly polar or lipophilic to better the chances of isolating a drug-like molecule. That being, one that has the ideal ADMET (absorption, distribution, excretion, toxicity) characteristics. This is referred to as pre-fractionation. Other compounds could include fatty acids and lipids, chromatography being the simplest strategy to achieve pre-fractionation, with $\mathrm{C}_{18}$ HPLC being the most common step, in order to generate a number of fractions per sample. Such pre-fractionation has shown to increase screen hit rates. ${ }^{26}$

Metabolomics arose from the concept of metabolic profiling, and is defined as the quantitative and qualitative analysis of all metabolites that are contained in an organism at a specific time under specific conditions. ${ }^{26,92,93}$ Ultimately, this allows the monitoring of gene function in the production of certain metabolites. A combination of metabolomics and genomics can be used to optimize a biosynthetic pathway to selectively produce biologically active secondary metabolites. This appears to be limited to just microbial sources, but often, metabolites we think come from marine invertebrates come from marine microorganisms in which the sponge has formed a symbiotic relationship with. ${ }^{26}$ Unfortunately many of these microbes are not able to be cultured in laboratory conditions. As of yet, it seems these approaches are not yet suitable for marine natural products but one day they may be, due to a lack in suitable metabolomic databases.

One of the most promising developments in screening for natural products, and one that has the most potential for application for marine natural products, is the use of GNPS (Global Natural Product Social Molecular Networking). The first example of this was published by Watrous et al. ${ }^{92}$ GNPS creates a molecular network of the metabolites present in a sample, based upon MS/MS fragmentation data. Traditionally, when MS/MS (tandem mass spec- 
trometry) spectra are compared to analyse similarity of fragmentation patterns, the mass-tocharge ratio $(\mathrm{m} / \mathrm{z})$ of the fragments are the main focus of analysis. However, this analysis does not account for the intensity of fragmentation patterns, or their partial similarity or likeness, and the metabolites' relationship as a result of that partial similarity (i.e. not just identical fragmentation patterns). GNPS Network generation involves the vectorisation of MS/MS data, to account for signal intensity in addition to fragmentation pattern. The result for any one parent ion is a cosine score, which can be compared to the cosine score of other compounds in the network. Their similarity is linked visually with a straight line of varying width. For example, a high cosine score (close to 1) between two parent ions will receive thick line. Two loosely-related compounds (e.g. a cosine score of 0.01) will be joined with a thin line. Two compounds not related at all, will stay in separate clusters of the visual and interactive network. This tool can be used to generate libraries or use specific MS/MS data and compare it to the molecular network in order to predict the class of molecule or structure, when it is unknown. ${ }^{94}$ This is a powerful tool that can be combined with other techniques such as MALDI-TOF (matrix-assisted laser desorption ionization-time of flight) MS/MS when analysing bacterial cultures on petri dishes, and perhaps their zones of inhibition. It can also serve as a valuable tool for dereplication of known metabolites. As it stands, GNPS has great potential to be used with marine natural products. At the moment, however, it lacks the large amount of data needed for MNPs to be a valuable resource.

\subsection{Isolated Compounds From Aaptos sp.}

Interest in the genus Aaptos (in particular, Aaptos aaptos) commenced in 1982 with the discovery of aaptamine, a novel heteroaromatic at the time. ${ }^{95}$ This discovery encouraged further investigation of the genus and since then, analogues such as isoaaptamine and demthyl(oxy)aaptamine have been isolated along with aaptosine, ${ }^{96}$ and aaptosamine.${ }^{97}$ Also isolated, and synthesised, have been an abundance of aaptamine derivatives, either by coincidence or in hopes of improving bioactivity. Aaptamine orginally showed $\alpha$-adrenoreceptor blocking activity ${ }^{95}$ while other aaptamines have shown 21 promoter activation, ${ }^{98}$ possession of antiviral activity ${ }^{99,100}$ anticancer and cytotoxic behaviour ${ }^{33,101-105}$ apoptosis-induction ${ }^{106}$ protea-

some inhibition and antifungal activity. ${ }^{107}$ Remarkably some of the bioactivities aaptamine 
possesses have only recently been revealed in the literature. ${ }^{103,105}$

Other classes of molecules have also been disovered, such as the ciliatamides ${ }^{108}$ and suberitines. ${ }^{109}$ Such classes have extended the chemical diversity of the genus, and with such a wide range of bioactive molecules, offered a higher probability of isolating new compounds.

\subsection{Research Aims}

The aim of the project was to isolate, purify and elucidate the structures of new and novel compounds from a selection of New Zealand marine sponges.The objectives were to:

1. Screen five New Zealand marine sponges whose genera have been shown to contain bioactive natural products.

2. Isolate and purify select compounds of interest from a selected sponge(s) using spectroscopicguided isolation methodology.

3. Identify the structure of these compounds by spectroscopic analysis.

4. Assess, with an unbiased geographic collection, the metabolites of the genera chosen to investigate.

VUW (Victoria University of Wellington) and the Marine Natural Products Research Group were provided with sponge and algae samples from NIWA (National Institue of Water and Atmospheric Research). These samples were collected from various locations around New Zealand. The remote locations from which these marine specimens were collected would have been otherwise inaccessible to our research group. Out of the extensive specimen library, five sponges were chosen for screening as their genera had previously yielded biologically active natural products, based on the hypothesis that species related by genus will also contain compounds of interest and perhaps have new secondary metabolites. These sponges included Aaptos confertus, Phorbas areolata, and Cliona celata. Also screened were Stelletta carter and Dictyodendrilla dendyi.

These samples were collected from around Three Kings Islands, where a wide range of diversity has been observed in marine life. Some of sponge specimens had not been previously 
studied according to currently available literature. This offered exciting opportunities to discover new compounds. Isolation was focused on compounds with aromatic systems or those containing a chromophore. In addition, dereplication (the act of comparing spectroscopic data of known compounds with the data of a discovered compound) was attempted using NMR data to encourage the pursuit of novel compounds. Samples containing compounds of interest were purified using normal and reversed-phase chromatography and their structures determined using predominantly NMR spectroscopy and mass spectrometry. 


\section{Chapter 2}

\section{Spectroscopic Screening Results}

Three marine sponges collected from Spirits Bay and the Three Kings Islands were screened using the VUW screening method. One sponge, Aaptos confertus, was selected for investigation based on it's promising results in the 1D and 2D NMR spectra screening method. Investigation of this sponge led to the isolation of two known compounds, and three potential new compounds.

\subsection{Dictyodendrilla dendyi}

Dictyodendrilla dendyi is a marine sponge species in the class Demospongiae, belonging to the family Dictyodendrillidae. The black-coloured sponge was collected on 05/12/2003 from the coast of Spritis Bay, North Cape (1838 g). The sponge (23 g) was screened, and the screen spectra of the $75 \% \mathrm{Me}_{2} \mathrm{CO} / \mathrm{H}_{2} \mathrm{O}$ fraction contained aromatic resonances that were of interest. Although interesting, further analysis was not sought as the sponge had previously been studied at VUW. (Figure D.1-D.3)

\subsection{Phorbas areolata}

Phorbas areolata is a marine sponge species also in the class Demospongiae, belonging to the family Hymedesmiidae. The black-coloured sponge was collected on 05/12/2003 off the coast of Great Island, Three Kings Islands (1322 g). The sponge (85 g) was screened, and the screen spectra of the $75 \% \mathrm{Me}_{2} \mathrm{CO} / \mathrm{H}_{2} \mathrm{O}$ fraction contained aromatic resonances that 
were of interest. Further purification and analysis of the sponge was desired, but not given priority. (Figure D.4)

\subsection{Aaptos confertus}

Aaptos confertus is a marine sponge belonging to the class Demospongiae, and the family Suberitidae. The sponge consisted of a black, encrusting exterior and a yellow interior and was collected on 23/11/2002 from the Princess Islands; seven small islets in close proximity to South West Island, of the Three Kings Islands (1764 g). The sponge (91 g) was screened, and the screen spectra of the $75 \% \mathrm{Me}_{2} \mathrm{CO} / \mathrm{H}_{2} \mathrm{O}$ fraction contained aromatic resonances that were of interest. (Figure D.5-D.7) A second, large-scale bulk extraction of the sponge (approximately $500 \mathrm{~g}$ ) was performed. Purification and analysis of the bulk extracts led to the isolation of two known compounds cyclo(Phe-Pro), and 3-((13methylhexadecyl)oxy)propane-1,2-diol, along with three unknown compounds CJP02_04CB, CJP02_20A and CJP02_20C, that are currently suspected to be novel compounds. Isolation and structural elucidation of the five compounds is discussed in chapters 3 and 4.

Initially, two other species of sponge, Cliona celata and Stelletta carter were planned for screening. Since the three sponges already screened (D. dendyi, P. areolata and A. confertus) had provided interesting leads, screening of the other two species was not pursued. 


\section{Chapter 3}

\section{Results}

Unfortunately, due to unforseen circumstances, the NMR spectrometer used to generate the majority of spectra suffered a major loss in sensitivity, affecting the signal-to-noise ratio of the spectra obtained. As a result, full structural elucidation of three potentially novel compounds (CJP02_04CB, CJP02_20A, and CJP02_20C) could not be completed. The results herein describe what data was able to be extracted, in addition to full data for known compounds cyclo(L-Phe-L-Pro) and 3-((13-methylhexadecyl)oxy)propane-1,2-diol.

\subsection{CJP02_04CB}

CJP02_04CB was isolated as a bright yellow oil. Positive ion HRESIMS analysis showed a possibility of three protonated molecules $[\mathrm{M}+\mathrm{H}]^{+}$at $\mathrm{m} / \mathrm{z} 294.1356,316.1192$ and 259.0907. Due to the ambiguity of the HRESIMS data, no molecular formula was confirmed. The ${ }^{13} \mathrm{C}$ NMR and multiplicity-edited spectra in $\mathrm{CD}_{3} \mathrm{OD}$ revealed three methylenes $\left(\delta_{\mathrm{C}} 60.8 ; \delta_{\mathrm{H}}\right.$ $3.67),\left(\delta_{\mathrm{C}} 63.0 ; \delta_{\mathrm{H}} 3.57,3.50\right)$, and $\left(\delta_{\mathrm{C}} 72.1, \delta_{\mathrm{H}} 3.55\right)$. Also observed was one methine $\left(\delta_{\mathrm{C}}\right.$ $\left.72.4 ; \delta_{\mathrm{H}} 3.63\right)$. (Figure F.4)

Due to the ${ }^{1} \mathrm{H}$ NMR signals being in such close proximity, no distinguishable signals were visible on the COSY spectrum. (Figure F.3) In addition, no signals were detected on the HMBC experiment due to the decreased resolution of the NMR spectrometer. (Figure F.5) Coupling patterns for the majority of peaks were also ambiguous, as all bar one were observed as multiplets. Since the HRESIMS data was also ambiguous, no substructures could be derived from the data. 
A small glycerol-like molecule is proposed, despite this being contradictory to the HRESIMS data. It is possible that a protonated molecular ion between $\mathrm{m} / \mathrm{z}, 100-200$ falls under the spectral width of the HRESIMS data and it is highly unlikely that a molecule with such few

${ }^{13} \mathrm{C}$ and ${ }^{1} \mathrm{H}$ NMR signals has a protonated molecular ion between $\mathrm{m} / \mathrm{z} 250$ and 50. Currently, no molecules with similar possible structures have been isolated from the genus Aaptos. The lack of conformity with current literature suggests it may be a novel compound, however, this cannot be confirmed without reliable 2D NMR data.

\subsection{CJP02_20A}

CJP02_20A was isolated as a yellow oil. Positive ion HRESIMS analysis showed a possibility of two protonated molecules $[\mathrm{M}+\mathrm{H}]^{+}$at $\mathrm{m} / \mathrm{z} 271.2100$ and 285.2551. Due to the conflicting nature of the HRESIMS data, no molecular formula was confirmed. The ${ }^{13} \mathrm{C}$ NMR data revealed six distinct carbon environments. (Figure F.7) It is likely that any other signals were masked by the low signal-to-noise ratio of the generated spectrum. As a result, no valuable information was able to be extracted from the HSQC (Figure F.9) or HMBC spectra obtained. (Figure F.10) The COSY spectrum shows distinct coupling between aromatic protons, and a number of other protons between $\delta_{\mathrm{H}} 1$ and 3 . However, it cannot be confirmed that these signals correspond to the desired compound. (Figure F.8)

Currently, no other compounds isolated from the genus Aaptos present with molecular ions of those described. This suggests it may be a compound new to the genus, however, further analysis may require purification by HPLC with a larger sample mass. Structural elucidation will require reliable 2D NMR data, most likely to be obtained from a spectrometer operating at a higher frequency (e.g. $900 \mathrm{MHz}$ ) or a functionining $600 \mathrm{MHz}$ NMR equipped with a functioning cold probe.

\subsection{CJP02 20C}

CJP02_20C was isolated as a yellow oil. Positive ion HRESIMS analysis showed three possible protonated molecules $[\mathrm{M}+\mathrm{H}]^{+}$at $\mathrm{m} / \mathrm{z}$, 146.0607, 245.1298, and 438.3715. The ${ }^{13} \mathrm{C}$ spectrum revealed nine carbon environments. (Figure F.12) It is possible that other carbon 
environments exist, however, they are most likely masked by the low signal-to-noise ratio of the spectrum. As a result, no valuable information was able to be extracted from the HSQC or HMBC spectra obtained. The COSY spectrum shows distinct coupling between aromatic protons, and a number of other protons between $\delta_{\mathrm{H}} 1$ and 3 . However, it cannot be confirmed that these signals correspond to the desired compound.

Currently, no other compounds isolated from the genus Aaptos present with molecular ions of those described. This suggests it may be a compound new to the genus, however, further analysis may require purification by HPLC with a larger sample mass. Structural elucidation will require reliable 2D NMR data, most likely to be obtained from a spectrometer operating at a higher frequency (e.g. $900 \mathrm{MHz}$ ) or reliability.

\subsection{2,5-Diketopiperazine Cyclo(L-Phe-L-Pro)}<smiles>O=C1N[C@H](Cc2ccccc2)C(=O)N2CCC[C@H]12</smiles>

Figure 3.1: Structure of the isolated 2,5-diketopiperazine cyclo(L-Phe-L-Pro) (42)

$(6 R, 9 R)$-3-benzylhexahydropyrrolo[1,2- $\alpha]$ pyrazine-1,4-dione (42) was isolated as an orange oil. The positive ion HRESIMS for the 2,5-diketopiperazine showed a protonated molecule $[\mathrm{M}+\mathrm{H}]^{+}$at $m / z 245.1287(\Delta=-0.84 \mathrm{ppm})$. This supported a formula of $\mathrm{C}_{14} \mathrm{H}_{16} \mathrm{~N}_{2} \mathrm{O}_{2}$ and eight degrees of unsaturation.

The ${ }^{13} \mathrm{C}$ and multiplicity-eidited HSQC NMR spectra in $\mathrm{CD}_{3} \mathrm{OD}$ revealed 14 carbon atoms, inlcuding: eight methines $\left(\delta_{\mathrm{C}} 57.9 ; 60.2 ;(2 \mathrm{x}) 129.6\right.$; $\left.(2 \mathrm{x}) 131.2 ;(2 \mathrm{x}) 128.2\right)$, and four methylenes $\left(\delta_{\mathrm{C}} 22.9 ; 29.5 ; 38.4 ; 46.1\right)$. (Figure E.2 and E.4) The remaining two carbons were assigned as non-protonated centres, comprised of two ketone carbonyls and one aromatic centre $\left(\delta_{\mathrm{C}} 137.5\right)$. The carbonyl signals were not observed on either ${ }^{13} \mathrm{C}$ or multiplicityedited HSQC NMR spectra, due to the low mass quantity and decreased sensitivity of the spectrometer available. 
The ${ }^{1} \mathrm{H}$ NMR spectrum $\left(\mathrm{CD}_{3} \mathrm{OD}\right)$ contained resonances that account for all protons in the molecule. (Figure E.1) An HSQC spectrum confirmed the attachment of all 16 protons to carbons, indicating the presence of one exchangeable proton $\left(\delta_{\mathrm{H}} 5.48\right)$. (Figure E.4) Three aromatic proton signals $\left(\delta_{\mathrm{C}} 7.24 ; 7.25 ; 7.24\right)$ were observed as a multiplet which accounted for five protons and indicated the presence of a mono-substituted benzene ring. Presence of the mono-substituted benzene ring was also reinforced by the presence of four carbon signals on the ${ }^{13} \mathrm{C}$ spectrum, opposed to the expected six signals for non-equivelant carbons. Their relative intensities in the ${ }^{13} \mathrm{C}$ spectrum were also indicative of mono-substitution, where C-4' displayed the lowest intensity, accounting for one carbon, and the other signals corresponding to C-2',3',5' and 6' were all of greater intensity, as they accounted for two carbons each. (Figure E.2) COSY correlations between aromatic protons H-2'(6') and H-3'(5'), and H3'(5') and H-4' established the assignments of the benzene ring. (Figure E.3) Although appearing as a multiplet in the ${ }^{1} \mathrm{H}$ NMR spectrum, HSQC and COSY signals were able to differentiate the aromatic protons.

COSY correlations established the structure of the proline component of the molecule, accounting for C3 - C6. Another COSY correlation from H-9 to H-10 suggested the presence of a methylene moiety. (Figure E.3) The lack of methyl carbons suggested this to be a methylene bridge connecting the aromatic ring to the rest of the molecule. The presence of the methylene bridge was confirmed by an HMBC corrleation from H-6' to C-10. Unfortunately no additional HMBC data was visible due to the decreased sensitivity of the spectrometer available. (Figure E.5)

The molecular formula suggested the presence of three more DBEs (double bond equivelants), and paired with the presence of two nitrogens and two oxygens, this was in accordance with a 2,5-diketopiperazine. The presence of the one exchangeable proton was confirmed by the signal $\delta_{\mathrm{H}} 5.48$.

A compound search within the MarinLit Database included the molecular formula, exact mass and the benzene ring as parameters. This search revealed four possible matches; three 2,5-diketopiperazines and one N,N-diacetyltryptamine. The diacetyltryptamine, however, was not in accordance with a mono-subsituted benzene ring. The chemical shifts of the 
isolated compound were compared with the three diketopiperazines, and were in close accordance with the structure above, cyclo(Pro-Phe).

The optical rotation $[\alpha]_{\mathrm{D}}^{25}-67^{\circ}\left(\mathrm{c}=0.1, \mathrm{CH}_{2} \mathrm{Cl}_{2}\right)$ was in accordance with the literature values for cyclo(L-Pro-L-Phe) as described by Li et al. ${ }^{110}$ The ${ }^{1 \mathrm{H}},{ }^{13} \mathrm{C}, \mathrm{HSQC}$ and the observed HMBC was also in accordance with the described 2,5-DKP, isolated from the sponge Stelletta tenuis collected from the South China Sea. ${ }^{110}$<smiles>O=C1NC(Cc2ccccc2)C(=O)N2CCCC12</smiles>

Figure 3.2: Assignments for the isolated 2,5-DKP cyclo(L-Phe-L-Pro)

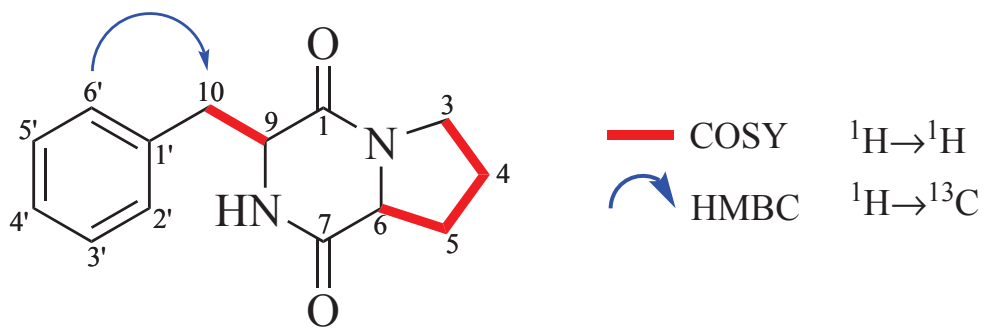

Figure 3.3: Observed COSY and HMBC correlations for the isolated 2,5-DKP cyclo(L-Phe-L-Pro)

\subsection{Branched-Chain Mono-Glycerol Ether}<smiles>CCCC(C)CCCCCCCCCCCCOCC(O)CO</smiles>

Figure 3.4: Structure of 3-((13-methylhexadecyl)oxy)propane-1,2-diol

3-((13-methylhexadecyl)oxy)propane-1,2-diol was isolated as a colourless solid, which afforded a pale yellow oil in solution. Positive ion HRESIMS analysis showed a protonated molecule $[\mathrm{M}+\mathrm{H}]^{+}$at $m / z 331.3217(\Delta=-0.03)$. This supported a formula of $\mathrm{C}_{20} \mathrm{H}_{42} \mathrm{O}_{3}$ and zero degrees of unsaturation. The ${ }^{13} \mathrm{C}$ NMR spectrum in $\mathrm{CD}_{3} \mathrm{OD}$ revealed four distinct 


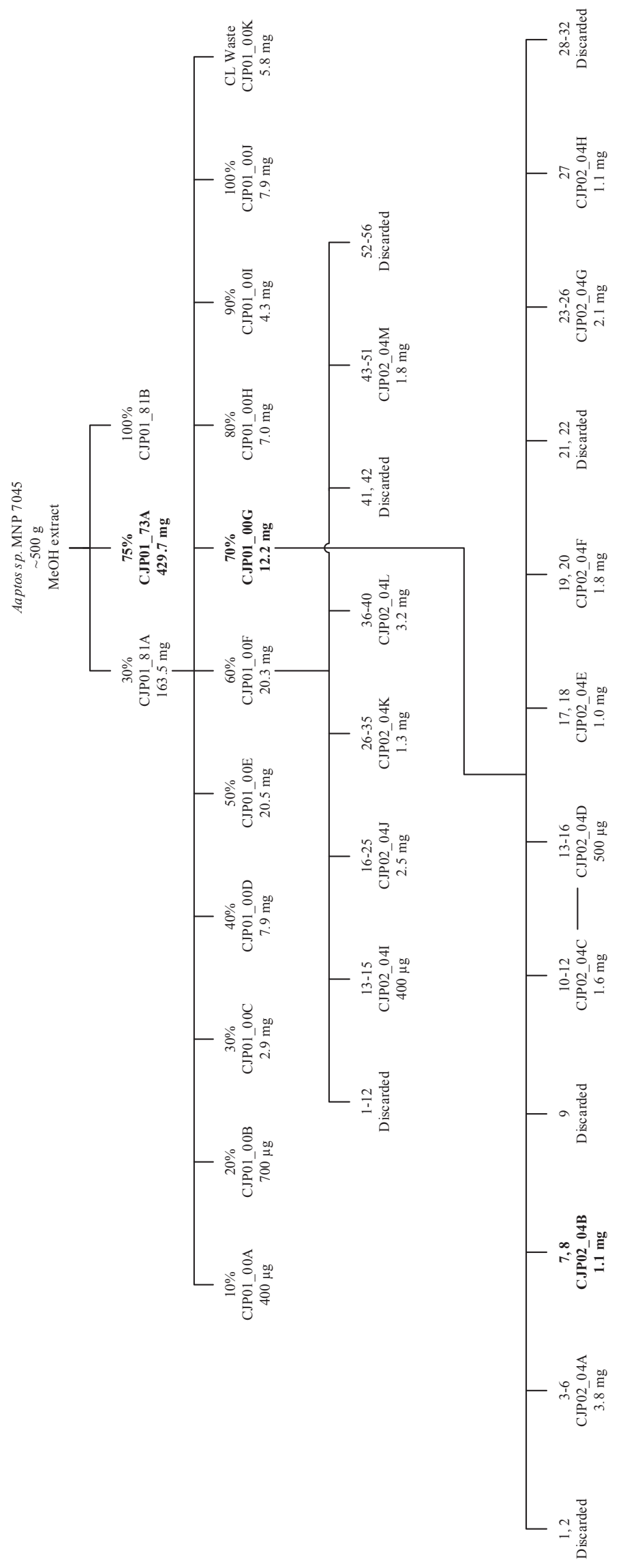

Scheme 3.1: Isolation scheme of 2,5-DKP cyclo(L-Phe-L-Pro) 
Table 3.1: ${ }^{1} \mathrm{H}(500 \mathrm{MHz})$ and ${ }^{13} \mathrm{C}(150 \mathrm{MHz})$ NMR data for 2,5-DKP cyclo(L-Phe-L-Pro) * $=$ signal not observed. $* *=$ not determinable

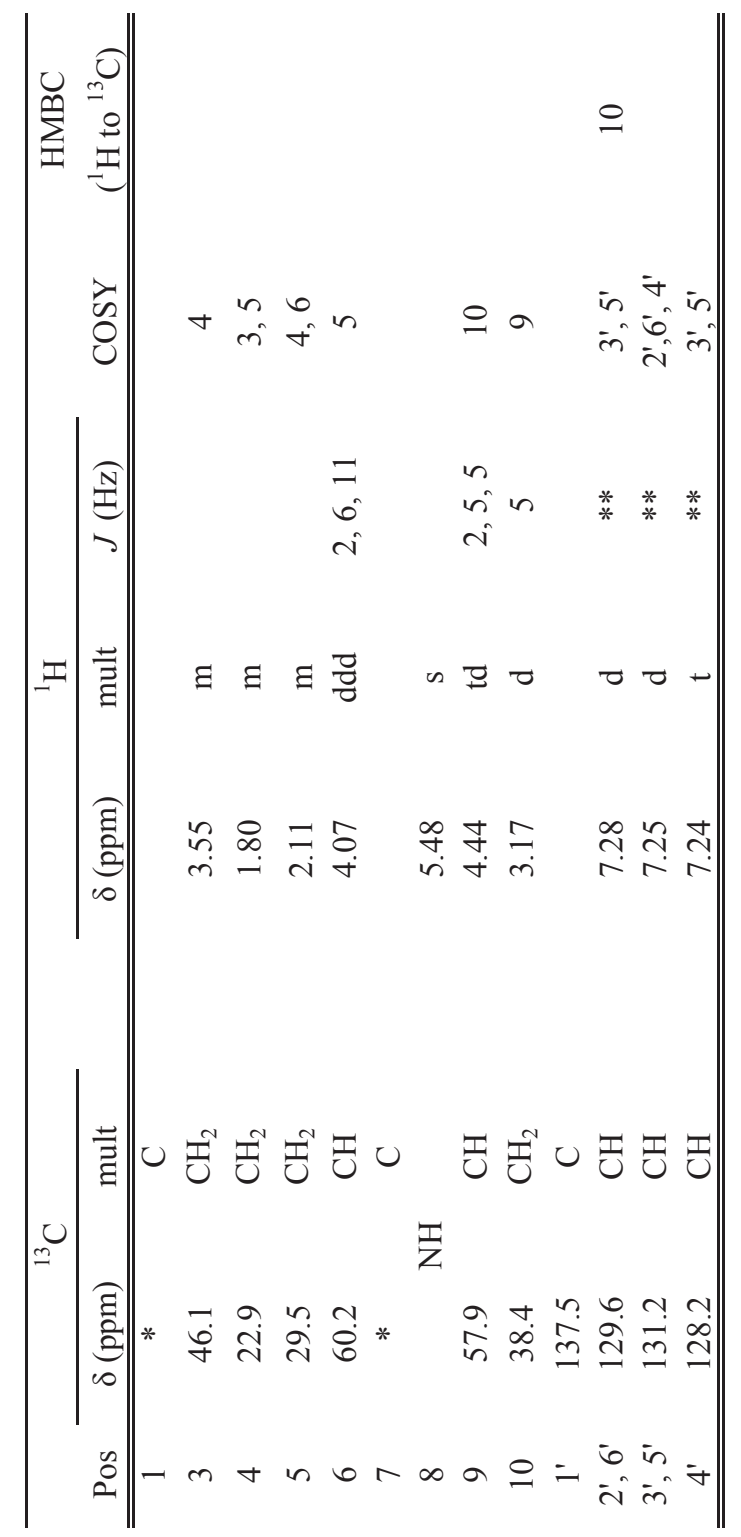

carbon environments. A multiplicity-edited HSQC spectrum in $\mathrm{CD}_{3} \mathrm{OD}$ revealed that $\mathrm{C}-1$ ( $\delta$ (Figure E.7) C 64.8) was a methylene $\left(\delta_{\mathrm{H}} 3.51,3.58\right), \mathrm{C}-2\left(\delta_{\mathrm{C}} 72.4\right)$ was a methine $(\delta \mathrm{H}$ 3.75) and C-3 ( $\delta \mathrm{C} 73.4)$ was a methylene $(\delta \mathrm{H} 3.41,3.47)$. (Figure E.9) COSY correlations between C-1, C-2 and C-3 were indicative of their linear arrangement, and coupled with their ${ }^{13} \mathrm{C}$ NMR chemical shifts, suggested they were attached to electron-withdrawing groups. (Figure E.8) The absence of carbonyl signals on the ${ }^{13} \mathrm{C}$ spectrum suggested alcohol functionalities. This was reinforced by the molecular formula given by positive ion HRESIMS analysis, which suggested three oxygens present in the molecule. The arrangement of C-1 to C-3 was confirmed by HMBC correlations; from H-1 to C-3. HMBC correlations also confirmed the presence and location of the ether bridge; to and from $\mathrm{H}-1$ to $\mathrm{H}-1$ ', and 
from H-3 to C-1'. (Figure E.10)

The ${ }^{13} \mathrm{C}$ NMR spectrum and multiplicity-edited HSQC spectrum also revealed another 16 carbon environments. This included 13 methylenes (Table 3.2), one methine at C-13 $\left(\delta_{\mathrm{C}}\right.$ $\left.33.3 ; \delta_{\mathrm{H}} 1.3\right)$ and two methyls: C-16 $\left(\delta_{\mathrm{C}} 14.7 ; \delta_{\mathrm{H}} 0.91\right)$ and $\mathrm{C}-19\left(\left(\delta_{\mathrm{C}} 20.3 ; \delta_{\mathrm{H}} 0.86\right)\right)$. The ${ }^{1} \mathrm{H}$ NMR spectrum $\left(\mathrm{CD}_{3} \mathrm{OD}\right)$ contained resonances that accounted for all protons, with the exception of two exchangeable protons belonging to the two alcohol moieties, at position 17 and 18. (Figure E.6) The HSQC spectrum permitted to the assignment of all protons to their corresponding carbons (Table 3.2)

Notably, the ${ }^{1} \mathrm{H}$ NMR spectrum contained a large methylene envelope $\left(\delta_{\mathrm{H}} 1.3\right)$, suggesting the presence of a long alkyl chain. The location of the alkyl chain, next to C-1', was suggested by COSY correlations between H-1', H-2', and H-3'. This was confirmed by the HMBC correlation from H-1' to H-4. The length of the alkyl chain was determined by HRESIMS, the molecular formula confirming a length of 16 carbons by deduction (C1 ' to C-16). Signals on the ${ }^{1} \mathrm{H}$ NMR spectrum $\left(\delta_{\mathrm{H}} 0.86,0.91\right)$ were indicative of terminal methyls. The doublet at $\delta_{\mathrm{C}} 0.86$ indicated that the corresponding C-19 $\left(\delta_{\mathrm{C}} 20.3\right)$ was internal, and the multiplet at $\mathrm{H}-16\left(\delta_{16}\right)$ suggested this was the terminal methyl. Their exact positions were determined by HMBC correlations; the HMBC spectrum showed long-range coupling from $\mathrm{H}-19$ to $\mathrm{C}-12$ and $\mathrm{C}-14$, which $\mathrm{H}-16$ was lacking. H-16, however, did show long-rage coupling to C-13 on the HMBC spectrum, which C-19 lacked. This confirmed that C-19 was adjacent to $\mathrm{C}-13$, and branched from this position. The large methylene envelope $\left(\delta_{\mathrm{H}}\right.$ 1.3) caused significant difficulty when assigning chemical shifts to the molecule. Because a large number of carbons corresponded to the broad methylene envelope, it was difficult to distinguish certian COSY, HSQC and HMBC correlations. In addition, some of the carbon signals, particularly C-5 to C-8 $\left(\delta_{\mathrm{C}} 30.93,30.94,30.9630 .97\right)$ were so close in chemical shift, that they could not be distinguished from each other.

A compound search within the MarinLit Database from the genus Aaptos, including the exact mass an molecular formula in the parameters, revealed the ether lipid, 3-((13-methylhexadecyl)oxy)propane-1,2-diol, to be a known compound. It was originally isolated from Aaptos sp. located near Taiwan, by Do and Erickson. ${ }^{111}$ The ${ }^{1} \mathrm{H}$ NMR data was in accordance with the literature values, despite some changes to certain coupling patterns, discussed in Chapter 


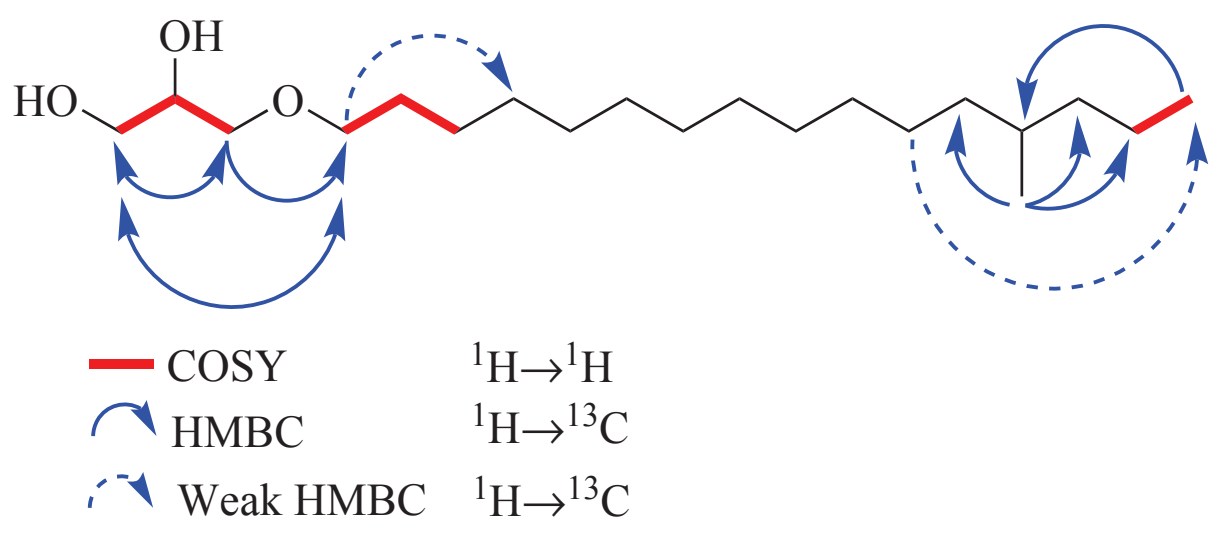

Figure 3.5: Observed COSY and HMBC correlations for 3-((13-methylhexadecyl)oxy)propane-1,2-diol

5.<smiles>CCCC(C)CC=CCCCCCCCCC(=O)OCC(O)C(C)O</smiles>

Figure 3.6: Assignments for 3-((13-methylhexadecyl)oxy)propane-1,2-diol 
Table 3.2: ${ }^{1} \mathrm{H}(600 \mathrm{MHz})$ and ${ }^{13} \mathrm{C}(150 \mathrm{MHz}) \mathrm{NMR}$ data for

3-((13-methylhexadecyl)oxy)propane-1,2-diol

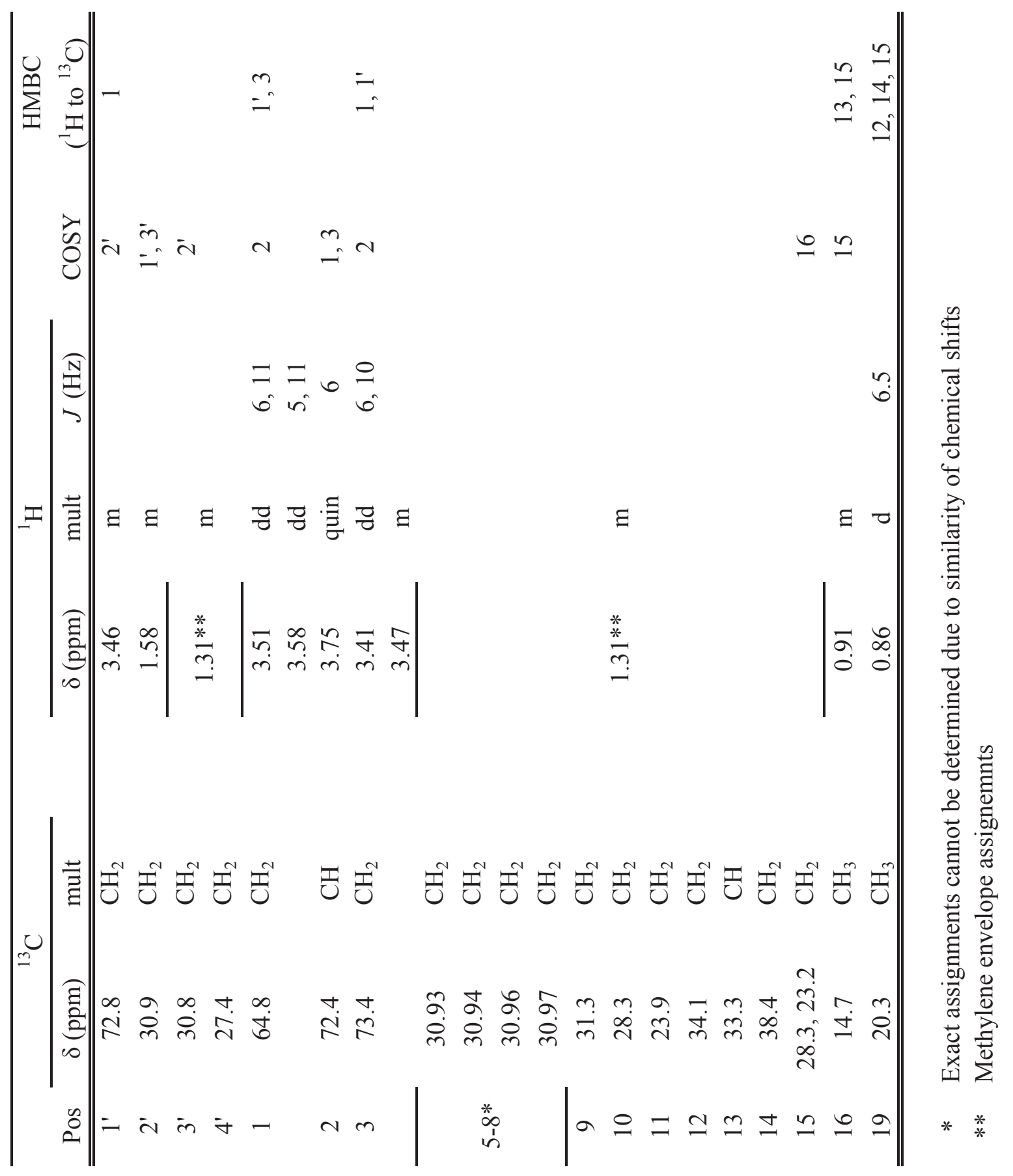




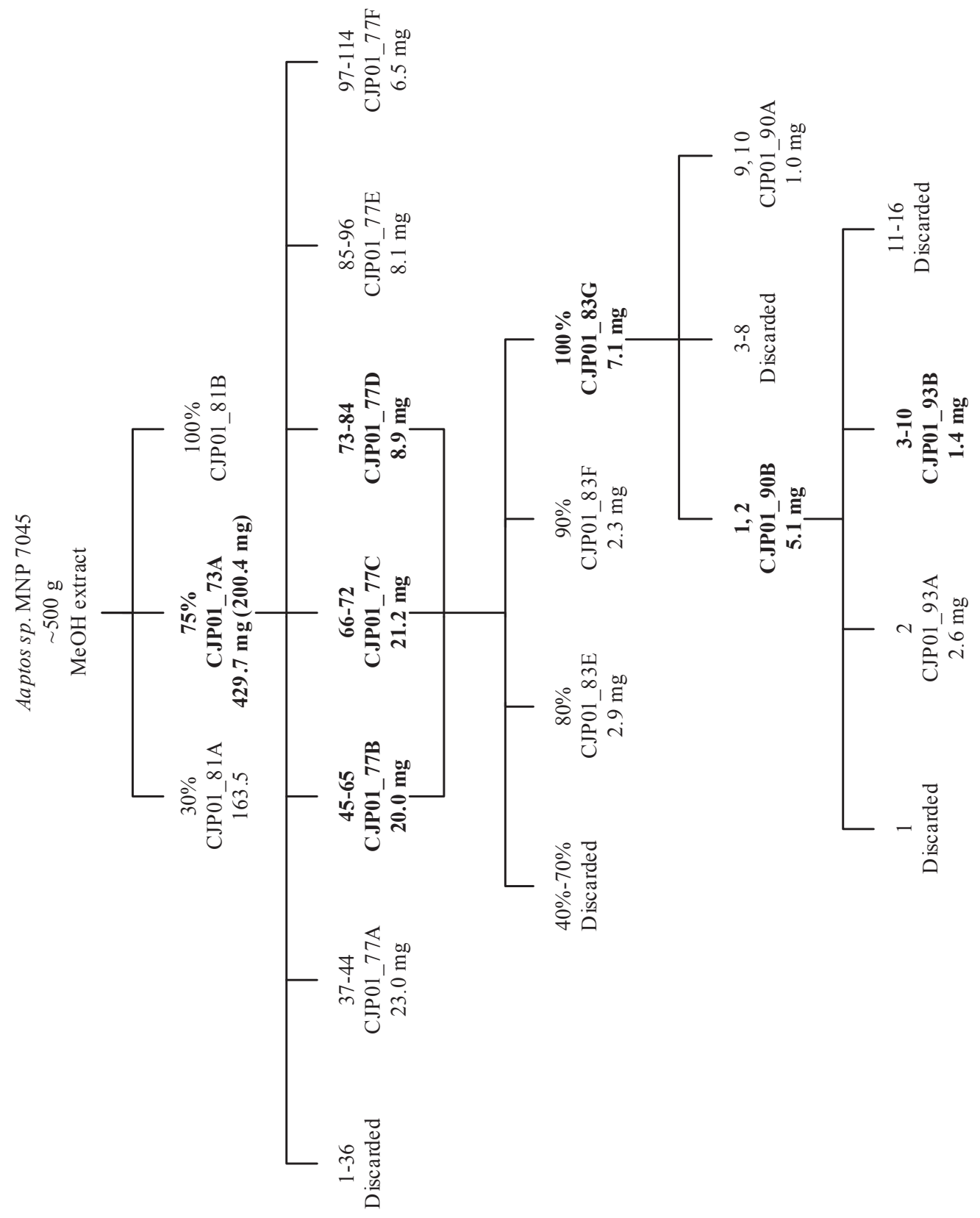

Scheme 3.2: Isolation scheme of 3-((13-methylhexadecyl)oxy)propane-1,2-diol 


\section{Chapter 4}

\section{Experimental}

\subsection{General Experimental}

Marine invertebrates were collected by the National Institute of Water and Atmospheric Research (NIWA). These organisms were stored and frozen at $-20{ }^{\circ} \mathrm{C}$ until required.

Normal-phase column chromatography was conducted using Supelco Discovery ${ }^{\circledR}$ DSCDIOL SPE functionalised silica: 3-(2,3-Dihidroxy-propoxy)-propyl-silica solid phase extraction (DIOL). Reversed-phase column chromatography was conducted using Supelco Diaion ${ }^{\circledR}$ HP-20 ${ }^{\circledR}$ HP-20ss poly(styrene-divinylbenzene) (PSDVB) resins.

Solvents utilised for columns and bench top work were of HPLC-grade (Fisher Scientific). Water was distilled and deionised prior to use. Solvent compositions used were all reported as the $\%$ v/v. TLC analyses were performed using Machery-Nagel Polygram ${ }^{\circledR}$ Sil G/UV254 plates and visualised under UV light $(\lambda=350 \mathrm{~nm})$. TLC plates were then stained in 5\% $\mathrm{H}_{2} \mathrm{SO}_{4}$ in $\mathrm{EtOH}$ followed by $0.1 \%$ vanillin in $\mathrm{EtOH}$ and heated for visualisation. The majority of NMR spectra were obtained using a Varian DirectDrive spectrometer operating at $600 \mathrm{MHz}$ for ${ }^{1} \mathrm{H}$ and $150 \mathrm{MHz}$ for ${ }^{13} \mathrm{C}$ nuclei, equipped with a triple resonance $\mathrm{HCN}$ cryogenic probe operating at $25 \mathrm{~K}$. As indicated, some spectra were obtained using the same Varian DirectDrive NMR spectrometer (600 MHz), equipped with a room temperature, direct probe operating at $22{ }^{\circ} \mathrm{C}$. The residual solvent peak was used as an internal reference for ${ }^{1} \mathrm{H}$ and ${ }^{13} \mathrm{C}$ chemical shifts. Some spectra were obtained using a three-channel Avance III 500 operating at $500 \mathrm{MHz}$ for ${ }^{1} \mathrm{H}$ and $125 \mathrm{MHz}$ for ${ }^{13} \mathrm{C}$ nuclei, equipped with a Bruker 
two-channel 5-mm broadband observe nuclei probe operating at $30{ }^{\circ} \mathrm{C}$. HRESIMS resuls were obtained from an Agilent 6530 Q-TOF mass spectrometer equipped with an Agilent 1260 HPLC for solvent delivery using JetStret ${ }^{\mathrm{TM}}$ electrospray ionisation source in positive ion mode. Optical rotations were run on a Rudolph Research Analytical Autopol II Automatic polarimeter, operating at $25{ }^{\circ} \mathrm{C}$. The emission wavelength of a sodium lamp was used (589 nm). Concentrations were reported in $\mathrm{g} / 100 \mathrm{~mL}$.

\subsection{Sponge Screening}

\subsubsection{Screen of Phorbas areolata}

A sample of marine sponge $P$. areolata was obtained (84.86 g wet weight) and divided into cubes of approximately $2 \mathrm{~cm}^{3}$ to represent all layers of sponge material. The sponge material was extracted in $\mathrm{MeOH}(400 \mathrm{~mL})$ for 22 hours. The first extract was filtered and the sponge material re-extracted and filtered in $\mathrm{MeOH}(400 \mathrm{~mL})$ for a further 48 hours. An $80 \mathrm{~mL}$ HP20 column was prepared and equilibrated in $\mathrm{MeOH}$. The second extract was passed through the column, followed by the first. The eluents were combined and cyclic loaded onto the column. The column was washed with $100 \mathrm{~mL}$ of $\mathrm{H}_{2} \mathrm{O}$ followed by elution with $250 \mathrm{~mL}$ volumes of $30 \%$ and $75 \% \mathrm{MeOH}$ in $\mathrm{H}_{2} \mathrm{O}$ and $100 \% \mathrm{Me}_{2} \mathrm{CO}$. A $40 \mathrm{~mL}$ backloading HP20 column was prepared and equilibrated in $\mathrm{MeOH}$. The $75 \% \mathrm{Me}_{2} \mathrm{CO}$ fraction from the previous column was cyclic loaded onto the backloading column, then eluted with $250 \mathrm{~mL}$ of $\mathrm{Me}_{2} \mathrm{CO}$. The eluent was then concentrated under reduced pressure, affording a mass of $182.5 \mathrm{mg}$.

\subsubsection{Screen of Dictyodenrilla dendyi}

A sample of marine sponge $D$. dendyi was obtained ( $23 \mathrm{~g}$ wet weight) and divided into cubes of approximately $2 \mathrm{~cm}^{3}$ which were extracted in $\mathrm{MeOH}(150 \mathrm{~mL})$ for 20 hours. The resulting extract was filtered to remove solids and sediment. The sponge material was extracted for a further 20 hours in $\mathrm{MeOH}(150 \mathrm{~mL})$, and similarly filtered. An $80 \mathrm{~mL}$ HP-20 column was prepared which was equilibrated in $\mathrm{MeOH}$ and washed with $\mathrm{H}_{2} \mathrm{O}$. The second extract was passed through column followed by the first extract. The two eluents were combined and 
cyclic loaded onto the $80 \mathrm{~mL}$ HP-20 column, which was subsequently washed with $150 \mathrm{~mL}$ of $\mathrm{H}_{2} \mathrm{O}$. The column was eluted with $250 \mathrm{~mL}$ volumes of $30 \% \mathrm{Me}_{2} \mathrm{CO}$ in $\mathrm{H}_{2} \mathrm{O}, 75 \% \mathrm{Me}_{2} \mathrm{CO}$ in $\mathrm{H}_{2} \mathrm{O}$ and $250 \mathrm{~mL}$ of $\mathrm{Me}_{2} \mathrm{CO}$, all collected as bulk fractions. A $40 \mathrm{~mL}$ backloading $\mathrm{HP}-20$ column was prepared, which was equilibrated in $\mathrm{MeOH}$ and washed with $\mathrm{H}_{2} \mathrm{O}$. The $75 \%$ $\mathrm{Me}_{2} \mathrm{CO}$ fraction was passed through column. The eluent was backloaded onto the column and eluted with $250 \mathrm{~mL}$ of $\mathrm{Me}_{2} \mathrm{CO}$. The resulting eluent was concentrated under reduced pressure, affording a mass of $78.3 \mathrm{mg}$.

\subsubsection{Screen of Aaptos confertus}

A sample of marine sponge A. confertus was obtained (90.56 g wet weight). The sponge material was cut into cubes of approximately $2 \mathrm{~cm}^{3}$ and extracted in $\mathrm{MeOH}(400 \mathrm{~mL})$ for 22 hours. The first extract was filtered and the sponge material extracted in $\mathrm{MeOH}(400 \mathrm{~mL})$ for a further 48 hours. The eluent was filtered to remove any solids. An 80 mL HP-20 column was prepared and equilibrated in $\mathrm{MeOH}$, followed by a wash with $\mathrm{H}_{2} \mathrm{O}$. The second extract was passed through column followed by the first extract. The two eluents were combined and cyclic loaded onto the column, which was then washed with $100 \mathrm{~mL}$ of $\mathrm{H}_{2} \mathrm{O}$. The column was then eluted with $250 \mathrm{~mL}$ volumes of $30 \%$ and $75 \% \mathrm{Me}_{2} \mathrm{CO}$ in $\mathrm{H}_{2} \mathrm{O}$ followed by $250 \mathrm{~mL}$ of $\mathrm{Me}_{2} \mathrm{CO}$. A $40 \mathrm{~mL}$ backloading HP-20 was column prepared and equilibrated in $\mathrm{MeOH}$. The column was washed with $\mathrm{H}_{2} \mathrm{O}$ and the $75 \% \mathrm{Me}_{2} \mathrm{CO}$ fraction was cyclic loaded into the column. This was again washed with $250 \mathrm{~mL}$ of $\mathrm{H}_{2} \mathrm{O}$. The backloading column was then eluted with $250 \mathrm{~mL}$ of $\mathrm{Me}_{2} \mathrm{CO}$. The eluent was concentrated under reduced pressure to afford a mass of $223.6 \mathrm{mg}$.

\subsection{Isolation of CJP01 93B}

\subsubsection{Large-scale extraction of Aaptos confertus}

Another sample of A. confertus was obtained (approximately $500 \mathrm{~g}$ wet weight). This was divided into two samples (approximately $250 \mathrm{~g}$ each, wet weight). The sponge material was cut into cubes approximately $2 \mathrm{~cm}^{3}$. Each $250 \mathrm{~g}$ sample was extracted with $500 \mathrm{~mL}$ of $\mathrm{MeOH}$ for 24 hours then filtered and re-extracted in another $500 \mathrm{~mL}$ of $\mathrm{MeOH}$ for another 24 
hours. The second extracts were filtered and two columns were prepared consisting of 100 $\mathrm{mL}$ of HP-20 beads each, equilibrated in $\mathrm{MeOH}$. The second extracts were passed through column followed by the first extracts. For each division of sponge material, the eluents were combined and cyclic loaded onto their respective columns. The column were each washed with $500 \mathrm{~mL}$ of $\mathrm{H}_{2} \mathrm{O}$, then eluted with $500 \mathrm{~mL}$ volumes of $30 \%$ and $75 \% \mathrm{Me}_{2} \mathrm{CO}$ in $\mathrm{H}_{2} \mathrm{O}$. Lastly, they were each eluted with $500 \mathrm{~mL}$ of $\mathrm{Me}_{2} \mathrm{CO}$. Each corresponding fraction was combined and concentrated under reduced pressure: CJP01_31A (30\% fraction, 139.8 mg),CJP01_31B (75\% fraction, $429.7 \mathrm{mg}$ ), and CJP01_31 (100\% fraction, $211.5 \mathrm{mg})$. The $75 \%$ fraction was sub-sampled to give $167.4 \mathrm{mg}$ for further purification.

The sub-sample was cyclic-loaded onto a $10 \mathrm{~mL} \mathrm{HP-20ss} \mathrm{column} \mathrm{equilibrated} \mathrm{in} \mathrm{MeOH}$ and washed with $\mathrm{H}_{2} \mathrm{O}$. The loaded HP-20ss beads were transferred as a slurry in $\mathrm{H}_{2} \mathrm{O}$ onto a 40 mL HP-20ss column that was equilibrated in $\mathrm{MeOH}$ and washed with $\mathrm{H}_{2} \mathrm{O}$. The column was eluted with $150 \mathrm{~mL}$ of $10 \%, 20 \%, 30 \%, 40 \%, 50 \%, 60 \%, 70 \%, 80 \%$ and $90 \% \mathrm{MeOH}$ in $\mathrm{H}_{2} \mathrm{O}$ followed by $300 \mathrm{~mL}$ of $\mathrm{MeOH}$. A total of 142 fractions were collected and combined based on TLC analysis, affording samples: A (37-44, $23 \mathrm{mg}), \mathrm{B}$ (45-65, $20 \mathrm{mg}), \mathrm{C}$ (66-72, $21.2 \mathrm{mg}), \mathrm{D}(73-84,8.9 \mathrm{mg})$ and $\mathrm{E}(85-96,8.1 \mathrm{mg})$.

Since separation was not satisfactory, the fractions were combined (75.4 mg). A subsample $(50.1 \mathrm{mg})$ was dissolved in $\mathrm{MeOH}(10 \mathrm{~mL})$ and cyclic loaded onto $5 \mathrm{~mL}$ HP-20ss which had been equilibrated in $\mathrm{MeOH}$ and washed with $\mathrm{H}_{2} \mathrm{O}$. The beads were transferred as a slurry in $\mathrm{H}_{2} \mathrm{O}$ onto a $40 \mathrm{~mL} \mathrm{HP}-20$ ss column which had been equilibrated in $\mathrm{MeOH}$ and washed with $\mathrm{H}_{2} \mathrm{O}$. The column was eluted with $150 \mathrm{~mL}$ solutions of $40 \%, 50 \%, 60 \%, 70 \%, 80 \%$ and $90 \% \mathrm{MeOH}$ in $\mathrm{H}_{2} \mathrm{O}$ followed by $150 \mathrm{~mL}$ of $100 \% \mathrm{MeOH}$. Fractions $\mathrm{E}$ (80\% fraction, 2.9 $\mathrm{mg}), \mathrm{F}(90 \%$ fraction, $23.2 \mathrm{mg})$ and $\mathrm{G}(100 \%$ fraction, $7.1 \mathrm{mg})$ were concentrated to dryness under reduced pressure and submitted for analysis by ${ }^{1} \mathrm{H}$ NMR. Fraction $\mathrm{G}$ was chosen for further purification due to the strong resonances between 3 and $4 \mathrm{ppm}$, and relatively clean spectrum.

Sample $\mathrm{G}$ was dissolved in $\mathrm{MeOH}$ and dry-loaded onto $1 \mathrm{~mL}$ of DIOL. A column was prepared consisting of $10 \mathrm{~mL}$ of DIOL equilibrated in Hexanes. The loaded DIOL was transferred in Hexanes onto the prepared $10 \mathrm{~mL}$ DIOL column. The column was washed with approximately $20 \mathrm{~mL}$ of Hexanes and eluted with $36 \mathrm{~mL}$ portions of the following solvents: 
$50 \%$ EtOAc in Hexanes, EtOAc, 10\% MeOH in EtOAc, $20 \% \mathrm{MeOH}$ in EtOAc, $50 \% \mathrm{MeOH}$ in EtOAc, $100 \% \mathrm{MeOH}$ and $50 \% \mathrm{MeOH}$ in $\mathrm{H}_{2} \mathrm{O}$. A total of 11 fractions were collected and combined based on TLC analysis. Fractions 1-2 and 9-10 were combined and concentrated under reduced pressure. Sample CJP01_90A (fractions 9 and 10) yielded $1 \mathrm{mg}$ of material and sample CJP01_90B yielded approximately $5.05 \mathrm{mg}$ of material. Samples were analysed by ${ }^{1} \mathrm{H}$ NMR to determine which fractions were worth pursuing. CJP01_90B was chosen to further purify due to the strong resonances between 3 and $4 \mathrm{ppm}$, and a relatively clean ${ }^{1} \mathrm{H}$ NMR spectrum.

CJP01_90B (5.05 mg) was dry-loaded onto $1 \mathrm{~mL}$ of DIOL. Another DIOL column was prepared $(5 \mathrm{~mL})$ and equilibrated in Hexanes. The loaded DIOL was then transferred in a slurry of Hexanes onto the prepared column. The column was eluted with $18 \mathrm{~mL}$ volumes of the following solvents: DCM, Hexanes, 50\% EtOAc in Hexanes, 10\% MeOH in EtOAc, $20 \% \mathrm{MeOH}$ in EtOAc, $50 \% \mathrm{MeOH}$ in EtOAc, $100 \% \mathrm{MeOH}$, and $50 \% \mathrm{MeOH}$ in $\mathrm{H}_{2} \mathrm{O}$. A total of 23 fractions were collected and analysed by TLC. Fractions 2, 3-10 and 16 were combined. Sample A (fraction 2) yielded $2.6 \mathrm{mg}$. Sample B (fractions 3-10) yielded $1.4 \mathrm{mg}$ and sample C (fraction 16) yielded $150 \mu \mathrm{g}$. CJP01_93B appeared to be a single compound based upon ${ }^{1} \mathrm{H}$ NMR analysis.

3-((13-methylhexadecyl)oxy)propane-1,2-diol (43). Colourless solid; for NMR Data see Table 3.2; HRESIMS, $[\mathrm{M}+\mathrm{H}]^{+}$, observed at $\mathrm{m} / \mathrm{z} 331.3217$, calculated 331.3168 for $\mathrm{C}_{20} \mathrm{H}_{42} \mathrm{O}_{3} \mathrm{H}$, $\Delta=-0.98 \mathrm{ppm}$.

\subsection{Isolation of CJP02 20A}

A subsample of the bulk $75 \%$ fraction mentioned previously, was sub-sampled $(220.1 \mathrm{mg})$ and cyclic loaded onto $10 \mathrm{~mL}$ HP-20ss which had been equilibriated in $\mathrm{MeOH}$ and washed with $\mathrm{H}_{2} \mathrm{O}$. A column was prepared consisting of $40 \mathrm{~mL} \mathrm{HP}-20$ ss equilibrated in $\mathrm{MeOH}$ and washed with $\mathrm{H}_{2} \mathrm{O}$. The sub-sample column was washed with $\mathrm{H}_{2} \mathrm{O}$ and transferred in a slurry of $\mathrm{H}_{2} \mathrm{O}$ into the $40 \mathrm{~mL}$ HP-20ss column. The cyclic loading waste was retained for spectral analysis. The column was eluted with $150 \mathrm{~mL}$ volumes of the following solvents in order: $60 \% \mathrm{MeOH}$ in $\mathrm{H}_{2} \mathrm{O}, 70 \% \mathrm{MeOH}$ in $\mathrm{H}_{2} \mathrm{O}, 80 \% \mathrm{MeOH}$ in $\mathrm{H}_{2} \mathrm{O}, 90 \% \mathrm{MeOH}$ in $\mathrm{H}_{2} \mathrm{O}$, and 
$100 \% \mathrm{MeOH}$. This afforded fraction A(cyclic loading waste, $2.2 \mathrm{mg}$ ), B (60\%, $2.0 \mathrm{mg}$ ), C (70\%, $5.1 \mathrm{mg}), \mathrm{D}(80 \%, 5.4 \mathrm{mg}), \mathrm{E}(90 \%, 27.3 \mathrm{mg}), \mathrm{F}(100 \%, 135.7 \mathrm{mg})$. Samples CJP01_97C and CJP01_97D showed aromatic resonances and fairly clean ${ }^{1} \mathrm{H}$ NMR spectra and were subsequently scheduled for further NMR experiments.

Both samples (CJP01_97C and CJP01_97D) were dry-loaded onto $1 \mathrm{~mL}$ of DIOL each following the DIOL dry-loading protocol. The loaded DIOL samples were then transferred onto $5 \mathrm{~mL}$ DIOL columns in Hexanes, equilibrated in Hexanes. Columns were eluted with $18 \mathrm{~mL}$ portions of DCM, Hexanes, 50\% EtOAc in Hexanes, $10 \% \mathrm{MeOH}$ in EtOAc, $20 \%$ $\mathrm{MeOH}$ in EtOAc, $50 \% \mathrm{MeOH}$ in EtOAc, $100 \% \mathrm{MeOH}$, and $50 \% \mathrm{MeOH}$ in $\mathrm{H}_{2} \mathrm{O}$. This afforded a total of 32 fractions for each sample, all of which were concentrated under reduced pressure. Fractions were combined based on TLC analysis, affording 97CA, 97CB, 97CC, 97DA, 97DB, and 97DC. Samples CJP01_97DA and CJP01_97CA displayed aromatic resonances and identical ${ }^{1} \mathrm{H}$ NMR spectra, and were combined to afford CJP02_20A (600 $\left.\mu \mathrm{g}\right)$. CJP02_20A appeared to be one purification step away from being a single compound, as per the ${ }^{1} \mathrm{H}$ NMR spectrum obtained.

\subsection{Further Purification of the 30\% HP-20 Fraction}

A subsample of the $30 \%$ bulk fraction $(163.5 \mathrm{mg}$ ) was cyclic-loaded onto $10 \mathrm{~mL}$ of HP20ss which had been equilibrated in $\mathrm{MeOH}$ and washed with $\mathrm{H}_{2} \mathrm{O}$. The column was washed with $\mathrm{H}_{2} \mathrm{O}$ and a column was prepared consisting of $40 \mathrm{~mL}$ HP-20ss which was equilibrated in $\mathrm{MeOH}$ and washed with $\mathrm{H}_{2} \mathrm{O}$. The HP-20ss beads loaded with sample were transferred to the $40 \mathrm{~mL}$ column in $\mathrm{H}_{2} \mathrm{O}$. The column was eluted with $150 \mathrm{~mL}$ volumes of the following solvents in order and collected as bulk fractions: $10 \% \mathrm{MeOH}$ in $\mathrm{H}_{2} \mathrm{O}(400 \mu \mathrm{g}), 20 \% \mathrm{MeOH}$ in $\mathrm{H}_{2} \mathrm{O}(700 \mu \mathrm{g}), 30 \% \mathrm{MeOH}$ in $\mathrm{H}_{2} \mathrm{O}(2.9 \mathrm{mg}), 40 \% \mathrm{MeOH}$ in $\mathrm{H}_{2} \mathrm{O}$ (7.9 mg), $50 \% \mathrm{MeOH}$ in $\mathrm{H}_{2} \mathrm{O}(20.5 \mathrm{mg}), 60 \% \mathrm{MeOH}$ in $\mathrm{H}_{2} \mathrm{O}$ (20.3 mg), 70\% MeOH in $\mathrm{H}_{2} \mathrm{O}$ (12.2 mg), 80\% MeOH in $\mathrm{H}_{2} \mathrm{O}(7 \mathrm{mg}), 90 \% \mathrm{MeOH}$ in $\mathrm{H}_{2} \mathrm{O}(4.3 \mathrm{mg}), 100 \% \mathrm{MeOH}(7.9 \mathrm{mg})$. This afforded samples CJP01_00A-K, where CJP01_00K was cyclic loading waste $(5.8 \mathrm{mg})$. A selection of these samples were chosen for purification. 


\subsection{F - Isolation of CJP02_04CB}

Sample CJP02_00F (20.3 mg) was loaded onto $2 \mathrm{~mL}$ of DIOL following the DIOL dryloading protocol. The sample was transferred onto a $10 \mathrm{~mL}$ DIOL column in Hexanes, which had been equilibrated in Hexanes. The column was eluted with $36 \mathrm{~mL}$ volumes of each of the the following solvents in order: 50\% EtOAc in Hexanes, EtOAc, $10 \% \mathrm{MeOH}$ in EtOAc, $20 \% \mathrm{MeOH}$ in EtOAc, $50 \% \mathrm{MeOH}$ in EtOAc, $100 \% \mathrm{MeOH}$ in EtOAc, and $50 \% \mathrm{MeOH}$ in $\mathrm{H}_{2} \mathrm{O}$. A total of 56 fractions were collected and concentrated under reduced pressure. Fractions were combined based on TLC analysis, affording: CJP02_04I: 13-15 (400 $\mu \mathrm{g})$, CJP02_04J: 16-25 (2.5 mg), CJP02_04K: 26-35 (1.3 mg), CJP02_04L: 36-40 (3.2 mg), and CJP02_04M: 43-51 (1.8 mg). CJP02_04J was the leading candidate and was submitted for further analysis by NMR.

CJP02_04J (2.5 mg) was loaded onto $1 \mathrm{~mL}$ of DIOL following the DIOL dry-loading protocol and transferred onto a $10 \mathrm{~mL}$ DIOL column in Hexanes, equilibrated in Hexanes. The column was eluted with $36 \mathrm{~mL}$ volumes of the following solvents in order: 50\% EtOAc in Hexanes, EtOAc, $10 \% \mathrm{MeOH}$ in EtOAc, $20 \% \mathrm{MeOH}$ in EtOAc, $50 \% \mathrm{MeOH}$ in EtOAc, $100 \% \mathrm{MeOH}$ in EtOAc, and $50 \% \mathrm{MeOH}$ in $\mathrm{H}_{2} \mathrm{O}$. Samples were concentrated and combined based on TLC analysis. This afforded three samples; CJP02_04JA, CJP02_04JB and CJP02_04JC. CJP02_04CB appeared to be a single compound based upon ${ }^{1} \mathrm{H}$ NMR analysis.

\subsection{G - Isolation of Cyclo(L-Phe-L-Pro)}

CJP02_00G (12.2 mg) was loaded onto $1 \mathrm{~mL}$ of DIOL following the DIOL dry-loading protocol. The loaded sample was transferred onto a $5 \mathrm{~mL}$ DIOL column in Hexanes, equilibrated in Hexanes. The column was eluted with $18 \mathrm{~mL}$ volumes of the following solvents in order: 50\% EtOAc in Hexanes, EtOAc, 10\% MeOH in EtOAc, 20\% $\mathrm{MeOH}$ in EtOAc, $50 \% \mathrm{MeOH}$ in EtOAc, $100 \% \mathrm{MeOH}$ in EtOAc, and 50\% $\mathrm{MeOH}$ in $\mathrm{H}_{2} \mathrm{O}$. A total of 32 fractions were collected and were concentrated to dryness under reduced pressure. The following fraction combinations (based on TLC analysis) and sample names are listed as follows: CJP02_04A: 3-6 (3.8 mg), CJP02_04B: 7-8 (1.1 mg), CJP02_04C: 10-12 (1.6

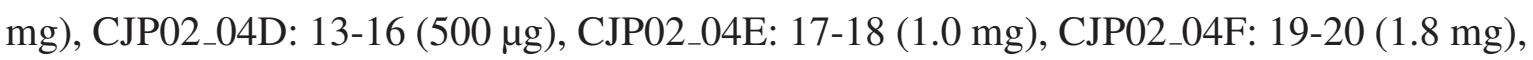


CJP02_04G: 23-26 (2.1 mg), and CJP02_04H: 27 (1.1 mg). CJP02_04B appeared to be a single compound based upon ${ }^{1} \mathrm{H}$ NMR analysis.

Cyclo(L-Phe-L-Pro) (42). Yellow oil; for NMR Data see Table 3.1; HRESIMS, $[\mathrm{M}+\mathrm{H}]^{+}$, observed at $m / z 254.1287$, calculated 254.1362 for $\mathrm{C}_{14} \mathrm{H}_{16} \mathrm{~N}_{2} \mathrm{O}_{2}, \Delta=-0.84 \mathrm{ppm}$.

\subsection{G - Isolation of CJP02 20C}

CJP02_04A (3.8 mg, from above) was dry-loaded onto DIOL following the dry-loading protocol. The loaded DIOL was then loaded in Hexanes to a $5 \mathrm{~mL}$ DIOL column, equilibated in Hexanes. The column was eluted with $18 \mathrm{~mL}$ volumes of: 50\% EtOAc in Hexanes, EtOAc, $10 \% \mathrm{MeOH}$ in EtOAc, 20\% MeOH in EtOAc, 50\% MeOH in EtOAc, $100 \% \mathrm{MeOH}$ in EtOAc, and $50 \% \mathrm{MeOH}$ in $\mathrm{H}_{2} \mathrm{O}$. A total of four fractions were collected; A, B, C and D. CJP02_20C (700 $\mu \mathrm{g})$ appeared to be a single compound based upon ${ }^{1} \mathrm{H}$ NMR analysis.

\subsection{Incomplete/Discarded Purifications}

\subsubsection{Further purification of OOK}

CJP01_00K (5.8 mg) was loaded onto $1 \mathrm{~mL}$ of DIOL and transferred onto a $5 \mathrm{~mL}$ DIOL column in Hexanes, equilibrated in Hexanes. The column was eluted with $18 \mathrm{~mL}$ volumes of: $50 \%$ DCM in Hexanes, DCM, 50\% DCM in EtOAc, EtOAc, 10\% MeOH in EtOAc, $20 \% \mathrm{MeOH}$ in EtOAc, 50\% MeOH in EtOAc, and 100\% MeOH. A total of 32 fractions were collected and concentrated to dryness under reduced pressure. Fractions were combined after TLC analysis, affording CJP02_14I, CJP02_14J, CJP02_14K, CJP02_14L, and CJP02_14M.

\subsubsection{Further purification of OOJ}

CJP02_00J (7.9 mg) was loaded onto $1 \mathrm{~mL}$ of DIOL and transferred onto a $5 \mathrm{~mL}$ DIOL column in Hexanes, equilibrated in Hexanes. The column was eluted with $18 \mathrm{~mL}$ volumes of: $50 \%$ EtOAc in Hexanes, EtOAc, 10\% MeOH in EtOAc, 20\% MeOH in EtOAc, $50 \% \mathrm{MeOH}$ in EtOAc, $100 \% \mathrm{MeOH}$ in EtOAc, and $50 \% \mathrm{MeOH}$ in $\mathrm{H}_{2} \mathrm{O}$. A total of 32 fractions were collected and concentrated to dryness under reduced pressure. Fractions were combined 
based on TLC analysis, affording: CJP02_07G: 2-3 (3.8 mg), CJP02_07B: 5-6 (200 $\mu \mathrm{g})$, CJP02_07H: 7-10 (800 $\mu \mathrm{g})$, CJP02_07D: 13-17 (600 $\mu \mathrm{g})$, and CJP02_07I: 18-32 (1.9 mg). CJP02_07G was chosen for further purification due to the presence of aromatic resonances.

A $150 \mathrm{~mm}$ Pasteur pipette was filled with 2/3 DIOL, loaded in hexanes. CJP02_07G was wet-loaded in DCM and a column was run using isocratic solvent system of 50\% EtOAc in Hexanes, followed by EtOAc and $\mathrm{MeOH}$ to strip the column. A total of 11 fractions were collected and combined based on TLC analysis to afford CJP02_11A (1.9 mg) and CJP02_11B $(500 \mu \mathrm{g})$. Neither fraction appeard to be a single compound based upon ${ }^{1} \mathrm{H}$ NMR analysis.

\subsubsection{Further purification of $\mathrm{OOH}$}

CJP02_00H (7.0 mg) was dry-loaded onto $1 \mathrm{~mL}$ of DIOL and transferred onto a $5 \mathrm{~mL}$ DIOL column in Hexanes, equilibrated in Hexanes. The column was eluted with $18 \mathrm{~mL}$ volumes of: $50 \%$ EtOAc in Hexanes, EtOAc, $10 \% \mathrm{MeOH}$ in EtOAc, $20 \% \mathrm{MeOH}$ in EtOAc, $50 \% \mathrm{MeOH}$ in EtOAc, $100 \% \mathrm{MeOH}$ in EtOAc, and $50 \% \mathrm{MeOH}$ in $\mathrm{H}_{2} \mathrm{O}$. A total of 32 fractions were collected. Fractions were concentrated to dryness under reduced pressure, and combined according to TLC analysis affording: CJP02_10A (5-7), CJP02_10B (8-10), CJP02_10C (1112), CJP02_10D (13-14), CJP02_10E (15-18), CJP02_10F (19-20), and CJP02_10G (21-30).

\subsubsection{Further purification of OOD}

CJP01_00D (7.9 mg) was dry-loaded onto $1 \mathrm{~mL}$ of DIOL and transferred onto a $5 \mathrm{~mL}$ DIOL column in Hexanes, equilibrated in Hexanes. The column was eluted with $18 \mathrm{~mL}$ volumes of: $50 \%$ DCM in Hexanes, 50\% DCM in EtOAc, EtOAc, 10\% MeOH in EtOAc, $20 \% \mathrm{MeOH}$ in EtOAc, $50 \% \mathrm{MeOH}$ in EtOAc, and $100 \% \mathrm{MeOH}$ in EtOAc. A total of 32 fractions were collected and concentrated to dryness under reduced pressure. Fractions were combined after TLC analysis, affording: CJP02_14A, CJP02_14B, and CJP02_14C.

\subsubsection{Further purification of OOC}

CJP01_00C (1.8 mg) was dry-loaded onto $1 \mathrm{~mL}$ of DIOL and transferred onto a $5 \mathrm{~mL}$ DIOL column in Hexanes, equilibrated in Hexanes. The column was eluted with $18 \mathrm{~mL}$ volumes 
of: 50\% DCM in Hexanes, DCM, 50\% DCM in EtOAc, EtOAc, 10\% MeOH in EtOAc, 20\% $\mathrm{MeOH}$ in EtOAc, $50 \% \mathrm{MeOH}$ in EtOAc, $100 \% \mathrm{MeOH}$ in EtOAc. A total of 32 fractions were collected. Fractions were concentrated to dryness under reduced pressure and combined after TLC analysis, affording: CJP02_14D (9,10), CJP02_14E (19), CJP02_14F (23), CJP02_14G $(26,27)$, and CJP02_14H (28-32). 


\section{Chapter 5}

\section{Conclusions}

\subsection{Diversity of Secondary Metabolites in a Temperate Cli- mate}

To date, compounds isolated from the genus Aaptos have only been studied from tropical collections of sponges. The findings from the study herein, highlight the relatively unacknowledged value of marine organisms collected from temperate climates. The compounds isolated in the present study represent a wide range of metabolites, including a 2,5-DKP; the first DKP reported from the genus Aaptos. Although the completed structures of other aromatic compounds CJP02_20A and 20C have not been elucidated, the NMR data indicates that they have not been reported in the genus before and may be novel compounds.

There exists the hypothesis that predation is higher in tropical than temperate habitats, and as a consequence, tropical sponge species have evolved more diverse and effective defences to deter predators. This theory was proposed over 25 years ago with little supporting evidence. ${ }^{112}$ A study published by Becerro et al. ${ }^{112}$ assessed the biogepgraphy of chemical sponge ecology, comparing tropical and chemical defences. The study discussed provides the first experimental test of latitudinal differences in effectiveness of sponge chemical defenses. The researchers collected 20 common sponge species belonging to 14 genera from the tropical Guam and temperate Northeast Spanish coasts, and conducted field-based feeding experiments with large and small fish predators in both geographic areas. They assessed the ability of sponge extracts against all predators, to test the theory that sponges are 
equipped with better chemical defenses in tropical climates. In their findings, the authors concluded that tropical and temperate sponges have comparable deterrence, suggesting that chemical defences from tropical and temperate sponges are equally strong. While this study does not assess the effectiveness of metabolites isolated from temperate and tropical climates, it does contribute to disproving the idea that tropical sponges have a higher chance of diverse defensive metabolites.

\subsection{2,5-Diketopiperazine cyclo(L-Phe-L-Pro)}

2,5-Diketopiperazines (DKPs) are common secondary metabolites of microbes, plants and other sources. They consist of dipeptides, produced by the condensation of two $\alpha$-amino acids in a "head-to-tail" fashion. ${ }^{113}$ There exists an overwhelming amount of variation in DKPs, as there are many combinations and variations of $\alpha$-amino acids, and these chiral templates have multiple sites for structural elaboration. The majority of DKPs isolated have incorporated D-amino acids, but DKPs produced by microbes can also incorporate L- amino acids, creating more opportunity for diversity beyond the normal 21 amino acids. This allows them to display a wide range of bioactivities, ${ }^{114,115}$ and also allows the development of drug-like physiochemical properties. ${ }^{113}$ In fact, a number of DKPs have entered drug development programmes which have led to drugs such as Tadalafil, Retosiban, Epelsiban and Apalviroc. ${ }^{114}$

A vast number of DKPs have been isolated as bioactive natural products. ${ }^{115}$ Included are DKPs from marine sponges. A heptacyclic alkaloid, 21-hydroxystephacidin, was isolated from the sponge A. ostianus (Pohnpei), pre-aurantiamine was isolated from A. aculeatus (sponge: Stylissa flabelliformis) and the DKP dimer eurocristatine was isolated from the endophytic fungus Eurotium cristatum (sponge: Mycale sp., Thailand). ${ }^{113}$ While it is possible that these metabolites are produced by the sponges themselves (through condensation reactions performed by cyclodipeptide synthases (CDPSs)), the DKP isolated in this project, cyclo(L-Phe-L-Pro) is a product of the condensation between the aromatic amino acids phenylalanine and proline. Most DKPs are formed using the NRPS (Non-Ribosomal Peptide Synthetase) biosynthetic pathway, however, aromatic amino acids are synthesised via the shikimate acid pathway, followed by the branched aromatic amino acid metabolic 
pathway, ${ }^{116}$ which is a pathway that sponges lack. This evidence suggests the isolated 2,5DKP originated from a microbial source in some way related to the sponge Aaptos confertus.

In terms of drug discovery and development, DKPs are a valuable source of bioactive compounds that have resulted in a number of approved drugs mentioned previously. Cyclo(PhePro) has shown a number of bioactivities itself in other published papers, including inhibition of an immune response through the NF- $\kappa$ B pathway in a microbial environment, ${ }^{117}$ modulation of the expression of ompU in Vibrio spp., ${ }^{118}$ induction of DNA damage in mammalian cells via reactive oxygen species, ${ }^{119}$ and antifungal activity. ${ }^{120}$ With several MOAs, it is possible the compound is somewhat of a promiscuous binder, but it is worth noting that these different MOAs may be due to stereochemical differences. Regardless, it has potential as a future therapeutic.

\subsection{Branched-Chain Mono-Glycerol Ether}

The isolated 3-((13-methylhexadecyl)oxy)propane-1,2-diol is a known metabolite of the genus Aaptos, originally isolated a Taiwanese sample. ${ }^{111}$ Originally, two lipid ethers were discovered, only varying in the length of the alkyl chain, isolated as $\mathrm{C}_{20} \mathrm{H}_{42} \mathrm{O}_{3}$ and $\mathrm{C}_{22} \mathrm{H}_{46} \mathrm{O}_{3}$.

Following the reisolation reported herein, some amendments were made to the original ${ }^{1} \mathrm{H}$ NMR data obtained. Since the original ${ }^{1} \mathrm{H}$ NMR spectrum was recorded on a $250 \mathrm{MHz}$ NMR, some of the splitting patterns have become better-resolved with the use of a more powerful instrument $(600 \mathrm{MHz})$. The authors originally noted a multiplet at $\delta 3.87$, which has appeared at $\delta 3.75$ for this isolation. The slight differences in chemical shifts may be attributed to the use of a different deuterated solvent (the deuterated solvent for NMR analysis was not declared). The two glycerol ethers were originally reported as an inseparable mixture, and may have overlapping or slightly different spectra, impacting the visualisation of the chemical shifts to some degree. The multiplet also appears in the current study as a pentet, opposed to a multiplet, due to the increased resolution of the generated spectrum.

The doublet of doublets assigned to the two non-equivelant protons at $\mathrm{C}-1$ remain similar in chemical shift and coupling pattern. The C-3 protons, however, were initially reported as equivalent protons, appearing as a doublet $(J)$ at $\delta 3.55$ and the C-1' protons reported as a 
triplet at $\delta 3.50$. However, these signals overlap with more complex splitting patterns. The HSQC spectrum clearly shows that the C-3 protons are inequivelant, appearing as a doublet of doublets at $\delta 3.41$ and $\delta 3.47$, however the doublet of doublets at $\delta 3.47$ is partially overlapping with the C-1' signal. This was originally not detected, due to the decreased resolution of the spectrometer. Therefore, the overlapping signals were not observed beneath the $\mathrm{C}-1$ ' triplet at $\delta 3.46$.

Of interest is the fact that in the original paper, the two glycerol ethers were present as an inseparable mixture. In the current study, neither the HRESIMS or NMR data indicated the presence of a second, longer glycerol ether. It is possible that the sponge Aaptos confertus has evolved to produce only one of these metabolites, or the biosynthetic pathway of the Taiwanese sponge had diverged in some way, to also create a longer glycerol ether. It is unlikey this observed difference is a result of their respective environments. It is also possible that the minor metabolite (longer chain glycerol ether) was separated from the major in this study, though it may be unlikely as separating two similar lipids would be challenging. These possibilities can only be speculated, however, as the biosynthetic pathway producing the glycerol ether is unknown.

As the authors state, marine sponges are a source of unusual compounds, including many novel fatty acids. ${ }^{111}$ In general, fatty glycerol esters are more common that glycerol ethers. This molecule falls under the class of monoalkyl glycerol ethers (MAGEs). Ether bonds are more stable than ester or amide bonds, and were initially viewed as biomarkers for sulftereducing bacteria, mediting anaerobic oxidation of methane in marine environments. ${ }^{121}$ Glyerol ether lipids (GELs) were initially found from organisms in marine hydrothermal vents (Bradley et al., 2009), cold seeps with anaerobic oxidation of methane (Hinrichs et al., 2000; Pancost et al., 2001), terrestrial hot springs (Jahnke et al., 2001), silica sinters (Pancost et al., 2005, 2006) and a natural $\mathrm{CO}_{2}$ vent in soil (Opperman et al., 2010). It is also common for these compounds to be found from temperate evironments like soil or marine water columns, ${ }^{121}$ but rarely from marine invertebrates such as sponges. The original research paper also notes that glycerol ethers have been recognized as components of marine animal liver oils, however there is no record of the cited research paper. ${ }^{111}$

Glycerol ethers have been reported from a small number of marine invertebrates since the 
original isolation paper, ${ }^{122,122-132}$ but no distinct origin, innate purpose, or MOA has been discovered of the class of molecules as a whole. Current research indicates a microbial source, however this is simply an indication. ${ }^{121}$ The only evidence of such compounds originating from marine inverebrates, and not microbes, is the identification of MAGEs forming the contents of gut walls of an Abyssal Holothurian (Oneirophanta mutabilis), a sea cucumber. ${ }^{133}$ Still, this could be attributed to gut microbes in the organism. This information would suggest that glycerol ethers are simply primary metabolite derivatives, but without further information on their biological activity, this conclusion cannot be confirmed.

The most similar compound from a marine invertebrate, which differs only in the location of the alkyl side-chain, was isolated guided by a shrimp lethality assay from the marine sponge Stelletta sp. collected from Chinese Seas. However, no MOA or possible innate purpose was discussed. ${ }^{125}$ The similarity between these two compounds is striking, considering they are separated taxonomically and geographically. If the compounds were found only from the Aaptos sp. and Stelletta sp. in Asia, one could postulate that their similar metabolites could be attributed to their similar environment. However, the compound isolated in this project came from a sponge from Three Kings Islands in New Zealand. This would suggest a taxonomic relationship, but it's potential as a biomarker for the genus Aaptos is undetermined, as this exact variation has been isolated from the species of another genus.

While the chemical's innate mechanism, or effect in humans, can only be postulated, it has the potential to be involved in a specific immune response to Mycobacterium tuberculosis. The monoalkyl glycerol ether bears similarities to some identified $\mathrm{C}_{22}$ and $\mathrm{C}_{26}$ trehalose monoesters (with single acyl chains) that were found to activate macrophges in a Mincle-dependent manner. ${ }^{134}$ Mincle is the abbreviated name of monoctye(or macrophage)inducible C-type lectin, and is an essential receptor for TDM, also known as trehalose-6-6'dimycolate (mycobacterial glycolipid). ${ }^{135}$ TDM is a poten immunostimulant, which plays a role in the formation of granulomas in tuberculosis (Mycobacterium tuberculosis). It provides a thick and waxy coating around the surface of Mycobacterium tuberculosis, thereby conferring resistance to externally-administered drugs. ${ }^{136}$ These trehalose monoesters therefore provide a framework for the rational design of other Mincle agonists, and so may the isolated monoalkyl gylcerol ether, due to its structural similarities with these identified trehalose 
monoesters. In a similar article, a selection of trehaolse glycolipids, also similar in structure to the glycerol ether and trehalose monesters, were shown to be upaken by macrophages in a Mincle-independant manner. ${ }^{136}$ These treahlose glycolipids also play an important role in the pathogenesis of Mycobacterium tuberculosis. This particular research paper revealed that although Mincle is essential for the activation of macrophages by trehalose glycolipids, the receptor does not partake in the uptake of the glycolipids by macrohphages. Due to the similarity between the isolated glycerol ether and the trehalose monoesters and trehalose glycolipids, the compound will be submitted for further analysis of it's immunomodulatory properties, and in particular, effects upon Mincle. 


\section{Appendix A}

\section{Screening Protocol}

\section{A.1 Existing Marine Chemistry Screening Protocol}

The current protocol was developed for screening New Zealand marine sponges.

Required Apparatus

- 1 x screening column packed with $80 \mathrm{~mL}$ of $\mathrm{HP}-20^{\circledR}$ beads, equilibrated in $\mathrm{MeOH}$.

- 1 x backloading column packed with $40 \mathrm{~mL}$ of $\mathrm{HP}-20^{\circledR}$ beads, equilibrated in $\mathrm{MeOH}$.

Procedure

1. Preparation of a Voucher Sample

- Obtain a voucher specimen of approximately $10 \mathrm{~g}$ of sponge material, ensuring both ectoderm and endoderm are represented.

- Store the voucher sample in $75 \%$ IPA in $\mathrm{H}_{2} \mathrm{O}$ and label.

2. Extraction

- Extract approximately $20 \mathrm{~g}$ of crude sponge material in $100 \mathrm{~mL} \mathrm{MeOH}$ for 24 hours.

- Filter the first extract.

- Re-extract the sponge material in $100 \mathrm{~mL} \mathrm{MeOH}$ for a further 24 hours.

- Filter the second extract. 
- Retain all sponge material (including filter paper) until the screen is complete. If the eluent is no longer needed after the screen, it may be discarded.

3. Cyclic Loading

- Pass the second extract through the screen column at an approximate flow rate of $10 \mathrm{~mL} / \mathrm{min}$.

- Pass the first extract through the screen column at an approximate flow rate of 10 $\mathrm{mL} / \mathrm{min}$.

- Combine the eluents and dilute to $50 \%$ of the original concentration with distilled $\mathrm{H}_{2} \mathrm{O}$.

- Pass the eluent through the screen column at an approximate flow rate of 10 $\mathrm{mL} / \mathrm{min}$.

- Collect the eluent and dilute to $50 \%$ of its concentration with distilled $\mathrm{H}_{2} \mathrm{O}(25 \%$ of the original concentration).

- Pass the eluent through the screen column at an approximate flow rate of 10 $\mathrm{mL} / \mathrm{min}$.

- If the eluent is still vibrantly-coloured, dilute again to $50 \%$ of its concentration with distilled $\mathrm{H}_{2} \mathrm{O}$ and pass through the screen column again, at an approximate flow rate of $10 \mathrm{~mL} / \mathrm{min}$.

- Retain the eluent until the screen is complete. If the eluent is no longer needed after the screen, it may be discarded.

\section{Elution}

- Elute the screen column with $100 \mathrm{~mL}$ of distilled $\mathrm{H}_{2} \mathrm{O}$ at an approximate flow rate of $10 \mathrm{~mL} / \mathrm{min}$.

- Discard the water eluent.

- Elute the screen column with $100 \mathrm{~mL}$ of $30 \% \mathrm{Me}_{2} \mathrm{CO}$ in distilled $\mathrm{H}_{2} \mathrm{O}(\% \mathrm{v} / \mathrm{v})$ with an approximate flow rate of $10 \mathrm{~mL} / \mathrm{min}$.

- Elute the screen column with $100 \mathrm{~mL}$ of $75 \% \mathrm{Me}_{2} \mathrm{CO}$ in distilled $\mathrm{H}_{2} \mathrm{O}(\% \mathrm{v} / \mathrm{v})$ with an approximate flow rate of $10 \mathrm{~mL} / \mathrm{min}$. 
- Elute the screen column with $100 \mathrm{~mL}$ of $100 \% \mathrm{Me}_{2} \mathrm{CO}$ with an approximate flow rate of $10 \mathrm{~mL} / \mathrm{min}$.

5. Backloading the $75 \% \mathrm{Me}_{2} \mathrm{CO}$ Fraction

- Dilute the $75 \% \mathrm{Me}_{2} \mathrm{CO}$ fraction with distilled $\mathrm{H}_{2} \mathrm{O}$ to $50 \%$ of its concentration.

- Pass the diluted eluent through the backloading column with an approximate flow rate of $8 \mathrm{~mL} / \mathrm{min}$.

- Dilute the eluent with distilled $\mathrm{H}_{2} \mathrm{O}$ to $50 \%$ of its concentration (25\% of the original concentration).

- Pass the diluted eluent through the backloading column with an approximate flow rate of $8 \mathrm{~mL} / \mathrm{min}$.

- Retain the eluent until the screen is complete, at which point it may be discarded.

- Elute the backloading column with $100 \mathrm{~mL} \mathrm{Me}_{2} \mathrm{CO}$.

6. Processing the $75 \% \mathrm{Me}_{2} \mathrm{CO}$ Fraction

- Concentrate the eluent to dryness under reduced pressure by rotary-evaporation.

- Transfer to a dried and pre-weighed sample vial, using solvent to transfer the mass. Filter any sediment by gravity filtration if present.

- Concentrate the sample to dryness under reduced pressure by rotary-evaporation and record the mass.

- If sufficient mass is obtained, sub-sample approximately $30 \mathrm{mg}$ for NMR analysis.

- If the sample is soluble in $\mathrm{CDCl}_{3}$, prepare a sample for NMR by dissolving the sub-sample in $500 \mu \mathrm{L}$ of $\mathrm{CDCl}_{3}$ and transfer to a $5 \mathrm{~mm}$ NMR tube which has been sufficiently dried.

- If the sample is not soluble in $\mathrm{CDCl}_{3}$, prepare a sample for $\mathrm{NMR}$ by dissolving the sub-sample in $200 \mu \mathrm{L}$ of $\mathrm{CD}_{3} \mathrm{OD}$ and transfer to a $3 \mathrm{~mm}$ NMR tube which has been sufficiently dried.

7. NMR Analysis of the $75 \% \mathrm{Me}_{2} \mathrm{CO}$ Fraction 
- Run a ${ }^{1} \mathrm{H}$ NMR spectrum of the sample on the $600 \mathrm{MHz}$ instrument using the standard parameter set with a run time of approximately four minutes.

- Run a COSY spectrum of the sample using the standard parameter set with a run time of approximately 20 minutes.

- Run an HSQC NMR spectrum of the sample using the standard parameter set with a run time of approximately 5.5 hours.

8. Backloading the $30 \% \mathrm{Me}_{2} \mathrm{CO}$ Fraction

- Dilute the $30 \% \mathrm{Me}_{2} \mathrm{CO}$ fraction with distilled $\mathrm{H}_{2} \mathrm{O}$ to $50 \%$ of its concentration.

- Pass the diluted eluent through the backloading column with an approximate flow rate of $8 \mathrm{~mL} / \mathrm{min}$.

- Dilute the eluent with distilled $\mathrm{H}_{2} \mathrm{O}$ to $50 \%$ of its concentration (25\% of the original concentration).

- Pass the diluted eluent through the backloading column with an approximate flow rate of $8 \mathrm{~mL} / \mathrm{min}$.

- Retain the eluent until the screen is complete, at which point it may be discarded.

- Elute the backloading column with $100 \mathrm{~mL} \mathrm{Me}_{2} \mathrm{CO}$.

9. Processing the $30 \% \mathrm{Me}_{2} \mathrm{CO}$ Fraction

- Concentrate the eluent to dryness under reduced pressure by rotary-evaporation.

- Transfer to a dried and pre-weighed sample vial, using solvent to transfer the mass. Filter any sediment by gravity filtration if present.

- Concentrate the sample to dryness under reduced pressure by rotary-evaporation and record the mass.

- If sufficient mass is obtained, sub-sample approximately $30 \mathrm{mg}$ for NMR analysis.

- If the sample is soluble in $\mathrm{CDCl}_{3}$, prepare a sample for NMR by dissolving the sub-sample in $500 \mu \mathrm{L}$ of $\mathrm{CDCl}_{3}$ and transfer to a $5 \mathrm{~mm}$ NMR tube which has been sufficiently dried. 
- If the sample is not soluble in $\mathrm{CDCl}_{3}$, prepare a sample for $\mathrm{NMR}$ by dissolving the sub-sample in $200 \mu \mathrm{L}$ of $\mathrm{CD}_{3} \mathrm{OD}$ and transfer to a $3 \mathrm{~mm}$ NMR tube which has been sufficiently dried.

10. NMR Analysis of the $30 \% \mathrm{Me}_{2} \mathrm{CO}$ Fraction

- Run a ${ }^{1} \mathrm{H}$ NMR spectrum of the sample on the $600 \mathrm{MHz}$ instrument using the standard parameter set with a run time of approximately four minutes.

11. Processing the $100 \% \mathrm{Me}_{2} \mathrm{CO}$ Fraction

- Concentrate the eluent to dryness under reduced pressure by rotary-evaporation.

- Transfer to a dried and pre-weighed sample vial, using solvent to transfer the mass. Filter any sediment by gravity filtration if present.

- Concentrate the sample to dryness under reduced pressure by rotary-evaporation and record the mass.

- If sufficient mass is obtained, sub-sample approximately $30 \mathrm{mg}$ for NMR analysis.

- If the sample is soluble in $\mathrm{CDCl}_{3}$, prepare a sample for NMR by dissolving the sub-sample in $500 \mu \mathrm{L}$ of $\mathrm{CDCl}_{3}$ and transfer to a $5 \mathrm{~mm}$ NMR tube which has been sufficiently dried.

- If the sample is not soluble in $\mathrm{CDCl}_{3}$, prepare a sample for $\mathrm{NMR}$ by dissolving the sub-sample in $200 \mu \mathrm{L}$ of $\mathrm{CD}_{3} \mathrm{OD}$ and transfer to a $3 \mathrm{~mm}$ NMR tube which has been sufficiently dried.

12. NMR Analysis of the $100 \% \mathrm{Me}_{2} \mathrm{CO}$ Fraction

- Run a ${ }^{1} \mathrm{H}$ NMR spectrum of the sample on the $600 \mathrm{MHz}$ instrument using the standard parameter set with a run time of approximately four minutes. 


\section{Appendix B}

\section{NMR Protocol}

\section{Sample Preparation}

- Obtain a sample of approximately $30 \mathrm{mg}$ to be analysed.

- Transfer to a pre-weighed, dried, sample vial.

- Concentrate to dryness under reduced pressure.

- Record the mass.

- If the sample is soluble in $\mathrm{CDCl}_{3}$, prepare the sample for NMR analysis in approximately $500 \mu \mathrm{L}$ of $\mathrm{CDCl}_{3}$ in a dry $5 \mathrm{~mm}$ NMR tube.

- If the sample is not soluble in $\mathrm{CDCl}_{3}$, prepare the sample for NMR analysis in approximately $250 \mu \mathrm{L}$ of $\mathrm{CD}_{3} \mathrm{OD}$ in a dry $3 \mathrm{~mm}$ NMR tube. 


\section{Appendix C}

\section{Routine Experimental Protocols}

\section{C.1 Cyclic Loading}

\section{C.1.1 Background}

Cyclic loading is an in-house chromatographic technique developed by West and Northcote at the Marine Chemistry Laboratory, VUW. ${ }^{137}$ It was developed in order to circumvent the relatively high loss of product through liquid-liquid partitioning (LLP). It further develops the Blunt and Munro C18 method, ${ }^{138}$ using reversed-phase poly(styrene-divinylbenzene) (PSDVB). PSDVB beads consist of a cross-linked polymer with large surface area. These beads are non-polar, but not as non-polar as C18 and allow compounds of intermediate polarity to adsorb to the column, and elute without irreversible binding. Compounds of intermediate polarity are of most interest, as they are more likely to allow transport across cellular membranes, but are not so non-polar that they cannot exert any affect in the cell. Often compounds are not known, but we assume most bioactive compounds are of intermediate polarity. Although highly polar compounds can be interesting, they are not compatible with reversed-phase chromatography. For compounds to be biologically active, they most often possess a mixture of hydrophilic and hydrophobic regions. This enables transport across membranes and barriers. PSDVB is also inert and stable across large $\mathrm{pH}$ range, allowing the use of ionic buffers. The absence of surface ligands eliminates possibility of stripping (as in $\mathrm{C} 18$ ) and remains chemically stable in aqueous solvents. In addition, PSDVB is also re-useable. 


\section{C.1.2 Procedure}

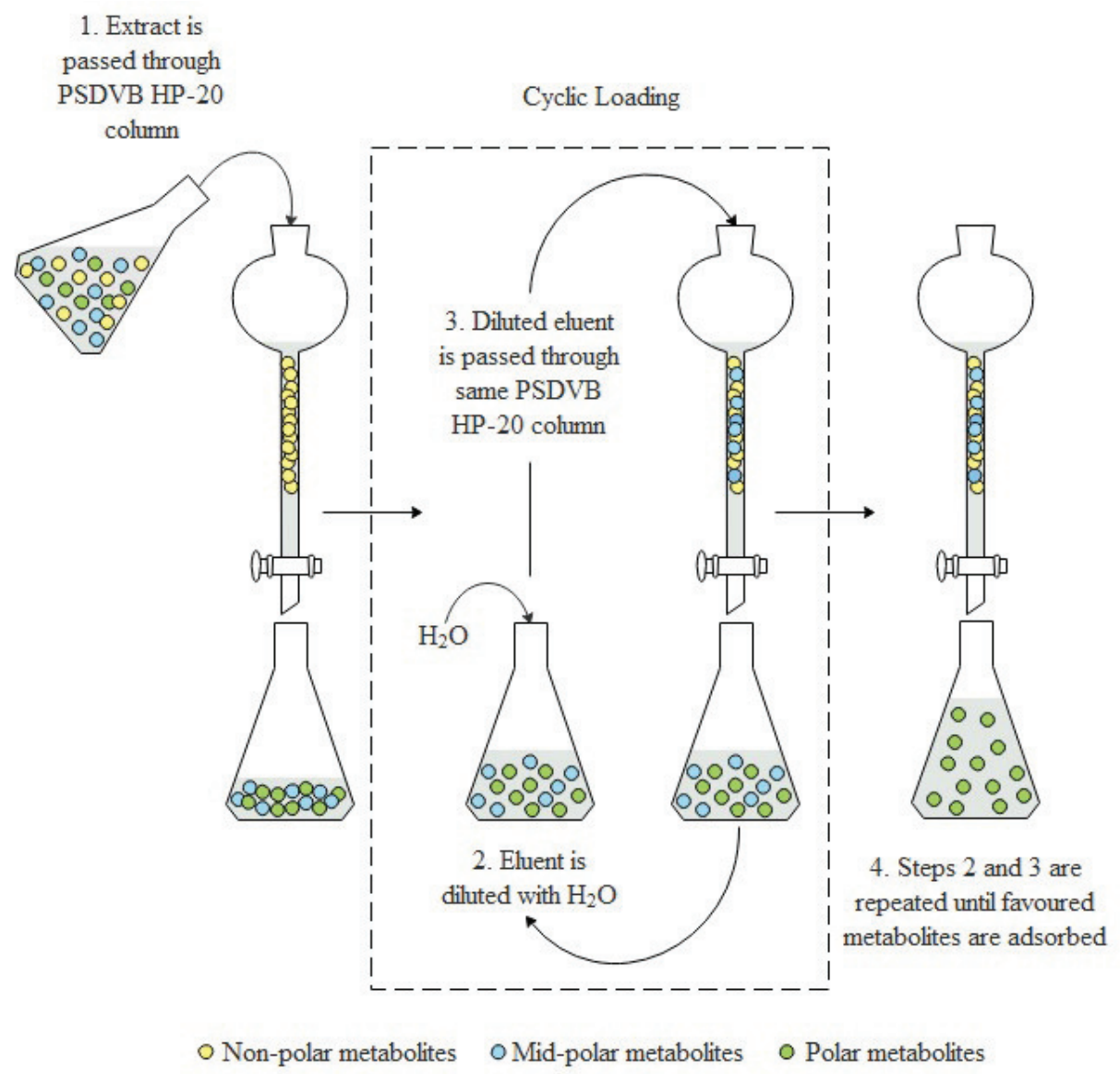

Figure C.1: Cyclic-Loading Procedure.

Firstly, a crude extract in $\mathrm{MeOH}$ is passed through PSDVB column, which is usually equilibrated in methanol and washed with water. Non-polar compounds in the extract will adhere to column. Next the eluent diluted with $\mathrm{H}_{2} \mathrm{O}$, to $50 \%$ of the original concentration. This dilution increases the polarity of the eluent/mobile phase. It is passed back through the column, allowing compounds of increasing polarity to preferentially adsorb to the stationary phase when passed through. This process is repeated until the metabolites of interest are retained on the column. This process is usually done twice, or until the eluent seems significantly dilute. Once all the material has been loaded on the column, it is sequentially eluted with solvents (and mixes) of decreasing polarity.

Cyclic loading has many advantages, other than increasing the overall yield of isolated compounds. Firstly, cyclic loading uses solvents of lower toxicity than LLP. When handling large volumes of crude extract, methanol and water are used which are relatively non-toxic, compared to solvents such as chloroform, butanol, DCM, hexanes and EtOAc often used in 
LLP. Liquid-liquid partitioning often results in the loss of product as a result of transfer between the organic and aqueous layers, especially with compounds of intermediate polarity. Cyclic loading avoids this, as metabolites of high, low, and intermediate polarity are easily eluted in separate stages.

The increased yield of small quantities of metabolites certainly outweighs the disadvantages. Often compounds of interest, used as defences by sponges, are potent in small quantities as in their natural environment, thus get diluted in water. Being able to isolate and purify these compounds is of primary importance. However, cyclic loading does come with its disadvantages. The most obvious is that it requires large quantities of solvent. A $1.6 \mathrm{~L}$ extract quickly becomes $3.2 \mathrm{~L}$ and then $6.4 \mathrm{~L}$. This requires a lot of time to pass through columns, and large, heavy equipment. Compounds still run the risk of irreversible binding to column, but this is less likely than with highly polar or non-polar columns.

Fractions with high water content also present other problems. Concentrating fractions under reduced pressure is often time-consuming and runs the risk of "bumping. Water has a high boiling point and is therefore harder to remove under vacuum. In addition, no azeotrope forms between $\mathrm{Me}_{2} \mathrm{CO}$ and $\mathrm{H}_{2} \mathrm{O}$ or $\mathrm{MeOH}$ and $\mathrm{H}_{2} \mathrm{O}$, increasing the chances of "bumping". A procedure known as back loading is used to overcome the issue of high water content in bulk fractions.

\section{Backloading}

A fraction with high $\mathrm{H}_{2} \mathrm{O}$ content is diluted with water. It is then cyclic loaded onto smaller PSDVB column so that all dissolved metabolites adhere to the column. It is then eluted with pure organic solvent, to eliminate as much water as possible from the fraction, which is now devoid of $\mathrm{H}_{2} \mathrm{O}$. The fraction can now be concentrated under reduced pressure with more ease, without bumping, and in a more timely fashion.

\section{C.2 DIOL Dry-Loading}

Dry-loading onto DIOL (DSC-DIOL SPE functionalised silica: 3-(2,3-Dihidroxy-propoxy)propyl-silica solid phase extraction) involves adhering a compound (or mixture of compounds) in a sample to the DIOL beads, in order to wet-load onto another DIOL column 
as preparation for running a column. When performed correctly, this results in an even, straight 'loading band' on the column, and assists loading where the sample is sparingly soluble in hexanes, or any other relatively non-polar solvent.

\section{C.2.1 Procedure}

1. For every $15 \mathrm{mg}$ of sample, prepare $1 \mathrm{~mL}$ of DIOL.

2. Dissolve the sample in approximately $2 \mathrm{~mL}$ of $\mathrm{MeOH}$, and add to it $1 \mathrm{~mL}$ of DIOL.

3. Concentrate the sample under reduced pressure.

4. Add approximately $1 \mathrm{~mL}$ of DCM to the sample, and dry as in step 3 .

5. Once dry, add approximately $1 \mathrm{~mL}$ of $\mathrm{n}$-hexanes to the sample, and dry as in step 3.

6. Wet-load the dry-loaded DIOL to an existing DIOL column (that has been equilibrated in n-hexanes) in a slurry of n-hexanes.

7. Run the column as usual. 
Appendix D

Spectra of Sponge Screens 


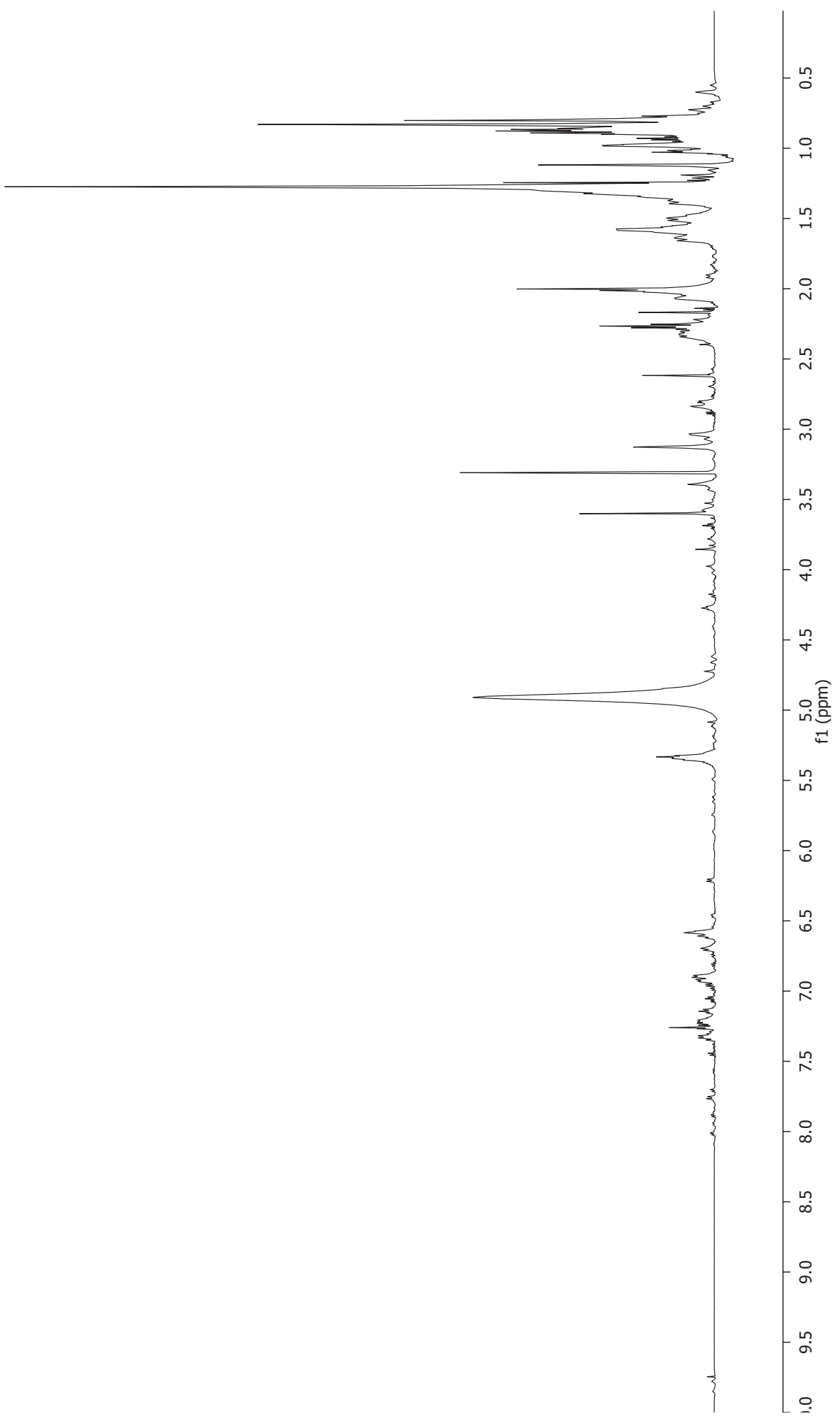

Figure D.1: ${ }^{1} \mathrm{H}$ spectrum of $75 \% \mathrm{HP}-20$ fraction from Dictyodendrilla dendyi $(600 \mathrm{MHz}$, $\left.\mathrm{CD}_{3} \mathrm{OD}\right)$ 
(mdd) If

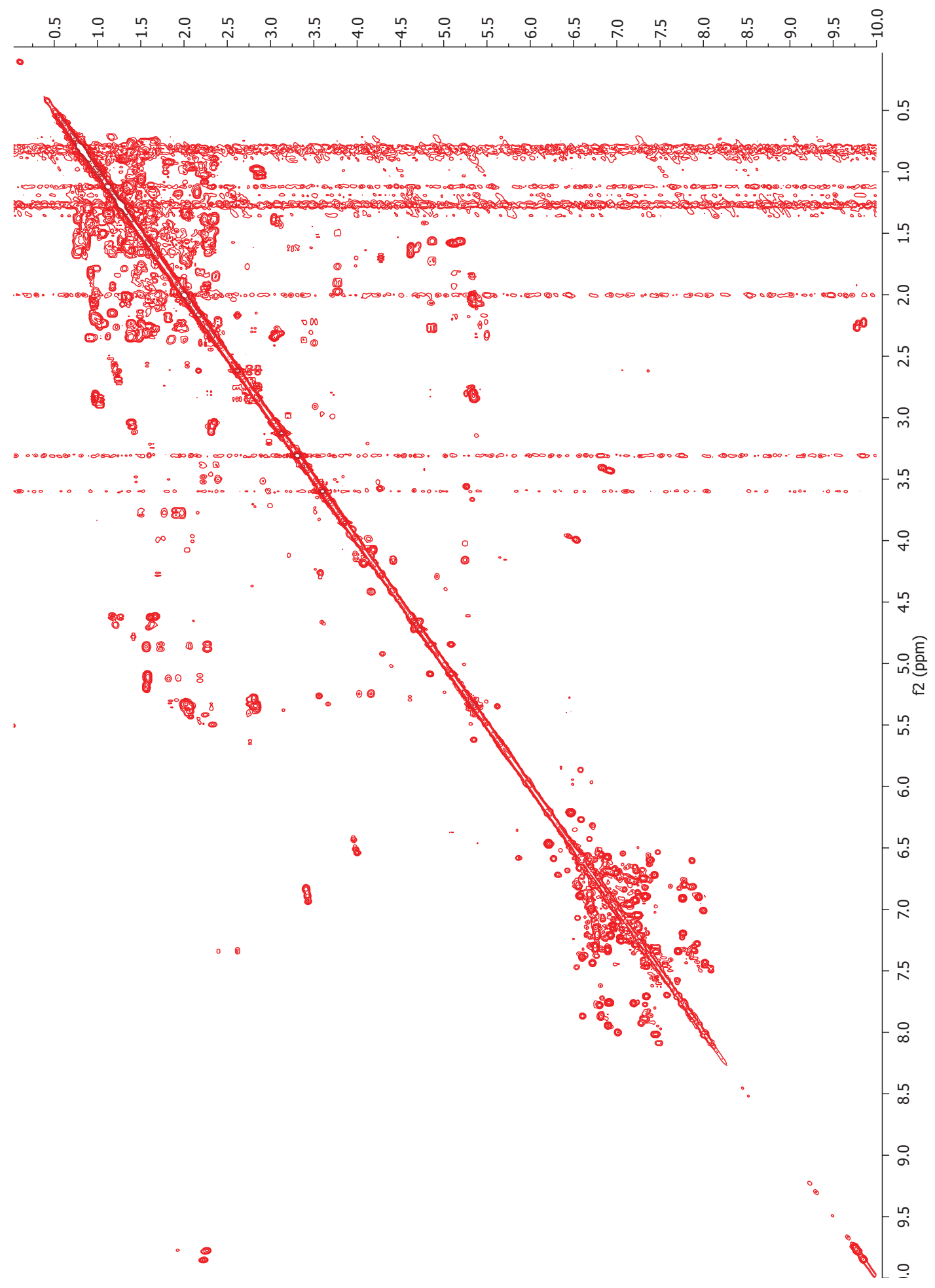

Figure D.2: COSY spectrum of 75\% HP-20 fraction from Dictyodendrilla dendyi 600 $\left.\mathrm{MHz}, \mathrm{CD}_{3} \mathrm{OD}\right)$ 
(mdd) If

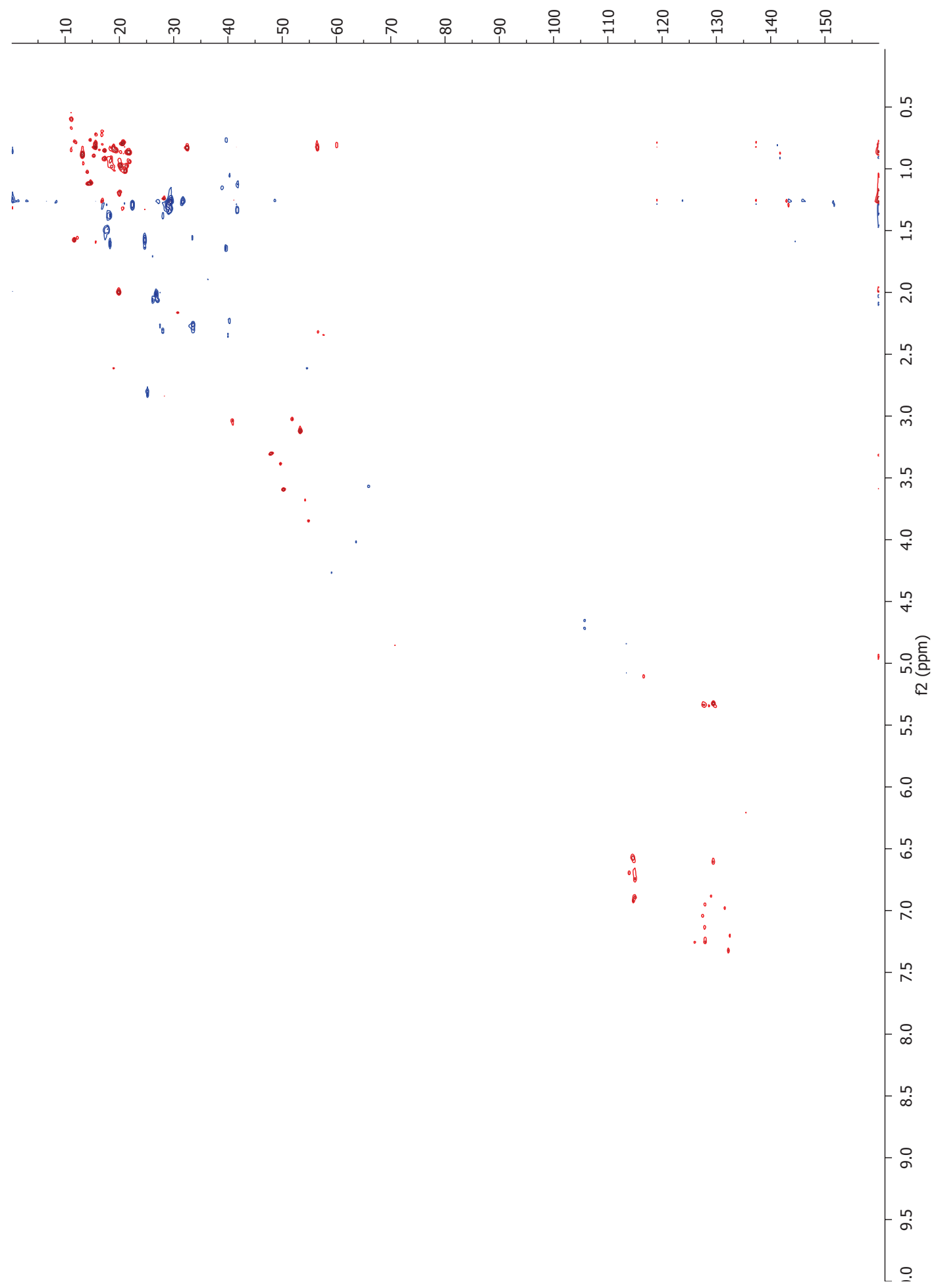

Figure D.3: Multiplicity-Edited HSQC spectrum of 75\% HP-20 fraction from Dictyodendrilla dendyi $\left(600 \mathrm{MHz}, \mathrm{CD}_{3} \mathrm{OD}\right)$ 


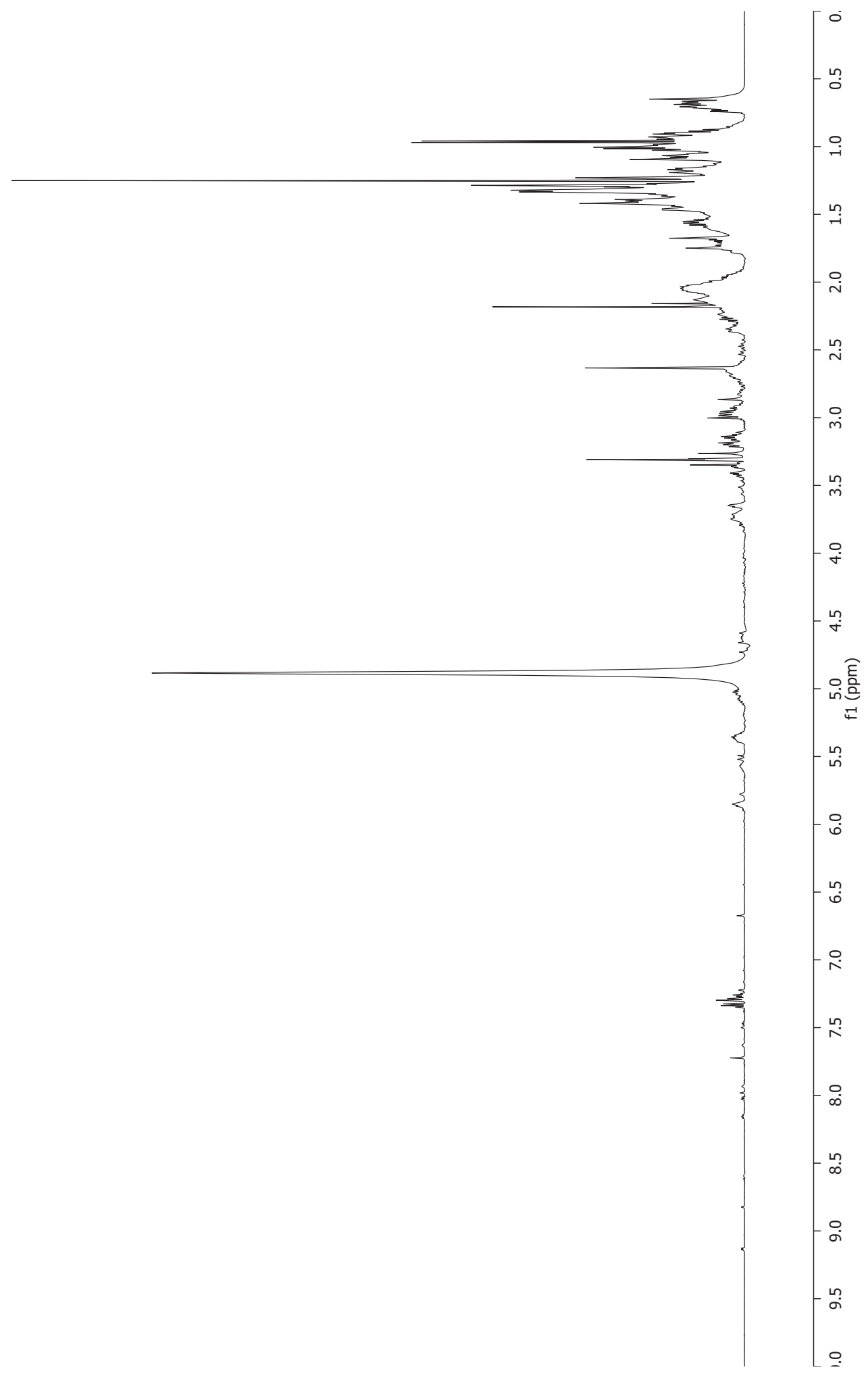

Figure D.4: ${ }^{1} \mathrm{H}$ spectrum of $75 \%$ HP-20 fraction from Phorbas areolata $(600 \mathrm{MHz}$, $\left.\mathrm{CD}_{3} \mathrm{OD}\right)$ 


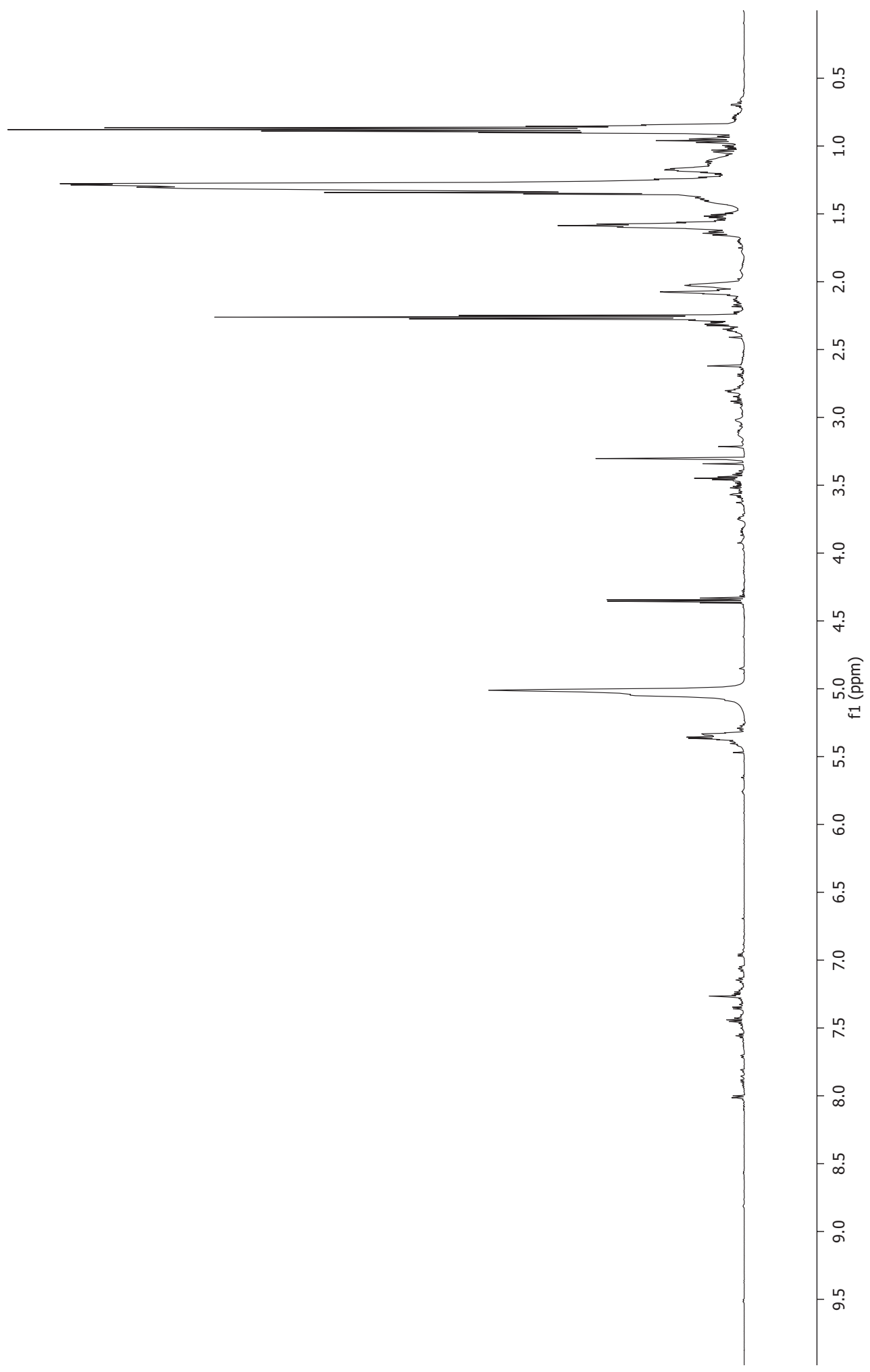

Figure D.5: ${ }^{1} \mathrm{H}$ spectrum of $75 \% \mathrm{HP}-20$ fraction from Aaptos confertus $(600 \mathrm{MHz}$, $\mathrm{CD}_{3} \mathrm{OD}$ ) 
(mdd) If

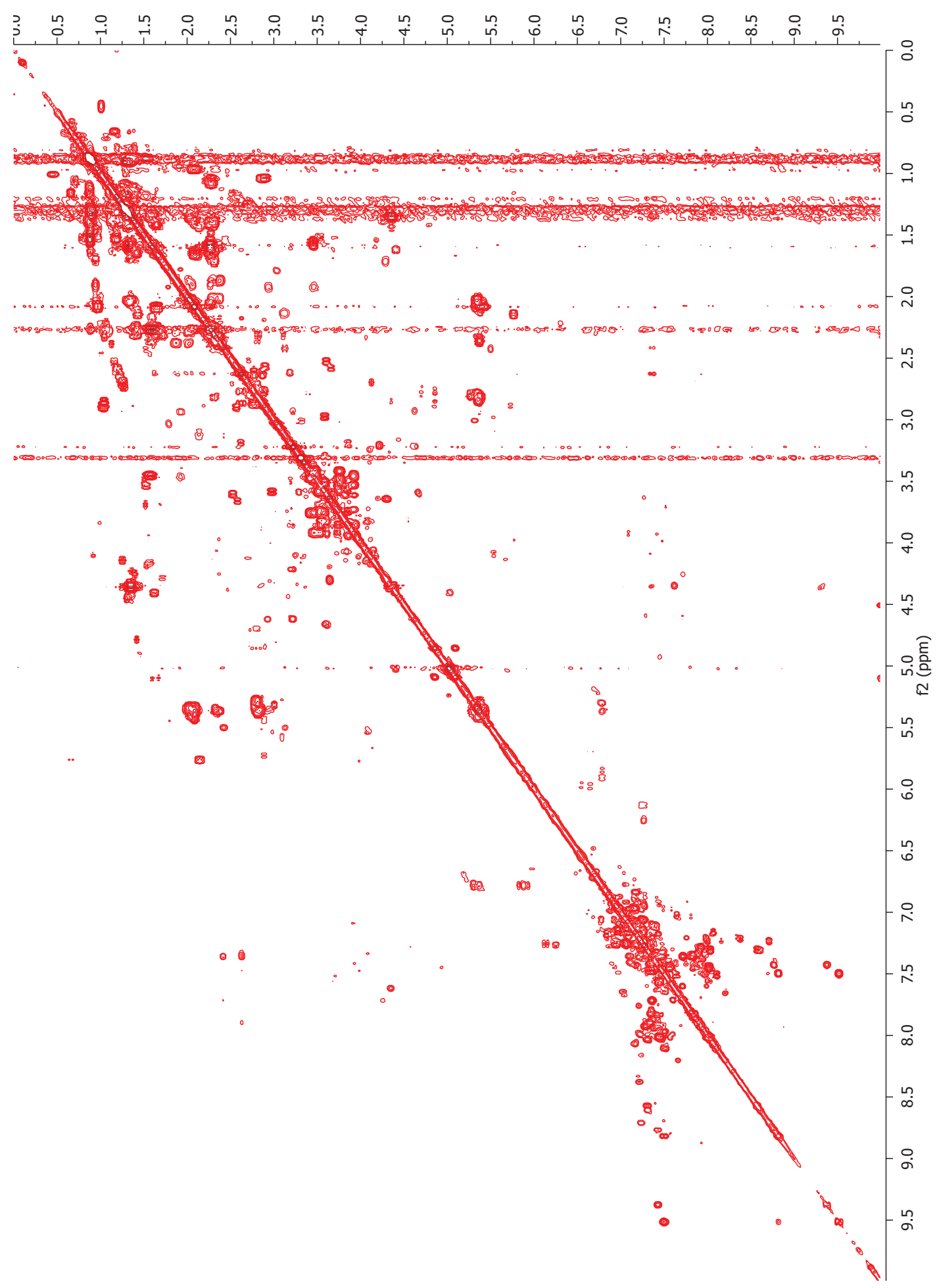

Figure D.6: COSY spectrum of 75\% HP-20 fraction from Aaptos confertus $(600 \mathrm{MHz}$, $\left.\mathrm{CD}_{3} \mathrm{OD}\right)$ 


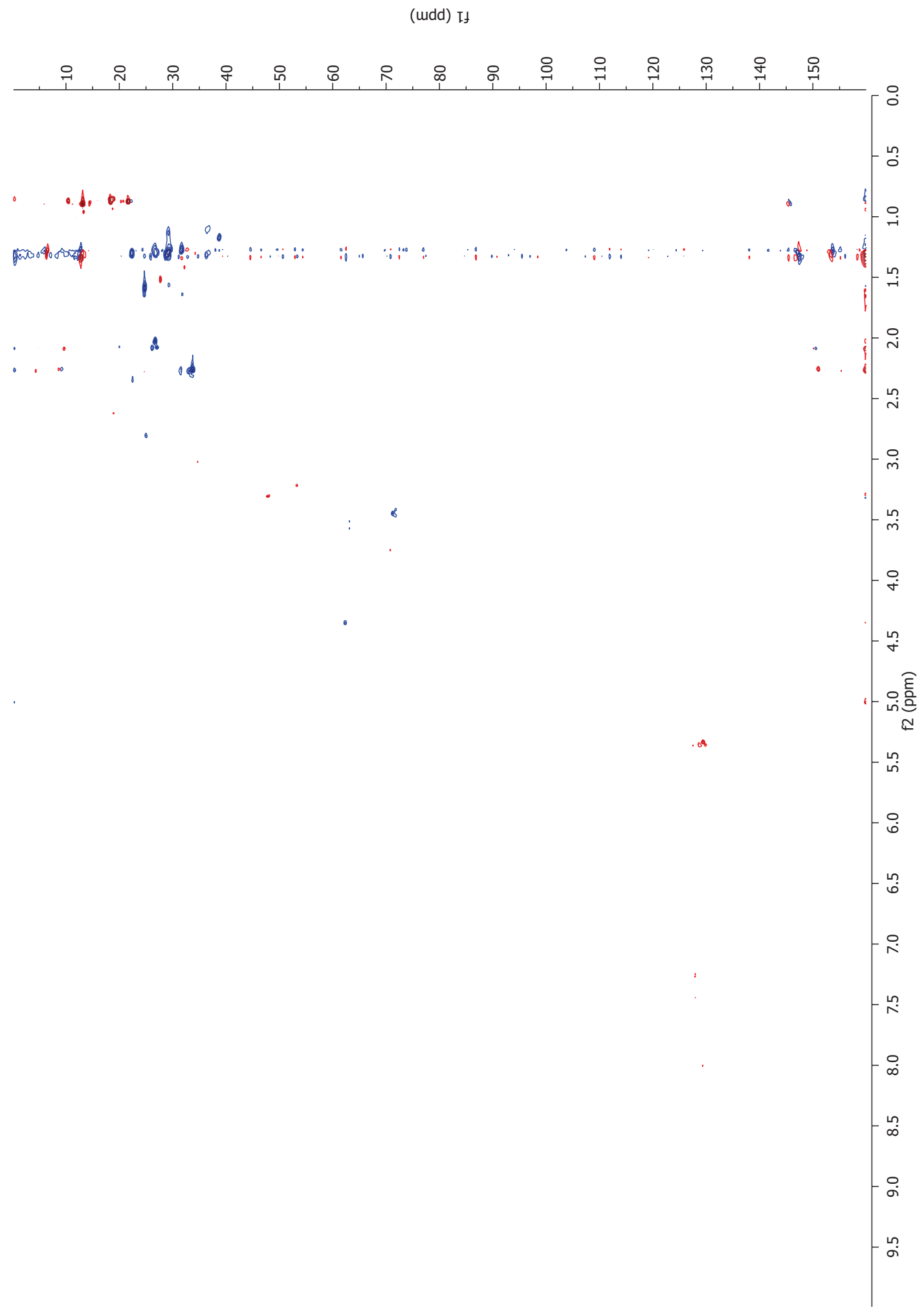

Figure D.7: Multiplicity-Edited HSQC spectrum of 75\% HP-20 fraction from Aaptos confertus showing methylenes in blue and methyls and methines in red (600 $\left.\mathrm{MHz}, \mathrm{CD}_{3} \mathrm{OD}\right)$ 
Appendix E

Spectra of Known Compounds 


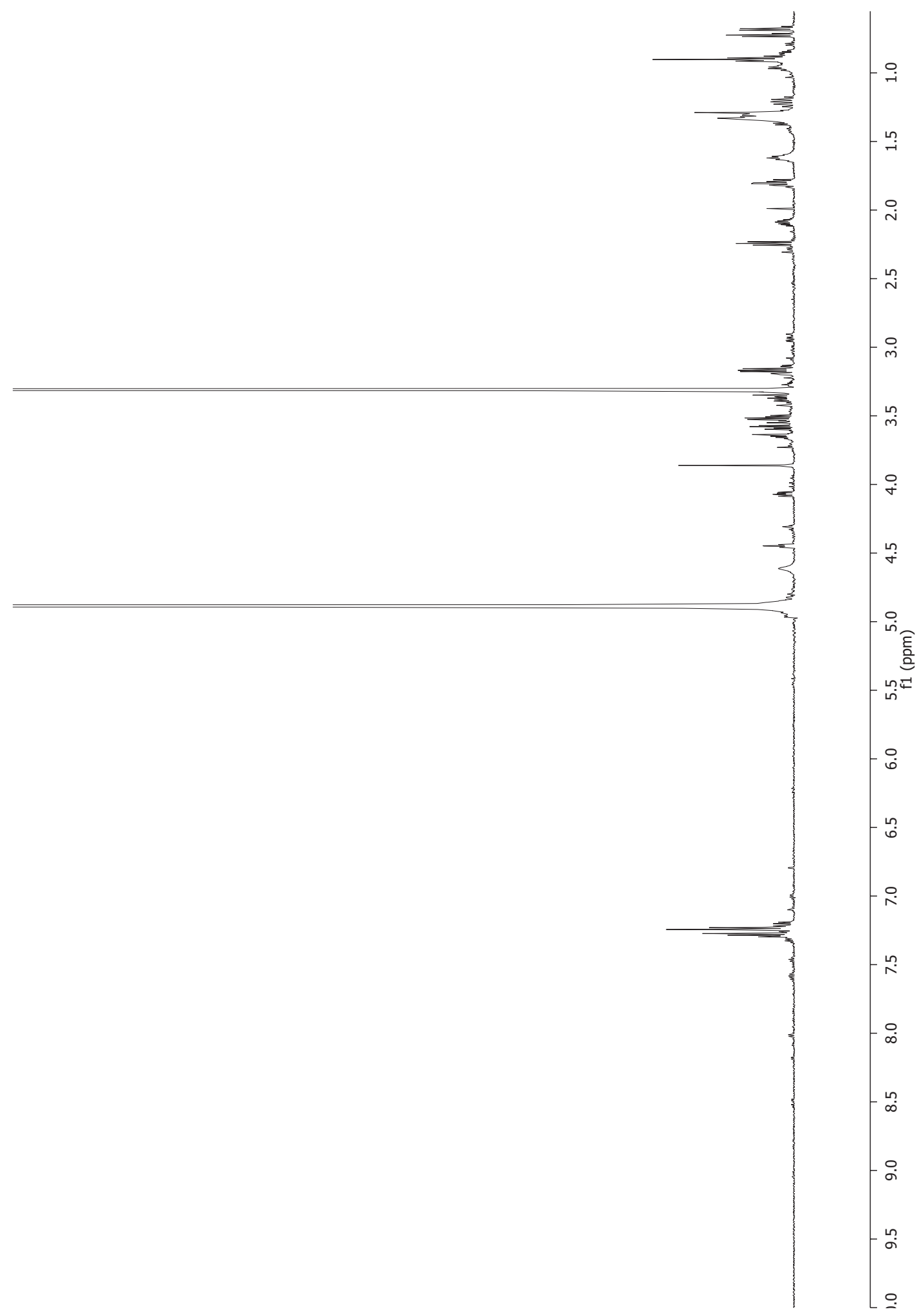

Figure E.1: ${ }^{1} \mathrm{H}$ spectrum of Cyclo(L-Phe-L-Pro) (500 MHz, $\left.\mathrm{CD}_{3} \mathrm{OD}\right)$ 


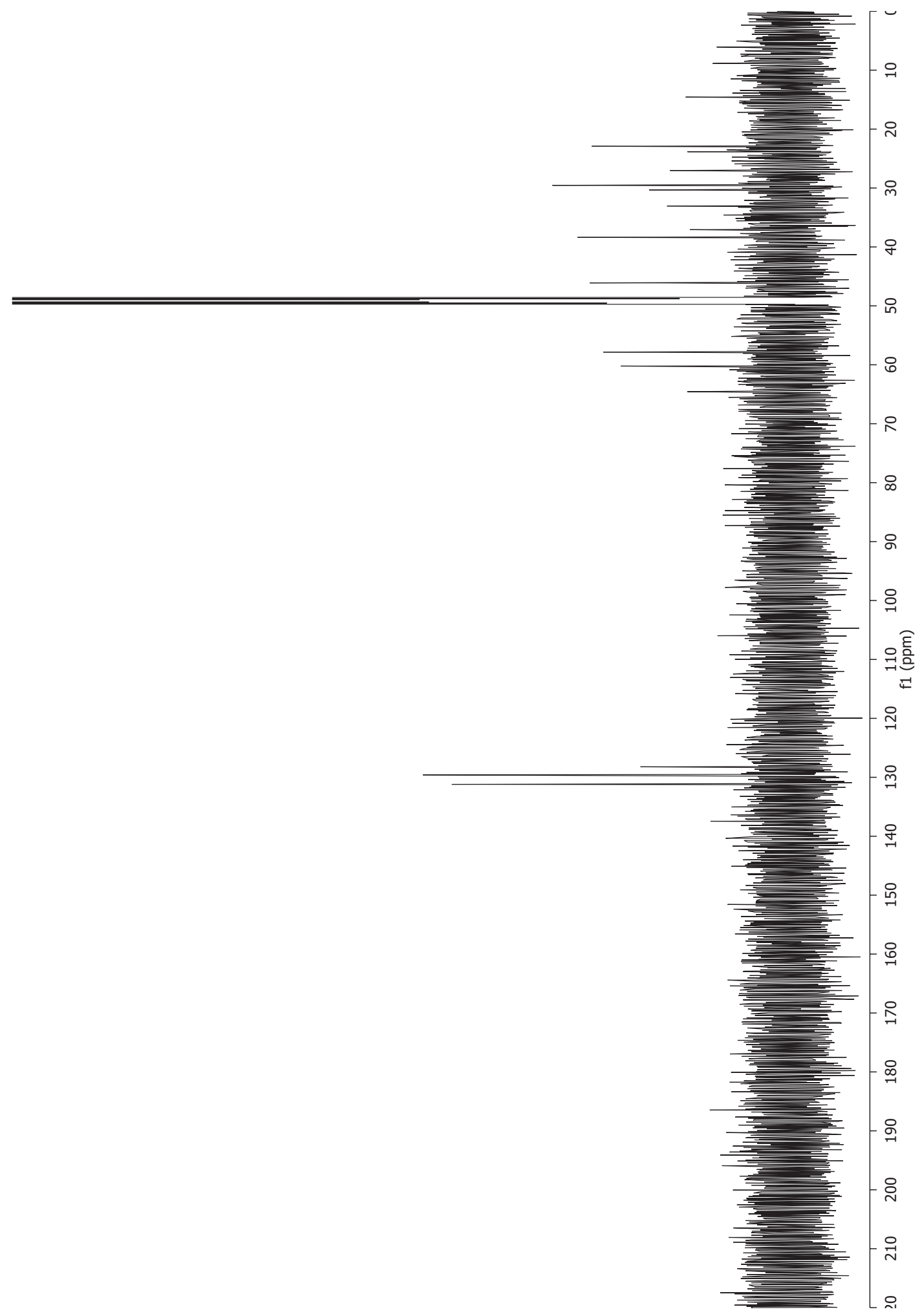

Figure E.2: ${ }^{13} \mathrm{C}$ spectrum of Cyclo(L-Phe-L-Pro) (125 MHz, $\left.\mathrm{CD}_{3} \mathrm{OD}\right)$ 


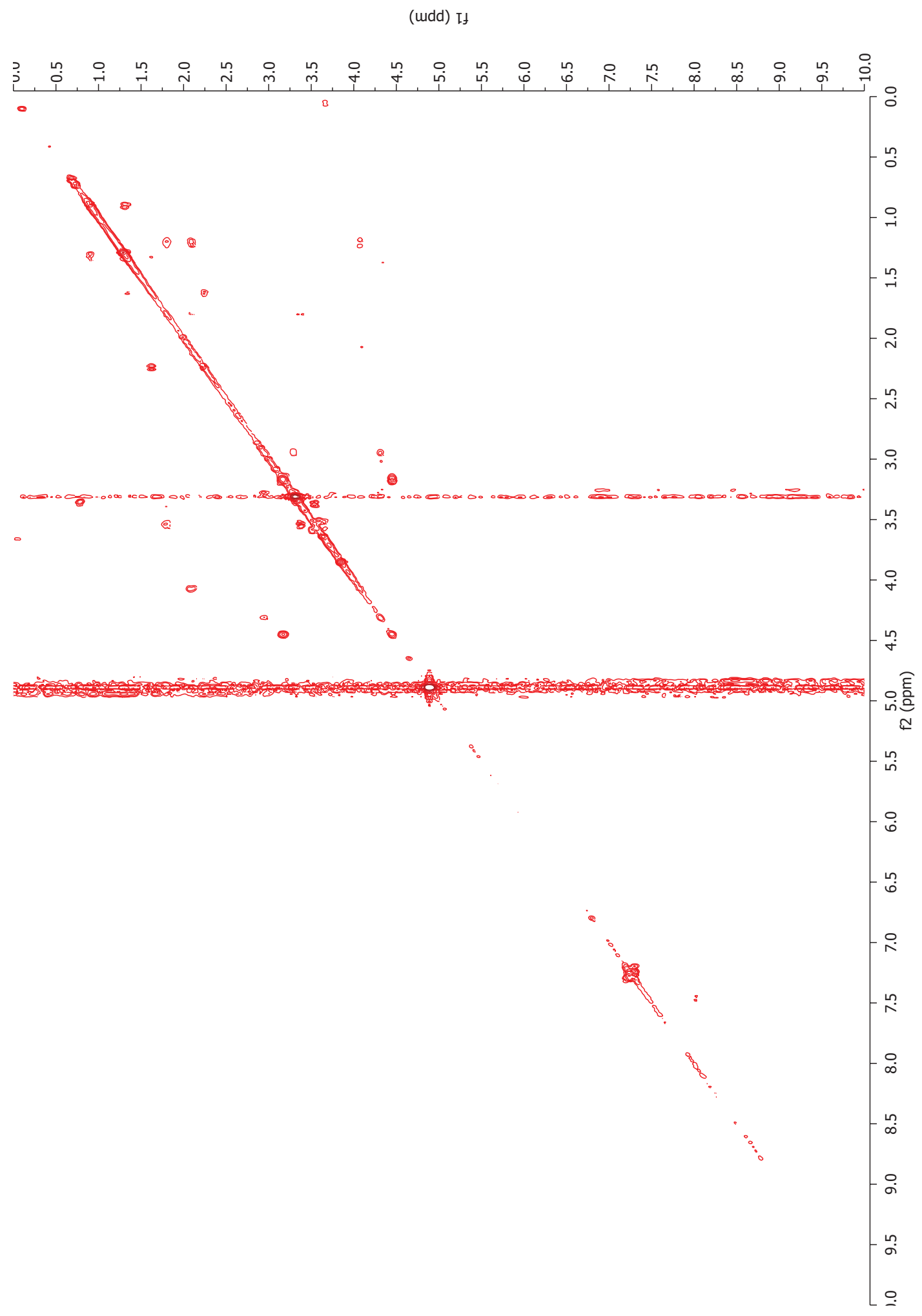

Figure E.3: COSY spectrum of Cyclo(L-Phe-L-Pro) $\left(500 \mathrm{MHz}, \mathrm{CD}_{3} \mathrm{OD}\right)$ 


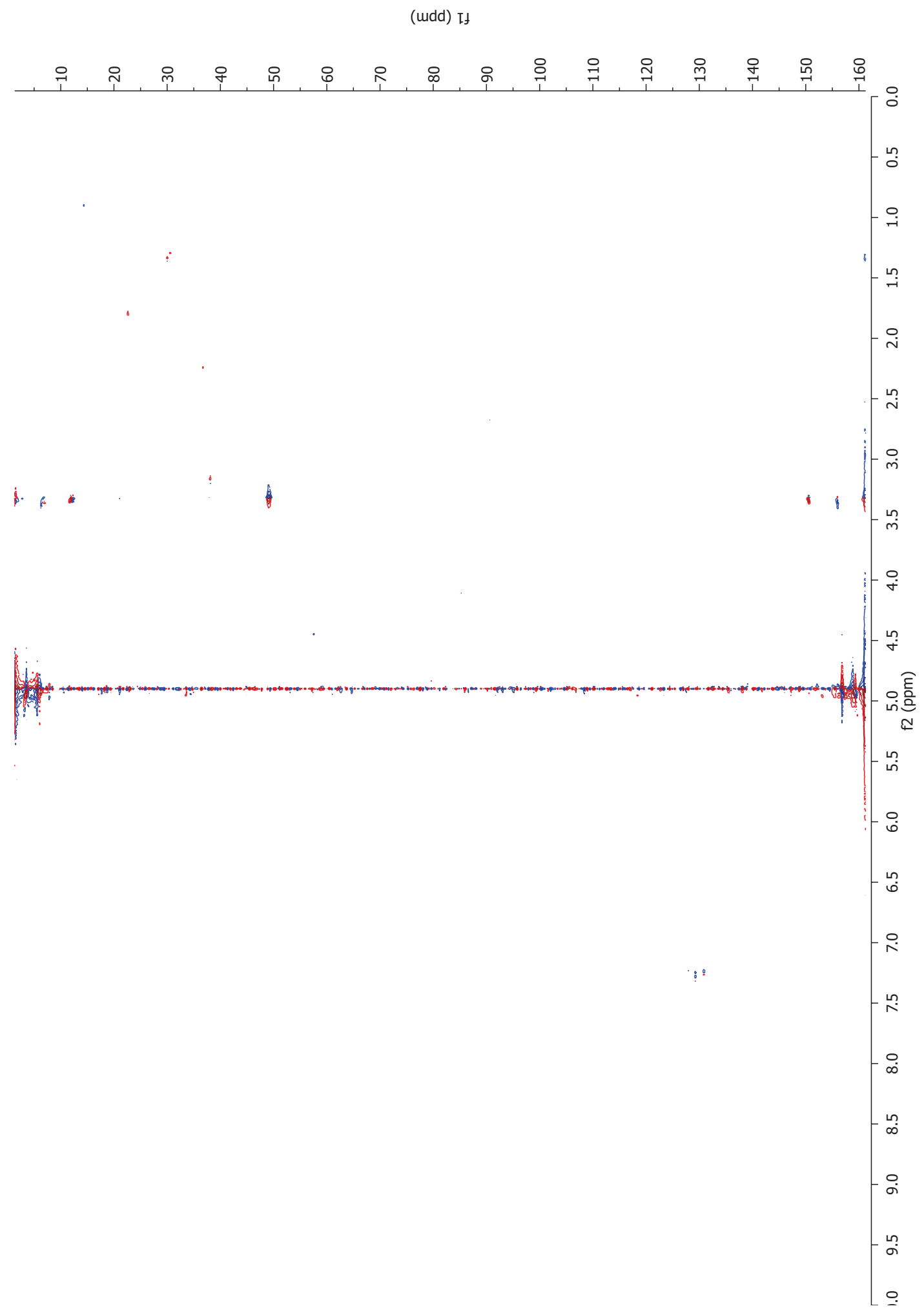

Figure E.4: Multiplicity-Edited HSQC spectrum of Cyclo(L-Phe-L-Pro) showing methylenes in blue and methyls and methines in red $\left(500 \mathrm{MHz}, \mathrm{CD}_{3} \mathrm{OD}\right)$ 
(udd) If

, 이, 운,

틀

Figure E.5: HMBC spectrum of Cyclo(L-Phe-L-Pro) (600 MHz, $\mathrm{CD}_{3} \mathrm{OD}$ ) 


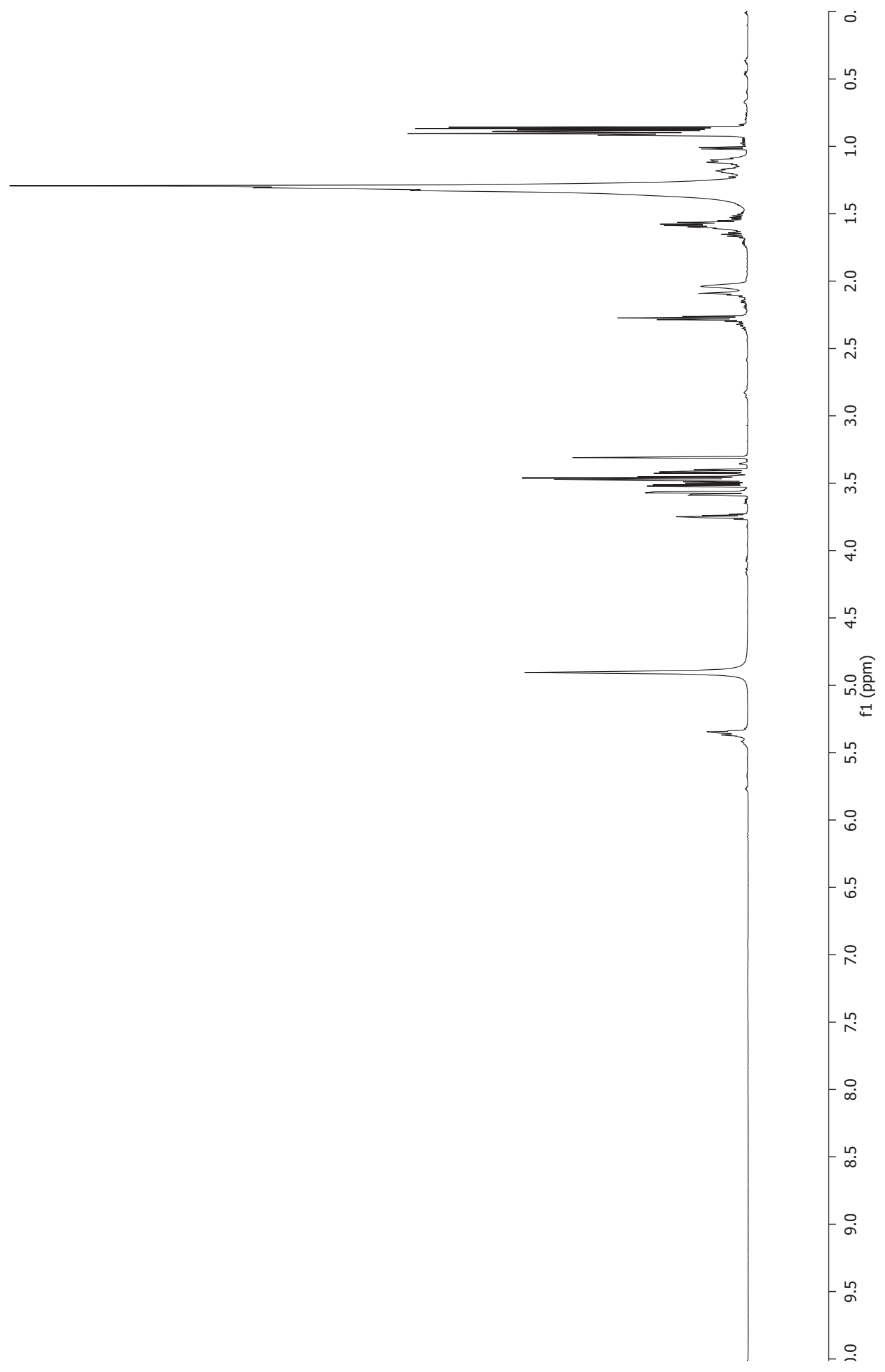

Figure E.6: ${ }^{1} \mathrm{H}$ spectrum of 3-((13-methylhexadecyl)oxy)propane-1,2-diol (600 MHz, $\left.\mathrm{CD}_{3} \mathrm{OD}\right)$ 


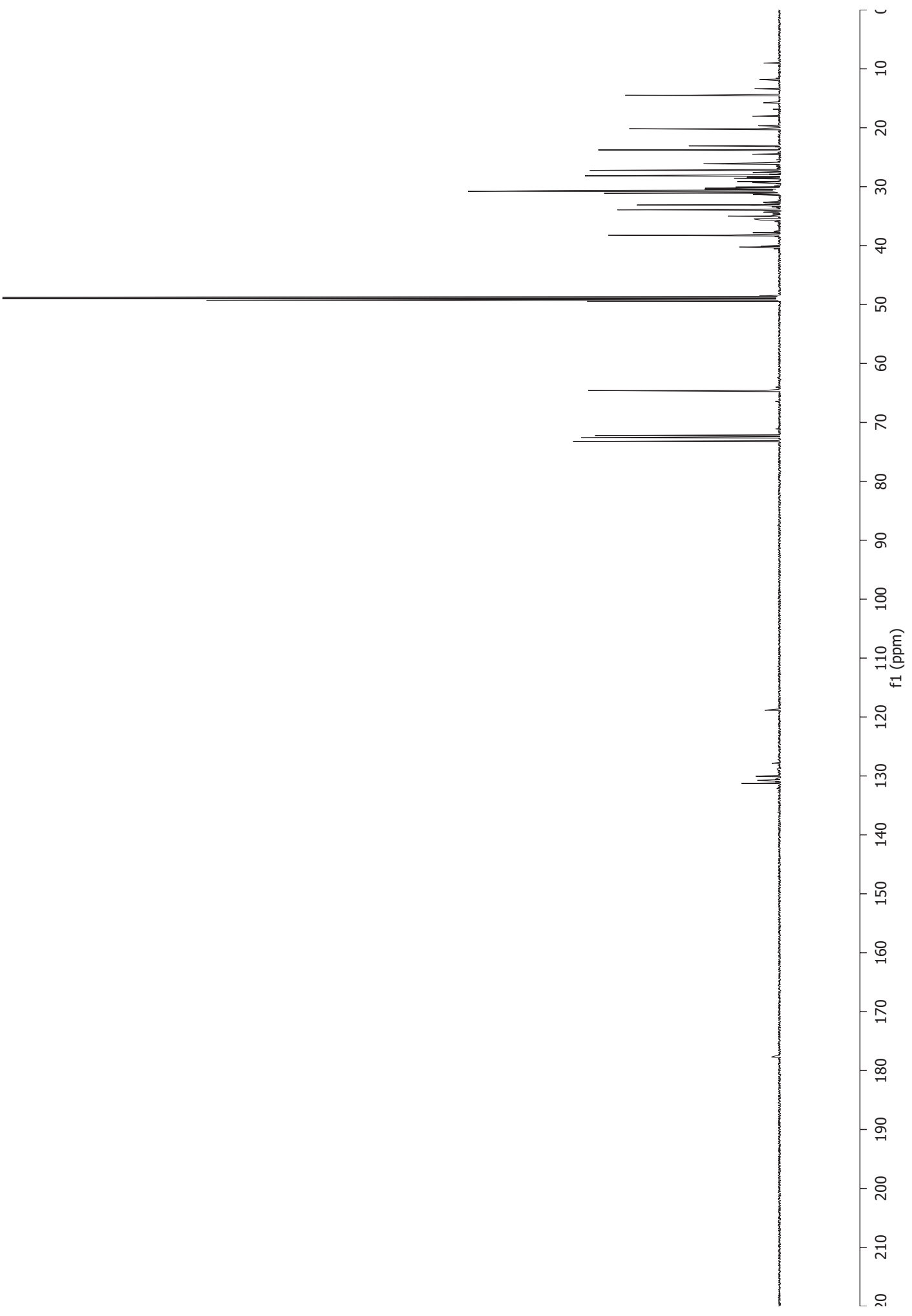

Figure E.7: ${ }^{13} \mathrm{C}$ spectrum of 3-((13-methylhexadecyl)oxy)propane-1,2-diol (150 MHz, $\left.\mathrm{CD}_{3} \mathrm{OD}\right)$ 


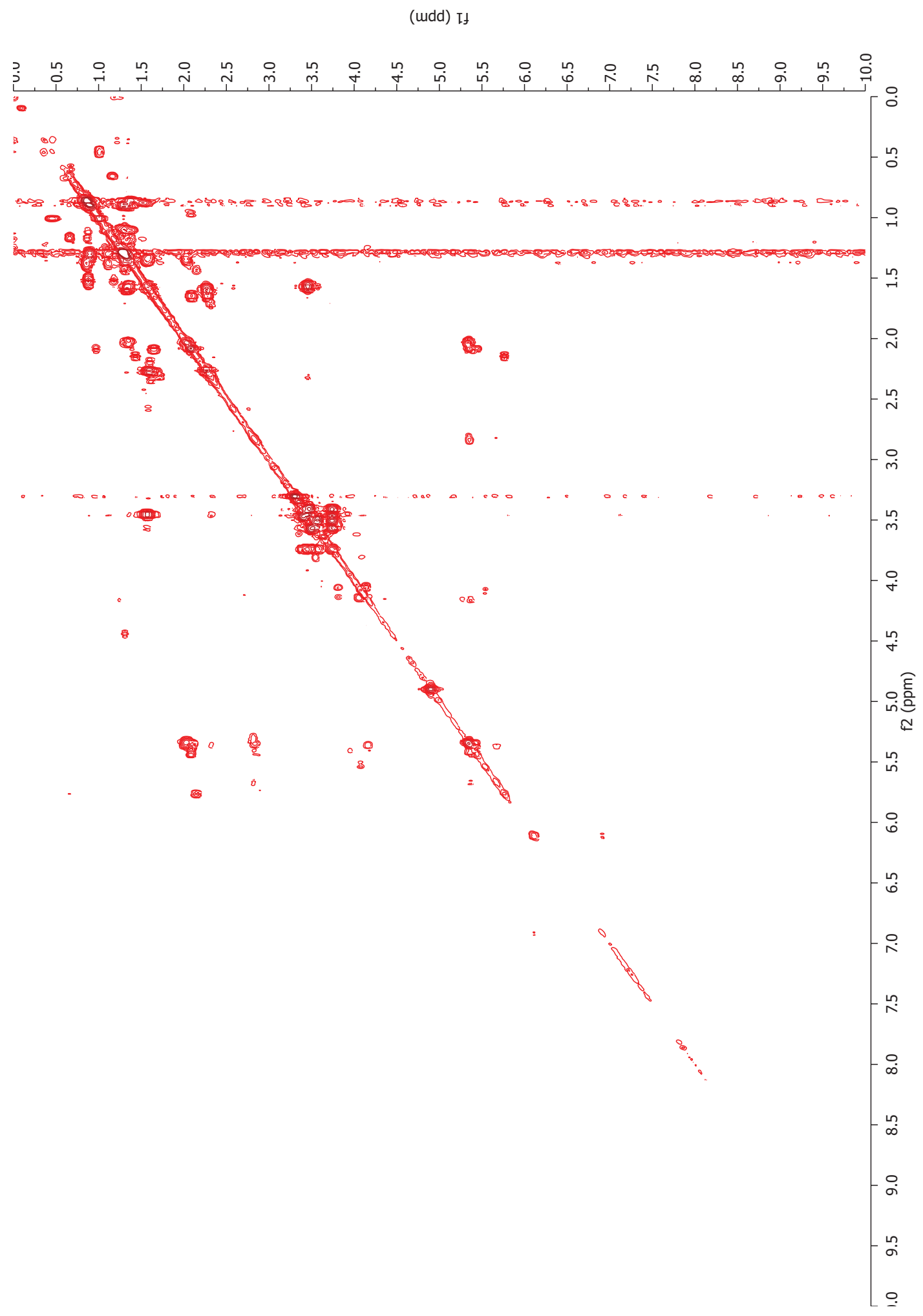

Figure E.8: COSY spectrum of 3-((13-methylhexadecyl)oxy)propane-1,2-diol (600 MHz, $\left.\mathrm{CD}_{3} \mathrm{OD}\right)$ 


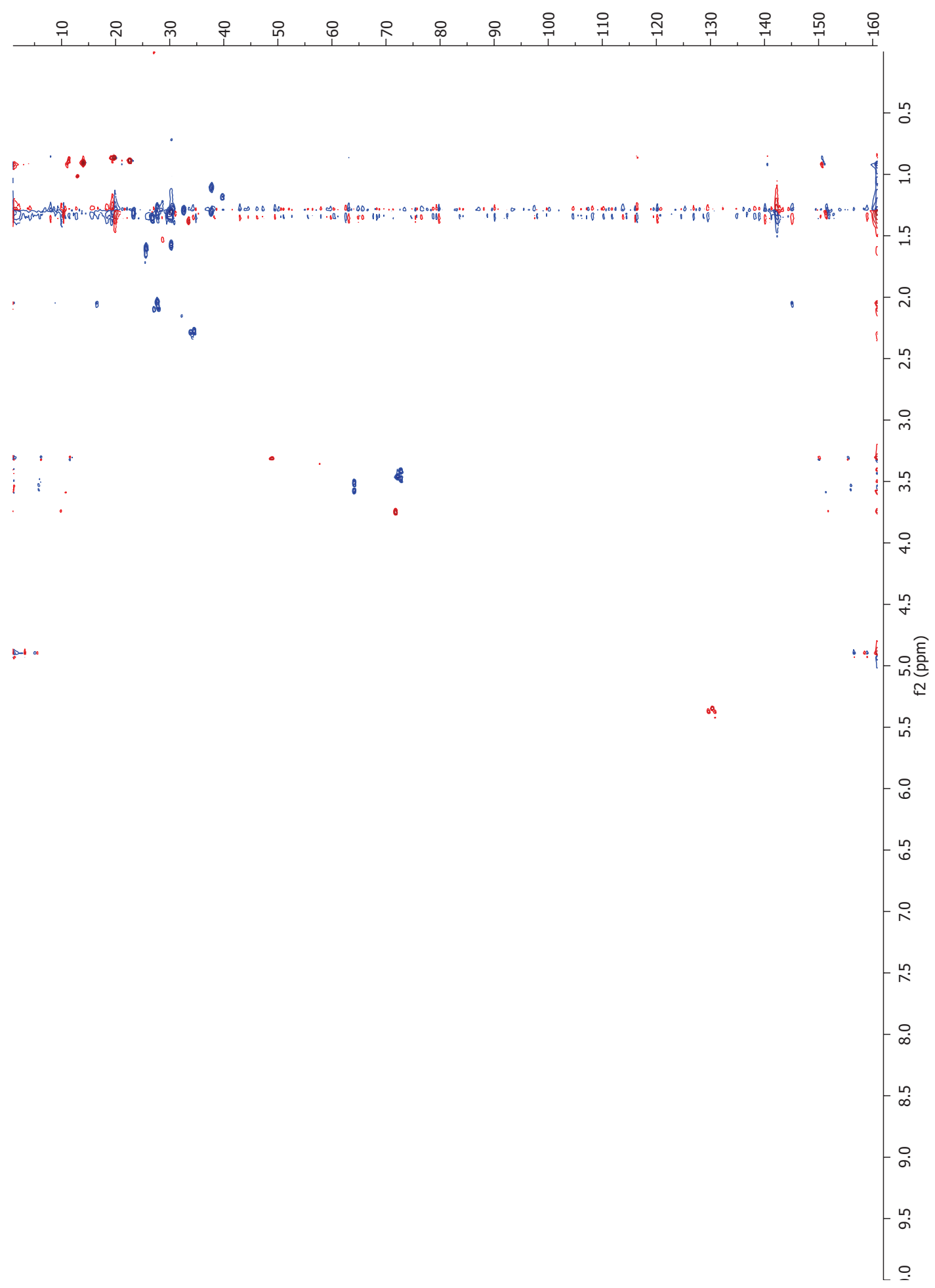

Figure E.9: Multiplicity-Edited HSQC spectrum of 3-((13-methylhexadecyl)oxy)propane-1,2-diol showing methylenes in blue and methyls and methines in red $\left(600 \mathrm{MHz}, \mathrm{CD}_{3} \mathrm{OD}\right)$ 


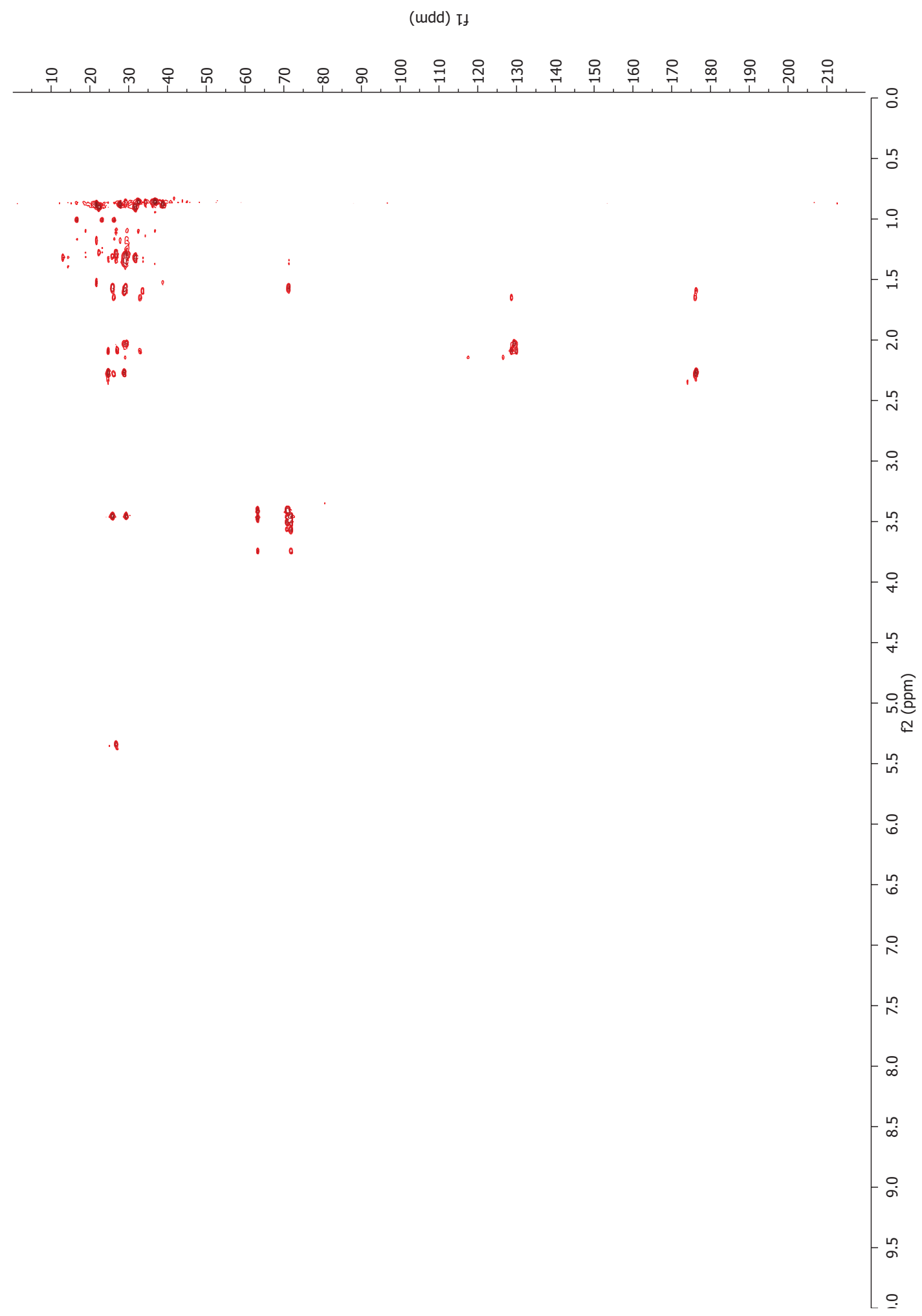

Figure E.10: HMBC spectrum of 3-((13-methylhexadecyl)oxy)propane-1,2-diol (600 MHz, $\left.\mathrm{CD}_{3} \mathrm{OD}\right)$ 
Appendix F

Spectra of Unkown Compounds 


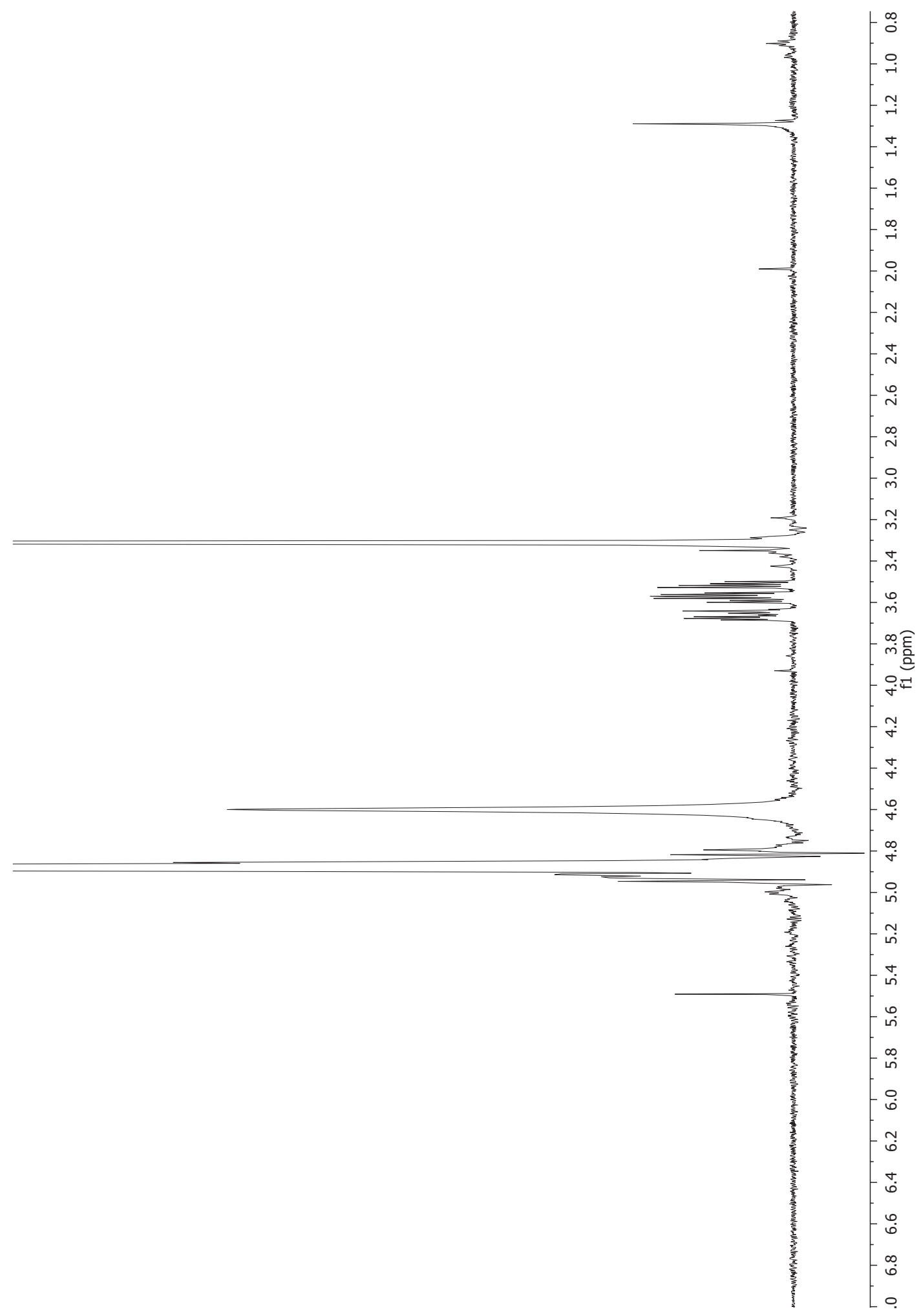

Figure F.1: ${ }^{1} \mathrm{H}$ spectrum of CJP02_04CB (600 MHz, CD $\left.{ }_{3} \mathrm{OD}\right)$ 


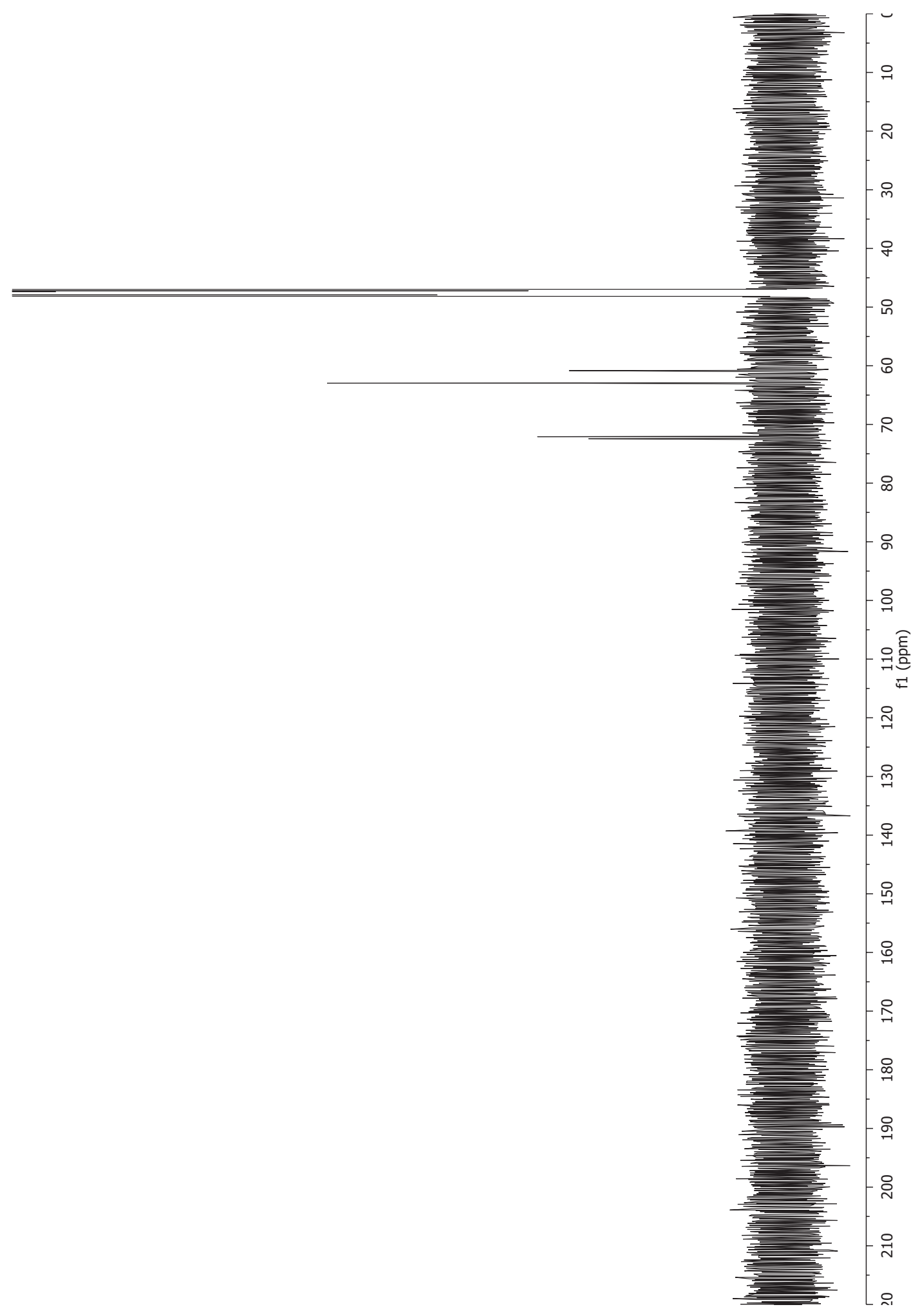

Figure F.2: ${ }^{13} \mathrm{C}$ spectrum of CJP02_04CB $\left(150 \mathrm{MHz}, \mathrm{CD}_{3} \mathrm{OD}\right)$ 


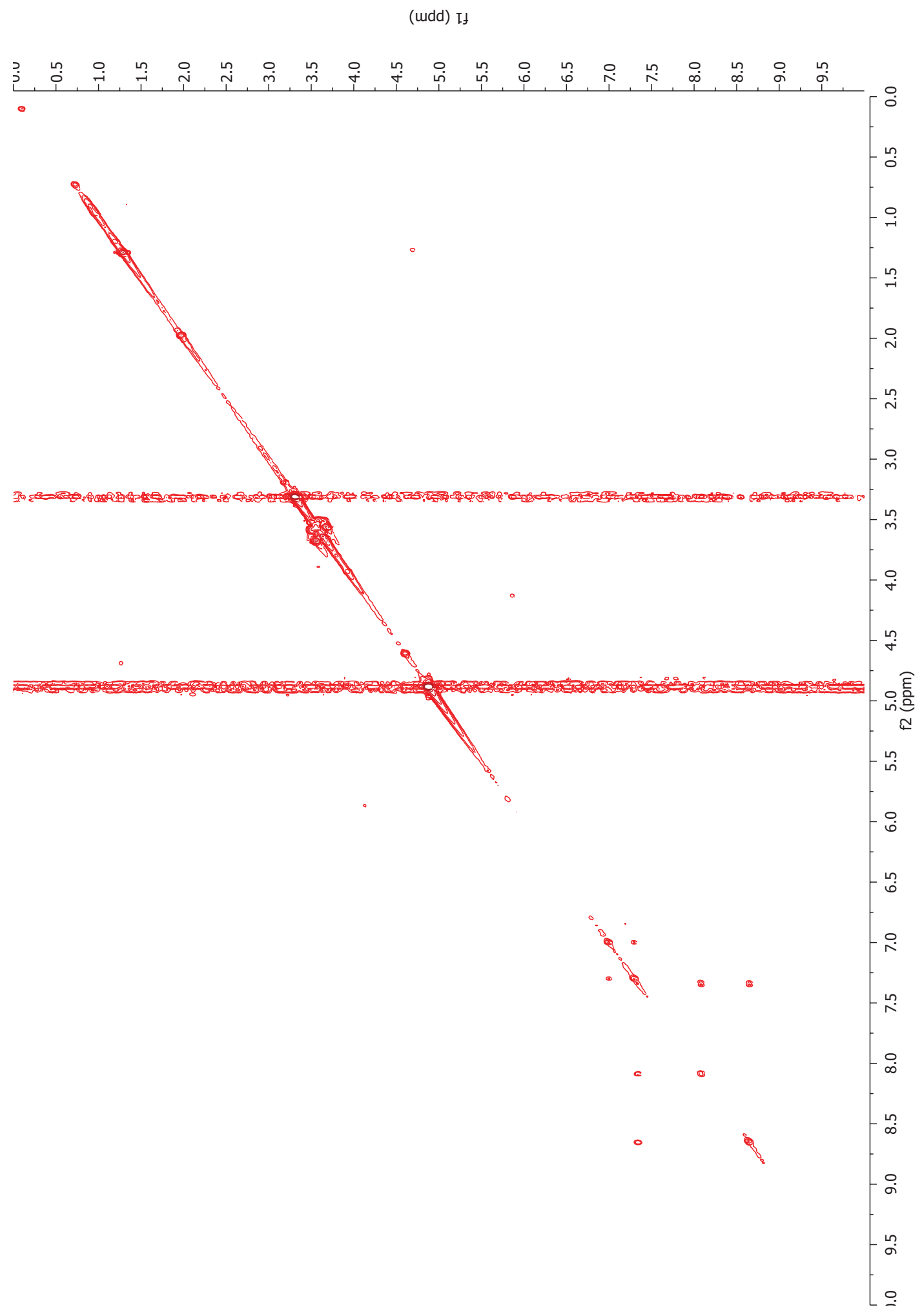

Figure F.3: COSY spectrum of CJP02_04CB (600 MHz, $\left.\mathrm{CD}_{3} \mathrm{OD}\right)$ 


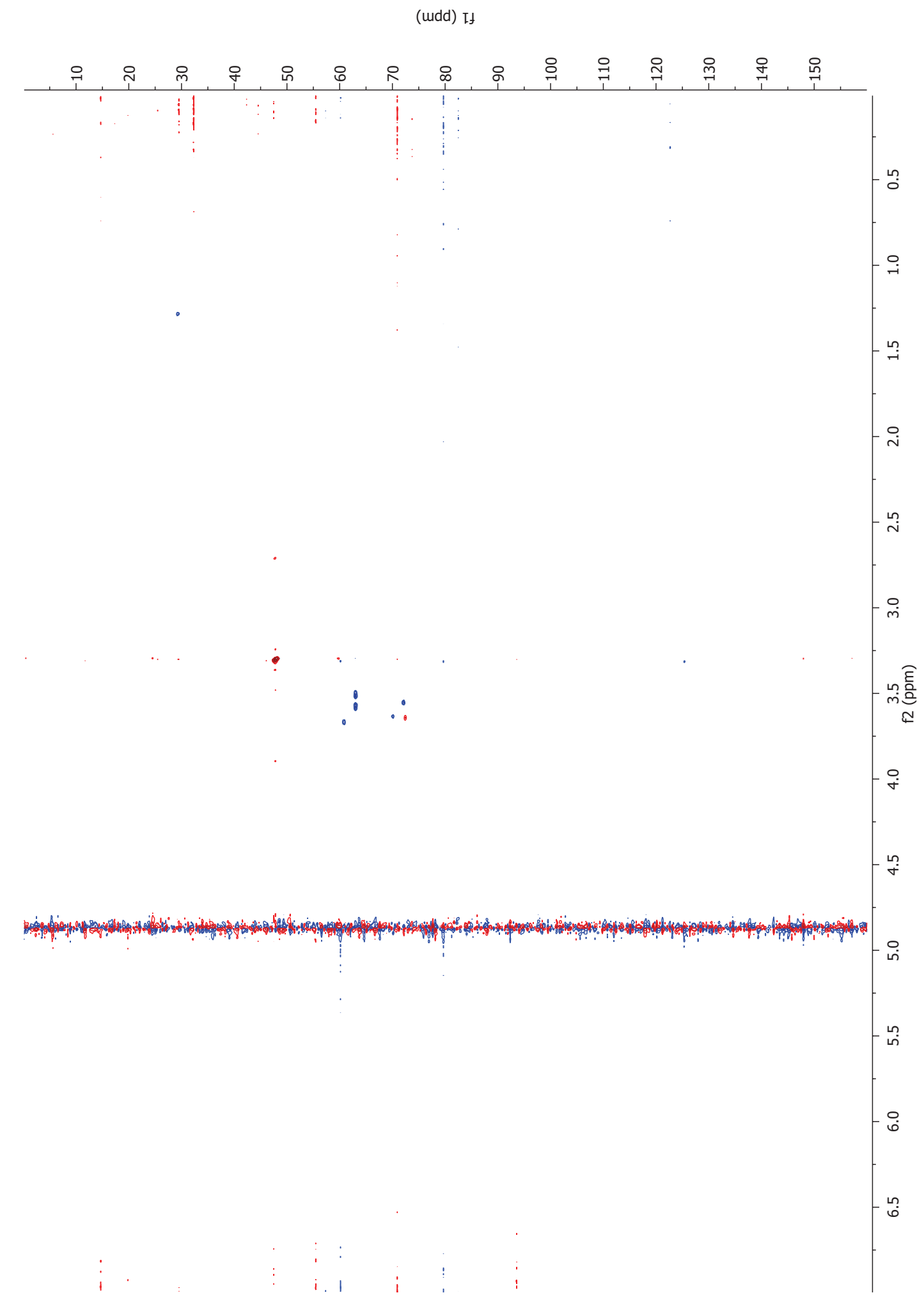

Figure F.4: Multiplicity-Edited HSQC spectrum of CJP02_04CB showing methylenes in blue and methyls and methines in red $\left(500 \mathrm{MHz}, \mathrm{CD}_{3} \mathrm{OD}\right)$ 
(udd) It

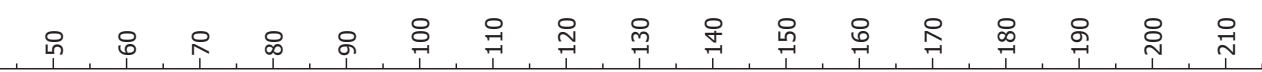

Figure F.5: HMBC spectrum of CJP02_04CB (600 MHz, $\left.\mathrm{CD}_{3} \mathrm{OD}\right)$ 


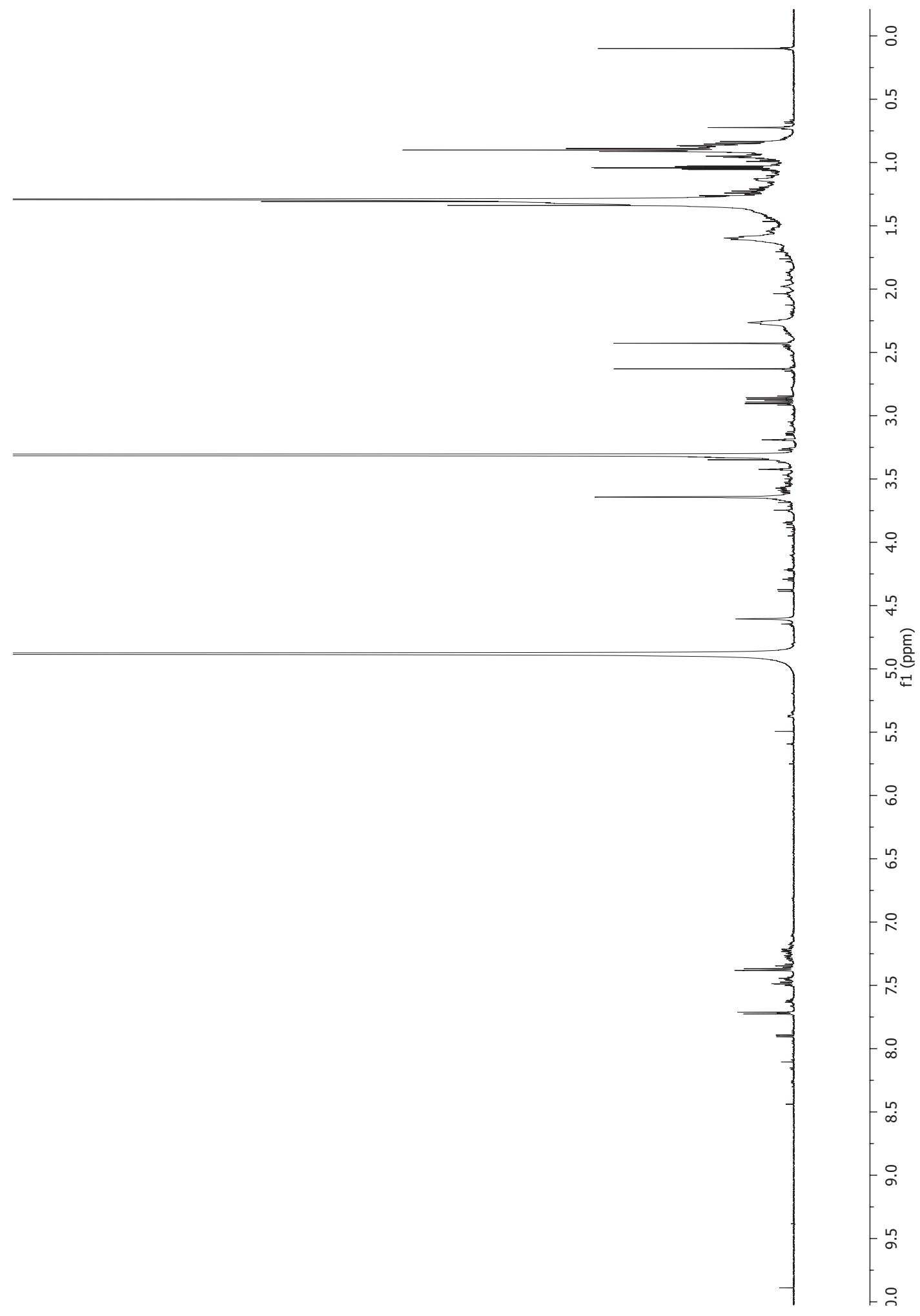

Figure F.6: ${ }^{1} \mathrm{H}$ spectrum of CJP02_20A (600 MHz, $\left.\mathrm{CD}_{3} \mathrm{OD}\right)$ 


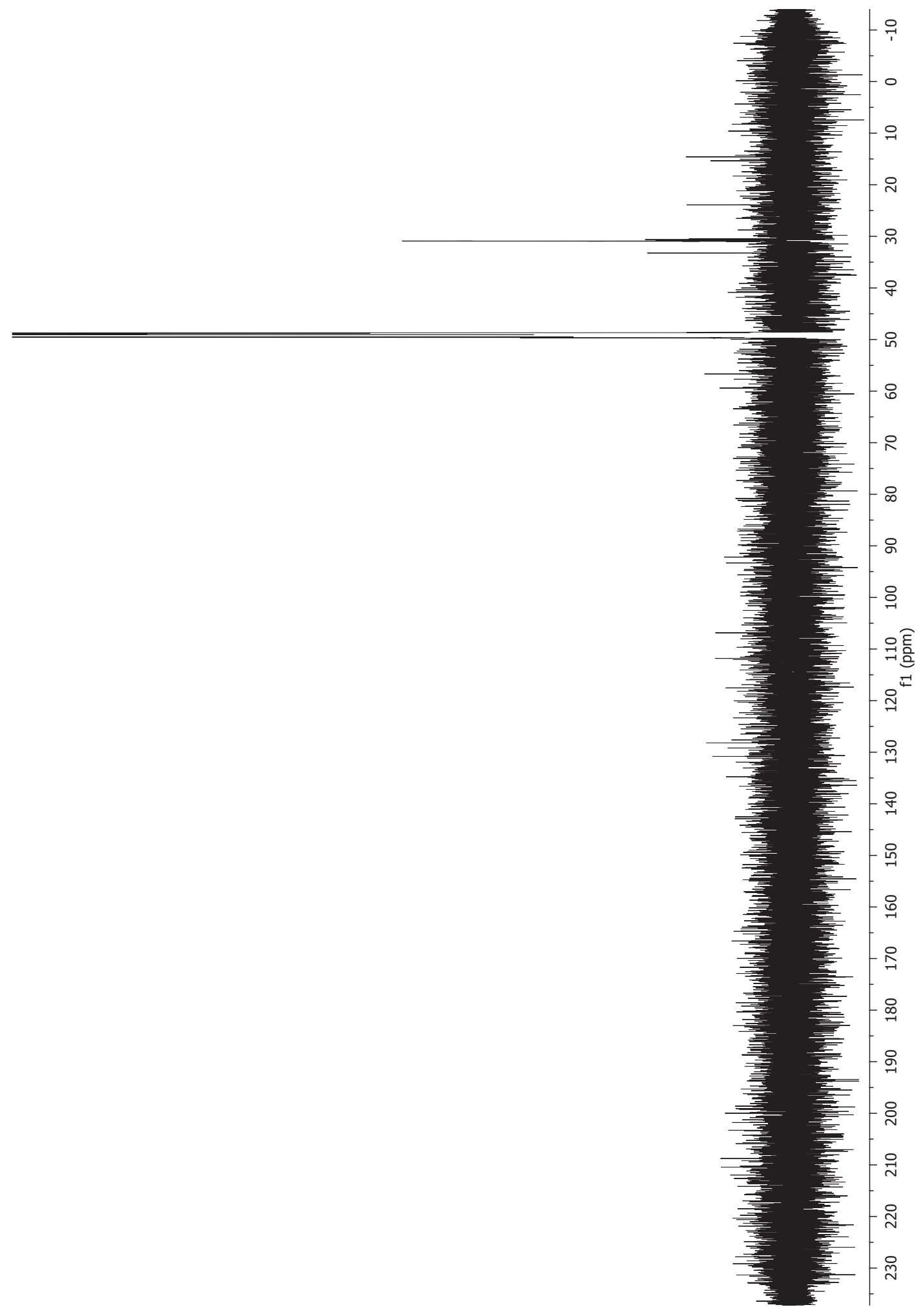

Figure F.7: ${ }^{13} \mathrm{C}$ spectrum of CJP02_20A (150 MHz, $\left.\mathrm{CD}_{3} \mathrm{OD}\right)$ 


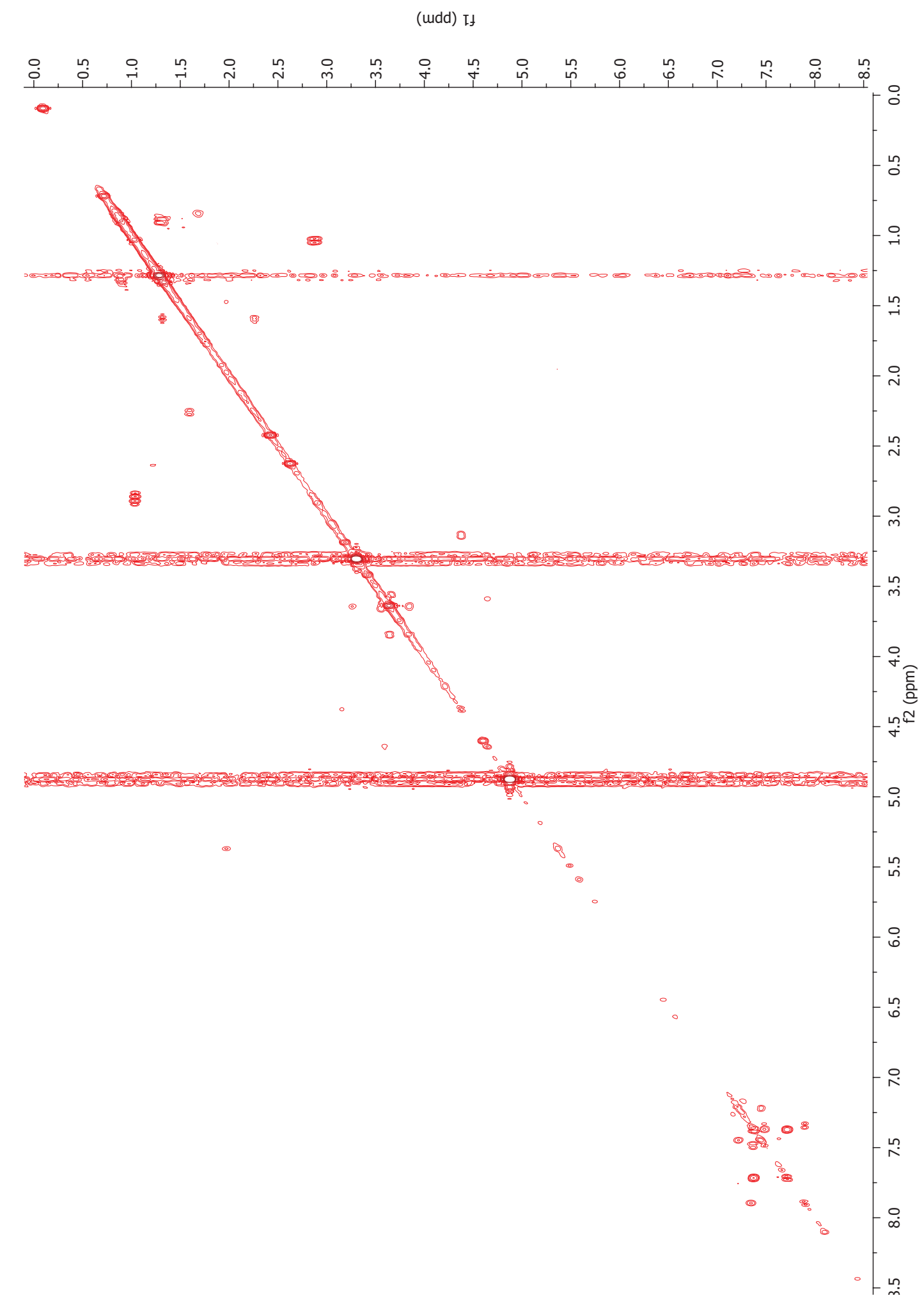

Figure F.8: COSY spectrum of CJP02_20A (600 MHz, $\left.\mathrm{CD}_{3} \mathrm{OD}\right)$ 


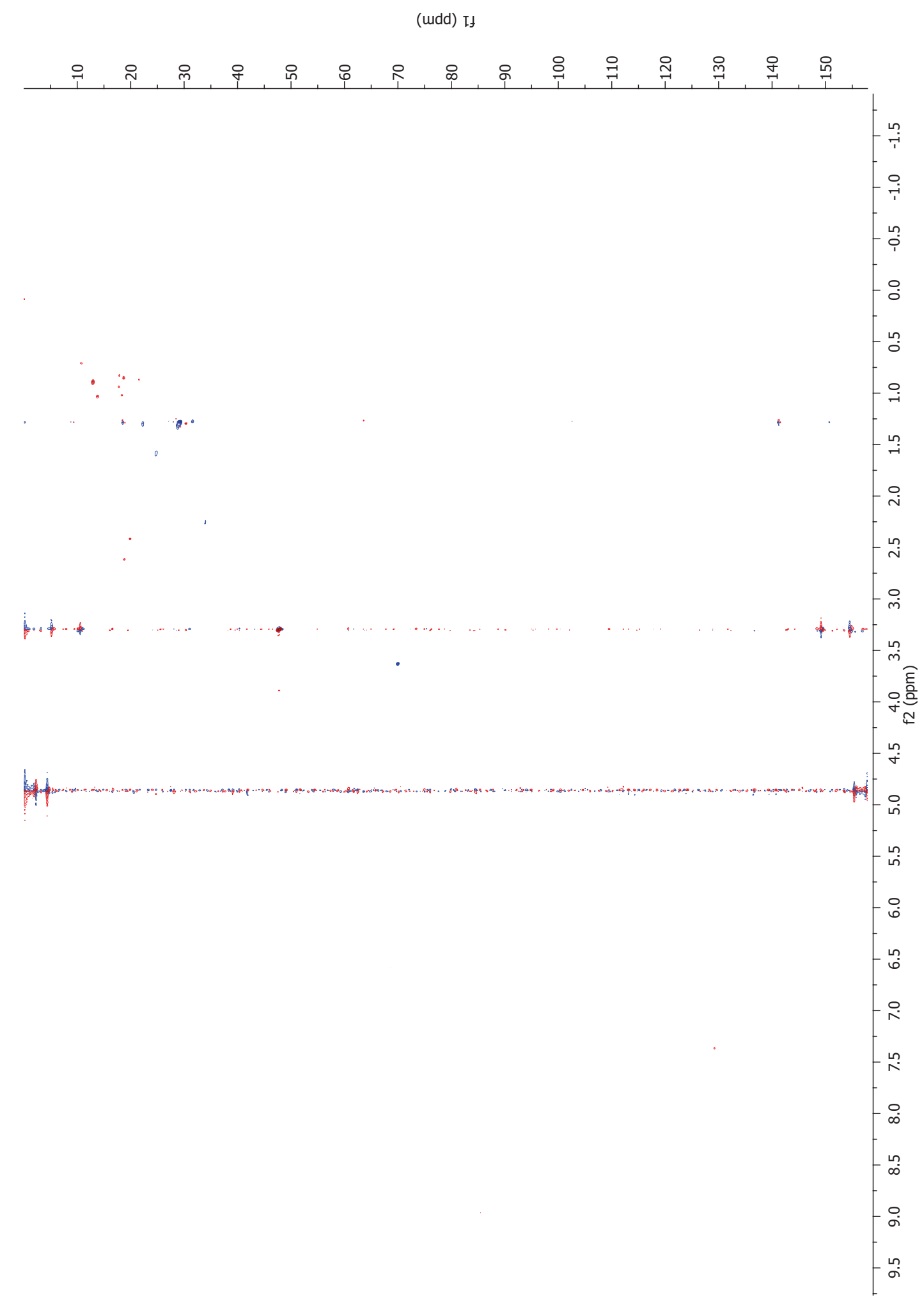

Figure F.9: Multiplicity-Edited HSQC spectrum of CJP02_20A showing methylenes in blue and methyls and methines in red $\left(600 \mathrm{MHz}, \mathrm{CD}_{3} \mathrm{OD}\right)$ 
(udd) If

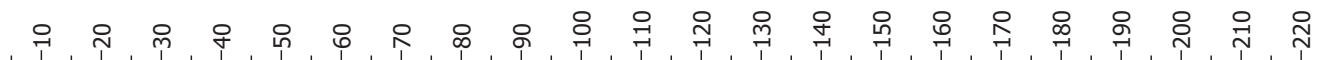

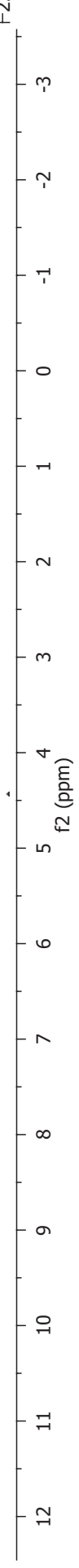

Figure F.10: HMBC spectrum of CJP02_20A (600 MHz, $\left.\mathrm{CD}_{3} \mathrm{OD}\right)$ 


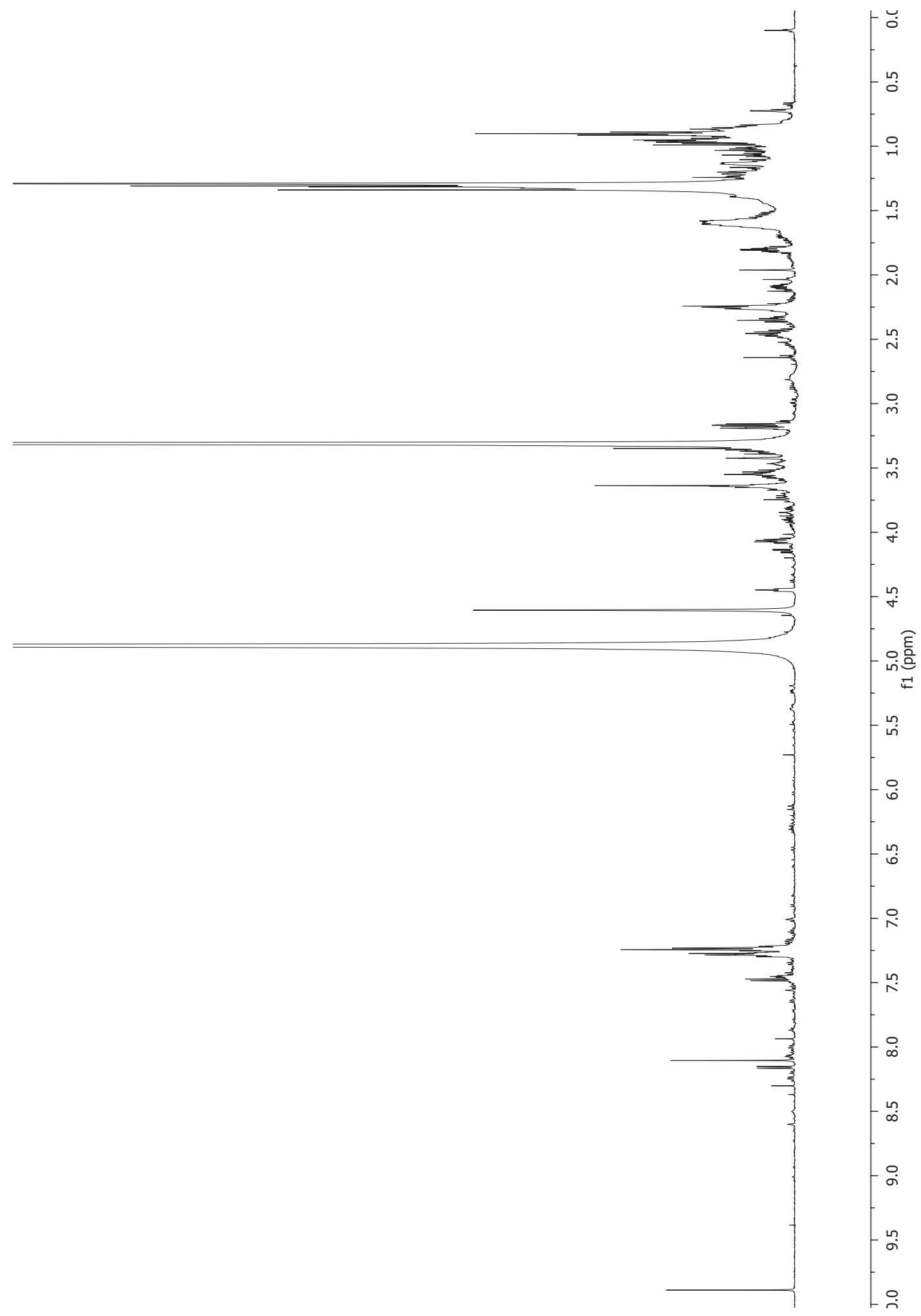

Figure F.11: ${ }^{1} \mathrm{H}$ spectrum of CJP02_20C $\left(600 \mathrm{MHz}, \mathrm{CD}_{3} \mathrm{OD}\right)$ 


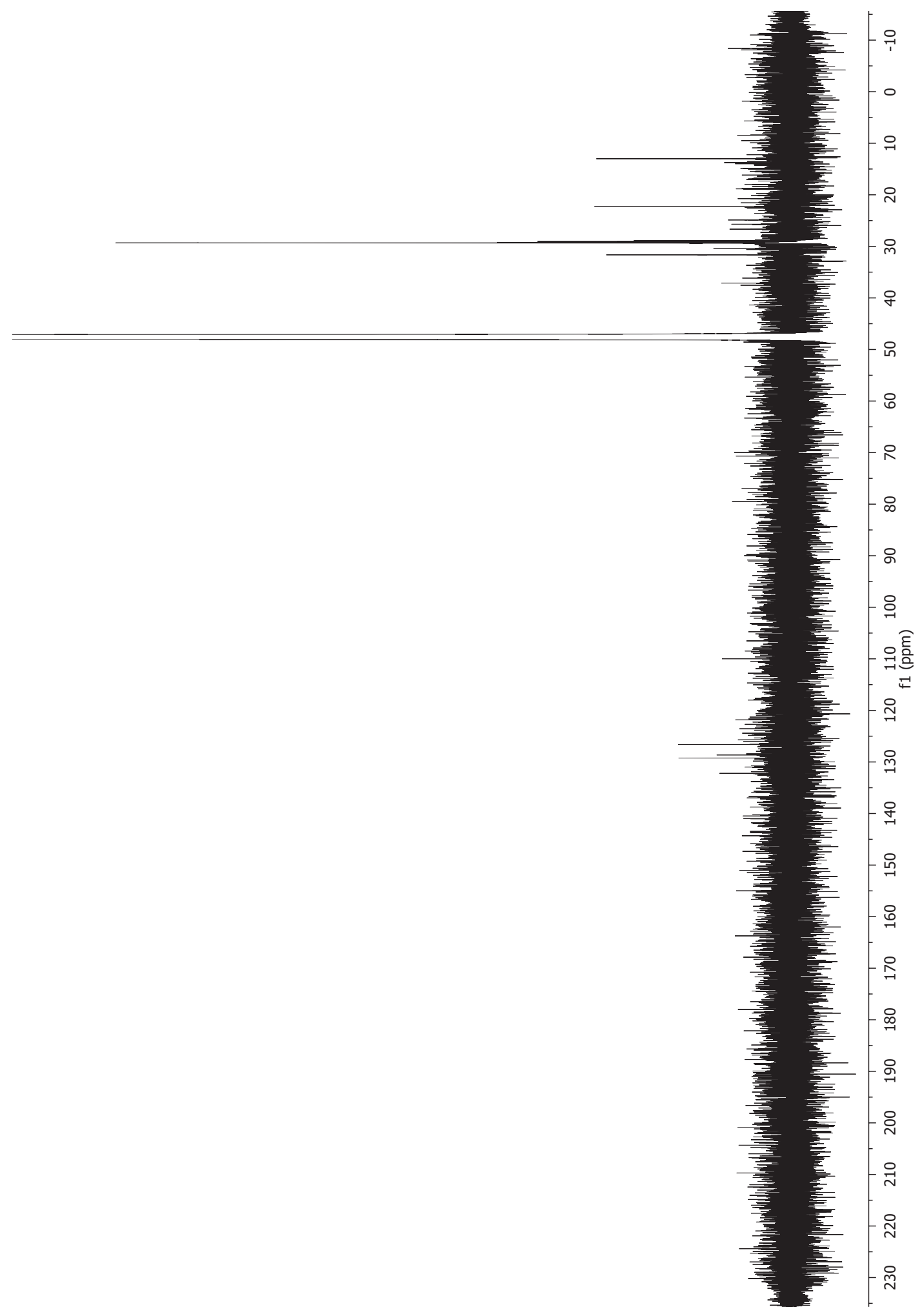

Figure F.12: ${ }^{13} \mathrm{C}$ spectrum of CJP02_20C (150 MHz, $\left.\mathrm{CD}_{3} \mathrm{OD}\right)$ 


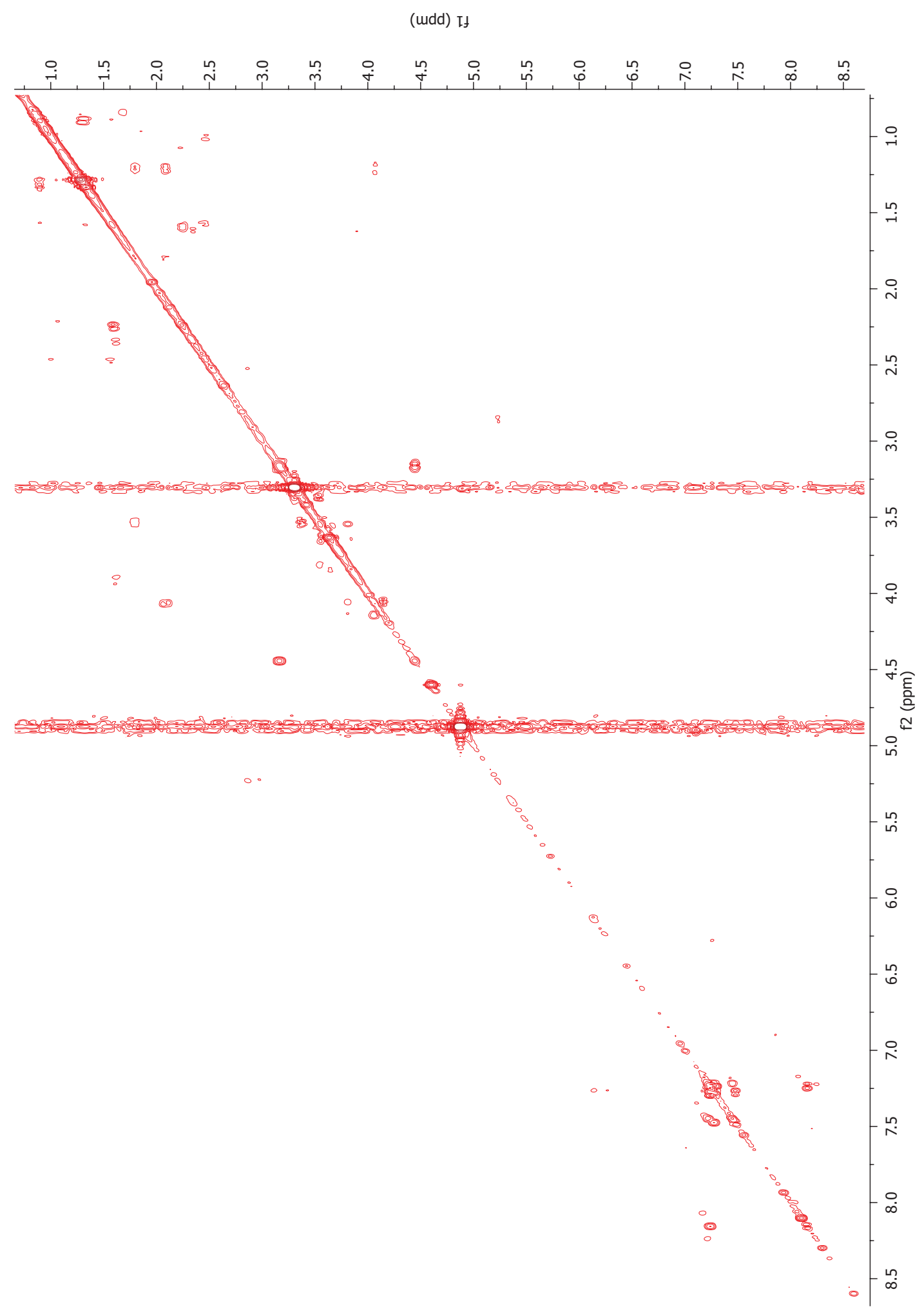

Figure F.13: COSY spectrum of CJP02_20C (600 MHz, CD 3 OD) 
(udd) If

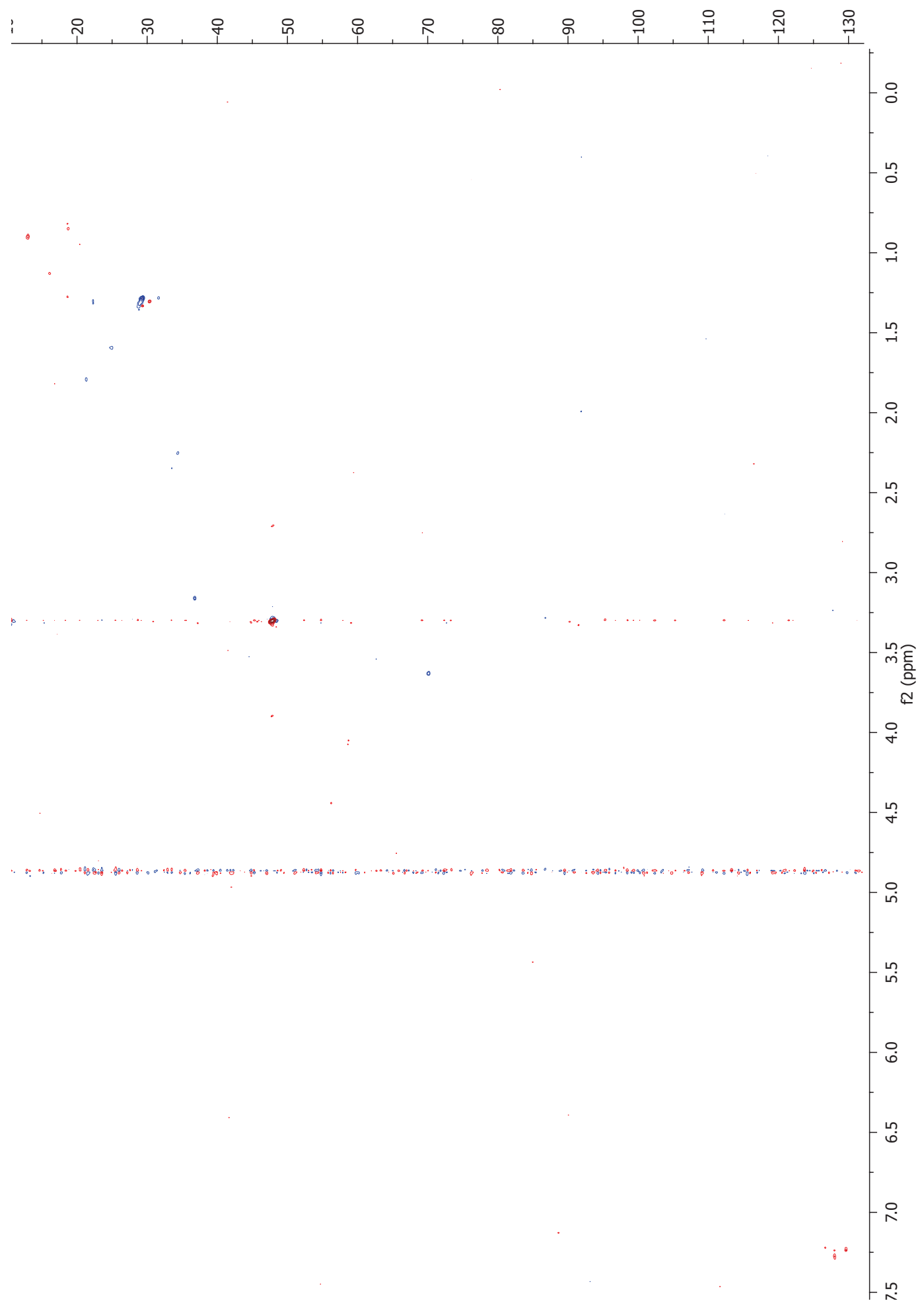

Figure F.14: Multiplicity-Edited HSQC spectrum of CJP02_20C showing methylenes in blue and methyls and methines in red $\left(600 \mathrm{MHz}, \mathrm{CD}_{3} \mathrm{OD}\right)$ 


\section{References}

[1] Cragg, G.; Newman, D. Planta Med 2014, 80, IL1.

[2] Koehn, F. E.; Carter, G. T. Nature Reviews Drug Discovery 2005, 4, 206-220.

[3] Newman, D. J.; Cragg, G. M. Journal of natural products 2016, 79, 629-661.

[4] Cragg, G. M.; Newman, D. J. Biochimica Et Biophysica Acta-General Subjects 2013, $1830,3670-3695$.

[5] Rodrigues, T.; Reker, D.; Schneider, P.; Schneider, G. Nature Chemistry 2016, 8, 531-541.

[6] Porter, R. The Cambridge Illustrated History of Medicine; Cambridge University Press, 2001.

[7] Parker, S. Kill or Cure: An Illustrated History of Medicine; Dorling Kindersley Limited: London, United Kingdom, 2013.

[8] Duin, N.; Sutcliffe, J. A History of Medicine: From Prehistory to the Year 2020; Simon \& Schuster: London, United Kingdon, 1992.

[9] Bynum, W.; Bynum, H. Great Discoveries in Medicine; Thames \& Hudson: London, United Kingdom, 2011.

[10] Halioua, B.; Ziskind, B. Medicine in the Days of the Pharaohs; The Belknap Press of Harvard University Press: London, United Kingdom, 2005.

[11] Dobson, M. The Story of Medicine: From Bloodletting to Biotechnology; Quercus Editions Ltd: London, United Kingdom, 2013.

[12] Lu, H. C. Traditional Chinese Medicine: How to Maintain Your Health and Treat Illness; Basic Health Publications, 2005.

[13] Mount, T. Dragon's Blood \& Willow Bark: The Mysteries of Medieval Medicine; Amberley Publishing Limited, 2015.

[14] Harvey, A. L. Drug Discovery Today 2008, 13, 894-901.

[15] Katz, L.; Baltz, R. H. Journal of Industrial Microbiology \& Biotechnology 2016, 43, $155-176$.

[16] Lipinski, C. A.; Lombardo, F.; Dominy, B. W.; Feeney, P. J. Advanced drug delivery reviews 1997, 23, 3-25.

[17] Cragg, G. M.; Newman, D. J. Pure and applied chemistry 2005, 77, 7-24.

[18] Ibbeson, B. M.; Laraia, L.; Alza, E.; O’Connor, C. J.; Tan, Y. S.; Davies, H. M.; McKenzie, G.; Venkitaraman, A. R.; Spring, D. R. Nature Communications 2014, 5. 
[19] Cavalier-Smith, T. Ciba Foundation Symposium 171 - Secondary Metabolites: their Function and Evolution; John Wiley \& Sons, Ltd., 2007; pp 64-87.

[20] Waterman, P. G. Ciba Foundation Symposium 171 - Secondary Metabolites: their Function and Evolution; John Wiley \& Sons, Ltd., 2007; pp 255-275.

[21] Newman, D. J.; Cragg, G. M. Journal of natural products 2007, 70, 461-477.

[22] Newman, D. J.; Cragg, G. M.; Snader, K. M. Natural Product Reports 2000, 17, 215234.

[23] Davies, J.; Von Ahsen, U.; Wank, H.; Schroeder, R. Ciba Foundation Symposium 171 - Secondary Metabolites: their Function and Evolution; John Wiley \& Sons, Ltd., 2007; Chapter 3, pp 24-44.

[24] Williams, D.; Maplestone, R. A. Ciba Foundation Symposium 171 - Secondary Metabolites: their Function and Evolution; John Wiley \& Sons, Ltd., 2007; Chapter 4, pp 45-63.

[25] Rohde, S.; Nietzer, S.; Schupp, P. J. PLoS One 2015, 10, e0132236.

[26] Harvey, A. L.; Edrada-Ebel, R.; Quinn, R. J. Nature Reviews Drug Discovery 2015, 14, 111-129.

[27] Newman, D. J.; Cragg, G. M. Planta Medica 2016, 82, 775-789.

[28] Molinski, T. F.; Dalisay, D. S.; Lievens, S. L.; Saludes, J. P. Nature Reviews Drug Discovery 2009, 8, 69-85.

[29] Proksch, P. Toxicon 1994, 32, 639-655.

[30] Pawlik, J. R. Chemical Reviews 1993, 93, 1911-1911.

[31] Pohnert, G. The Chemistry of Pheromones and Other Semiochemicals I; Springer, 2004; pp 179-219.

[32] Wulff, J. L. Canadian Journal of Zoology 2006, 84, 146-166.

[33] Shaari, K.; Ling, K. C.; Mat Rashid, Z.; Jean, T. P.; Abas, F.; Raof, S. M.; Zainal, Z.; Lajis, N. H.; Mohamad, H.; Ali, A. M. Marine drugs 2008, 7, 1-8.

[34] Newman, D. J.; Cragg, G. M. Marine drugs 2014, 12, 255-278.

[35] McIntosh, M.; Cruz, L.; Hunkapiller, M.; Gray, W.; Olivera, B. Archives of Biochemistry and Biophysics 1982, 218, $329-334$.

[36] Akcan, M.; Clark, R. J.; Daly, N. L.; Conibear, A. C.; de Faoite, A.; Heghinian, M. D.; Sahil, T.; Adams, D. J.; Mar, F.; Craik, D. J. Peptide Science 2015, 104, 682-692.

[37] Sneader, W. E. Drug discovery (the history); Wiley Online Library, 2005.

[38] others, et al. Cancer research 2003, 63, 1838-1845.

[39] Nishikawa, T.; Isobe, M. The Chemical Record 2013, 13, 286-302.

[40] Muñoz-Alonso, M. J.; González-Santiago, L.; Martínez, T.; Losada, A.; Galmarini, C. M.; Muñoz, A. Current opinion in investigational drugs (London, England: 2000) 2009, 10, 536-542. 
[41] Malve, H. Journal of pharmacy \& bioallied sciences 2016, 8, 83.

[42] Science Learning Hub: Marine Biodiversity in New Zealand. https://www.sciencelearn.org.nz/resources/1120-marine-biodiversity-in-new-zealand (accessed 17/05/2017).

[43] West, L. M.; Northcote, P. T.; Battershill, C. N. Journal of Organic Chemistry 2000, $65,445-449$.

[44] Prota, A. E.; Bargsten, K.; Northcote, P. T.; Marsh, M.; Altmann, K.-H.; Miller, J. H.; Fernando Diaz, J.; Steinmetz, M. O. Angewandte Chemie-International Edition 2014, $53,1621-1625$.

[45] Kanakkanthara, A.; Rowe, M. R.; Field, J. J.; Northcote, P. T.; Teesdale-Spittle, P. H.; Miller, J. H. Cancer Letters 2015, 365, 251-260.

[46] Kanakkanthara, A.; Northcote, P. T.; Miller, J. H. Natural Product Reports 2016, 33, 549-561.

[47] Hood, K. A.; West, L. M.; Rouwe, B.; Northcote, P. T.; Berridge, M. V.; Wakefield, S. J.; Miller, J. H. Cancer Research 2002, 62, 3356-3360.

[48] Miller, J. H.; Singh, A. J.; Northcote, P. T. Marine Drugs 2010, 8, 1059-1079.

[49] Chan, A.; Singh, A. J.; Northcote, P. T.; Miller, J. H. Investigational New Drugs 2015, $33,564-574$.

[50] Chan, A.; Singh, A. J.; Northcote, P. T.; Miller, J. H. Investigational New Drugs 2016, $34,424-438$.

[51] Kanakkanthara, A.; Rawson, P.; Northcote, P. T.; Miller, J. H. Pharmaceutical Research 2012, 29, 3022-3032.

[52] Meyer, C. J.; Krauth, M.; Wick, M. J.; Shay, J. W.; Gellert, G.; De Brabander, J. K.; Northcote, P. T.; Miller, J. H. Molecular Cancer Therapeutics 2015, 14, 1816-1823.

[53] O’Sullivan, D.; Miller, J. H.; Northcote, P. T.; La Flamme, A. C. Immunology and Cell Biology 2013, 91, 583-592.

[54] Kanakkanthara, A.; Eras, J.; Northcote, P. T.; Cabral, F.; Miller, J. H. Current Cancer Drug Targets 2014, 14, 79-90.

[55] Hanna, R.; Maass, D. R.; Atkinson, P. H.; Northcote, P. T.; Teesdale-Spittle, P. H.; Bellows, D. S.; Miller, J. H. Molecular Biosystems 2014, 10, 110-116.

[56] Brackovic, A.; Harvey, J. E. Chemical Communications 2015, 51, 4750-4765.

[57] Northcote, P. T.; Blunt, J. W.; Munro, M. H. Tetrahedron letters 1991, 32, 6411-6414.

[58] Page, M.; West, L.; Northcote, P.; Battershill, C.; Kelly, M. Journal of Chemical Ecology 2005, 31, 1161-1174.

[59] Hood, K. A.; West, L. M.; Northcote, P. T.; Berridge, M. V.; Miller, J. H. Apoptosis 2001, 6, 207-219.

[60] Kuznetsov, G. et al. Molecular Cancer Therapeutics 2009, 8, 1250-1260. 
[61] Matthews, J. H.; Maass, D. R.; Northcote, P. T.; Atkinson, P. H.; Teesdale-Spittle, P. H. Zeitschrift Fur Naturforschung Section C-a Journal of Biosciences 2013, 68, 406415.

[62] Popa, A.; Lebrigand, K.; Barbry, P.; Waldmann, R. Bmc Genomics 2016, 17.

[63] Bordeleau, M.-E.; Cencic, R.; Lindqvist, L.; Oberer, M.; Northcote, P.; Wagner, G.; Pelletier, J. Chemistry \& Biology 2006, 13, 1287-1295.

[64] Dang, Y.; Kedersha, N.; Low, W.-K.; Romo, D.; Gorospe, M.; Kaufman, R.; Anderson, P.; Liu, J. O. Journal of Biological Chemistry 2006, 281, 32870-32878.

[65] Low, W. K.; Dang, Y. J.; Schneider-Poetsch, T.; Shi, Z. G.; Choi, N. S.; Merrick, W. C.; Romo, D.; Liu, J. O. Molecular Cell 2005, 20, 709-722.

[66] Low, W.-K.; Li, J.; Zhu, M.; Kommaraju, S. S.; Shah-Mittal, J.; Hull, K.; Liu, J. O.; Romo, D. Bioorganic \& Medicinal Chemistry 2014, 22, 116-125.

[67] Romo, D.; Rzasa, R. M.; Shea, H. A.; Park, K.; Langenhan, J. M.; Sun, L.; Akhiezer, A.; Liu, J. O. Journal of the American Chemical Society 1998, 120, 1223712254.

[68] Rzasa, R. M.; Shea, H. A.; Romo, D. Journal of the American Chemical Society 1998, 120, 591-592.

[69] Cumming, A. H.; Brown, S. L.; Tao, X.; Cuyamendous, C.; Field, J. J.; Miller, J. H.; Harvey, J. E.; Teesdale-Spittle, P. H. Organic \& Biomolecular Chemistry 2016, 14, 5117-5127.

[70] Chen, R.; Zhu, M.; Chen, Y.; Skillern, W.; Qin, Q.; Wierda, W. G.; Hull, K. G.; Romo, D.; Plunkett, W. Cancer Research 2017, 77.

[71] Association of Molecular Pathology v. Myriad Genetics, Inc., 569 U.S. 12398 (U.S. Supreme Court 2013).

[72] Mayo v. Prometheus, 132 U.S 1289, (US Supreme Court 2012).

[73] Diamond v. Chakrabarty, 447 U.S 303, (U.S. Supreme Court 1980).

[74] Wong, A. Y.-T.; Chan, A. W.-K. Chinese Medicine 2014, 9.

[75] Hall, J.; Lee, M.; Newman, B.; Morrow, J.; Anderson, L.; Huey, B.; King, M. Science 1990, 250, 1684-1689.

[76] Miki, Y.; Swensen, J.; Shattuck-Eidens, D.; Futreal, P.; Harshman, K.; Tavtigian, S.; Liu, Q.; Cochran, C.; Bennett, L.; Ding, W.; et, a. Science 1994, 266, 66-71.

[77] Skolnick, M.; Goldgar, D.; Miki, Y.; Swenson, J.; Kamb, A.; Harshman, K.; ShattuckEidens, D.; Tavtigian, S.; Wiseman, R.; Futreal, P. 17Q-linked breast and ovarian cancer susceptibility gene. US 5,747,282, August 12, 1994.

[78] Tavtigian, S.; Kamb, A.; Simard, J.; Couch, F.; Rommens, J.; Weber, B. Chromosome 13-linked breast cancer susceptibility gene. US 5,837,492, December 18, 1995.

[79] Shattuck-Eidens, D.; Simard, J.; Durocher, F.; Emi, M.; Nakamura, Y. Linked breast and ovarian cancer susceptibility gene. US 5,693,473, August 12, 1994. 
[80] Shattuck-Eidens, D.; Simard, J.; Durocher, F.; Emi, M.; Nakamura, Y. Linked breast and ovarian cancer susceptibility gene. US 5,709,999, August 12, 1994.

[81] Skolnick, M.; Goldgar, D.; Miki, Y.; Swenson, J.; Kamb, A.; Harshman, K.; ShattuckEidens, D.; Tavtigian, S.; Wiseman, R.; Futreal, P. 17q-linked breast and ovarian cancer susceptibility gene. US 5,710,001, August 12, 1994.

[82] Skolnick, M.; Goldgar, D.; Miki, Y.; Swenson, J.; Kamb, A.; Harshman, K.; ShattuckEidens, D.; Tavtigian, S.; Wiseman, R.; Futreal, P. 170-linked breast and ovarian cancer susceptibility gene. US Patent 5,753,441, August 12, 1994.

[83] Tavtigian, S.; Kamb, A.; Simard, J.; Couch, F.; Rommens, J.; Weber, B. Chromosome 13-linked breast cancer susceptibility gene. US Patent 6,033,857, December 18, 1995.

[84] Parke-Davis \& Co. v. H.K. Mulford Co., 189 F. 95, (S.D.N.Y 1911).

[85] Merck \& Co., v. Olin Mathieson Chem Corp., 253 F.2d 156 (4th Cir 1958).

[86] Funk Brothers Seed Co. v. Kalo Inoculant Co., 333 U.S. 127, (U.S. Supreme Court 1948).

[87] General Electric Co. v. De Forest Radio Co., 28 F.2d 641, (3rd Cir 1928).

[88] Bucar, F.; Wube, A.; Schmid, M. Natural Product Reports 2013, 30, 525-545.

[89] Rakshith, D.; Santosh, P.; Pradeep, T. P.; Gurudatt, D. M.; Baker, S.; Rao, H. C. Y.; Pasha, A.; Satish, S. Chromatographia 2016, 79, 1625-1642.

[90] Ciesla, L.; Moaddel, R. Natural Product Reports 2016, 33, 1131-1145.

[91] Gerwick, W. H.; Moore, B. S. Chemistry \& Biology 2012, 19, 85-98.

[92] Watrous, J.; Roach, P.; Alexandrov, T.; Heath, B. S.; Yang, J. Y.; Kersten, R. D.; van der Voort, M.; Pogliano, K.; Gross, H.; Raaijmakers, J. M.; Moore, B. S.; Laskin, J.; Bandeira, N.; Dorrestein, P. C. Proceedings of the National Academy of Sciences 2012, 109, E1743E1752.

[93] Cuperlovic-Culf, M.; Culf, A. S. Expert Opinion on Drug Discovery 2016, 11, 759770.

[94] Wang, Nature biotechnology 2016, 34, 828-837.

[95] Nakamura, H.; Kobayashi, J.; Ohizumi, Y.; Hirata, Y. Tetrahedron Letters 1982, 23, 5555-5558.

[96] Rudi, A.; Kashman, Y. Tetrahedron letters 1993, 34, 4683-4684.

[97] Tinto, W. F. Heterocycles 1998, 48, 2089-2093.

[98] Aoki, S.; Kong, D.; Suna, H.; Sowa, Y.; Sakai, T.; Setiawan, A.; Kobayashi, M. Biochemical and biophysical research communications 2006, 342, 101-106.

[99] Yu, H.-B.; Yang, F.; Sun, F.; Li, J.; Jiao, W.-H.; Gan, J.-H.; Hu, W.-Z.; Lin, H.-W. Marine drugs 2014, 12, 6003-6013.

[100] Souza, T. M. L.; Abrantes, J. L.; Epifanio, R. d. A.; Fontes, C. F. L.; Frugulhetti, I. C. Planta medica 2007, 73, 200-205. 
[101] Bowling, J. J.; Pennaka, H. K.; Ivey, K.; Wahyuono, S.; Kelly, M.; Schinazi, R. F.; Valeriote, F. A.; Graves, D. E.; Hamann, M. T. Chemical biology \& drug design 2008, $71,205-215$.

[102] Dyshlovoy, S. A.; Fedorov, S. N.; Shubina, L. K.; Kuzmich, A. S.; Bokemeyer, C.; Keller-von Amsberg, G.; Honecker, F. BioMed research international 2014, 2014.

[103] Dyshlovoy, S. A.; Venz, S.; Shubina, L. K.; Fedorov, S. N.; Walther, R.; Jacobsen, C.; Stonik, V. A.; Bokemeyer, C.; Balabanov, S.; Honecker, F. Journal of proteomics 2014, 96, 223-239.

[104] Yu, H.-B.; Yang, F.; Sun, F.; Ma, G.-Y.; Gan, J.-H.; Hu, W.-Z.; Han, B.-N.; Jiao, W.H.; Lin, H.-W. Journal of natural products 2014, 77, 2124-2129.

[105] others,, et al. Anti-Cancer Agents in Medicinal Chemistry (Formerly Current Medicinal Chemistry-Anti-Cancer Agents) 2015, 15, 291-297.

[106] Essack, M.; Bajic, V. B.; Archer, J. A. Marine drugs 2011, 9, 1580-1606.

[107] Tsukamoto, S.; Yamanokuchi, R.; Yoshitomi, M.; Sato, K.; Ikeda, T.; Rotinsulu, H.; Mangindaan, R. E.; de Voogd, N. J.; van Soest, R. W.; Yokosawa, H. Bioorganic \& medicinal chemistry letters 2010, 20, 3341-3343.

[108] Nakao, Y.; Kawatsu, S.; Okamoto, C.; Okamoto, M.; Matsumoto, Y.; Matsunaga, S.; van Soest, R. W.; Fusetani, N. Journal of natural products 2008, 71, 469-472.

[109] Liu, C.; Tang, X.; Li, P.; Li, G. Organic letters 2012, 14, 1994-1997.

[110] Li, Z.; Peng, C.; Shen, Y.; Miao, X.; Zhang, H.; Lin, H. Biochemical Systematics and Ecology 2008, 36, 230-234.

[111] Do, M. N.; Erickson, K. L.

[112] Becerro, M. A.; Thacker, R. W.; Turon, X.; Uriz, M. J.; Paul, V. J. Oecologia 2003, 135, 91-101.

[113] Huang, R.-M.; Yi, X.-X.; Zhou, Y.; Su, X.; Peng, Y.; Gao, C.-H. Marine drugs 2014, $12,6213-6235$.

[114] Borthwick, A. D. Chemical reviews 2012, 112, 3641-3716.

[115] Braganza, C. D. Validation of a Spectroscopic Screening Method for Secondary Metabolites from New Zealand Extremophilic Microbes. MBmedSc. Thesis, VUW. 2014.

[116] Tzin, V.; Galili, G. The Arabidopsis Book 2010, e0132.

[117] Kim, K.; Kim, N.-J.; Kim, S. Y.; Kim, I. H.; Kim, K.-S.; Lee, G. R. Infection and immunity 2015, 83, 1150-1161.

[118] Park, D.-K.; Lee, K.-E.; Baek, C.-H.; Kim, I. H.; Kwon, J.-H.; Lee, W. K.; Lee, K.-H.; Kim, B.-S.; Choi, S.-H.; Kim, K.-S. Journal of bacteriology 2006, 188, 2214-2221.

[119] Lee, K.; Jeong, J. E.; Kim, I. H.; Kim, K.-S.; Ju, B.-G. Journal of cellular and molecular medicine 2015, 19, 2851-2864. 
[120] Ström, K.; Sjögren, J.; Broberg, A.; Schnürer, J. Applied and environmental microbiology 2002, 68, 4322-4327.

[121] Yang, H.; Zheng, F.; Xiao, W.; Xie, S. Science China Earth Sciences 2015, 58, 10051017.

[122] Guella, G.; Mancini, I.; Pietra, F. Helv. Chim. Acta 1987, 70, 1400-1411.

[123] Gonthier, I. Tetrahedron Lett. 2001, 42, 2795-2797.

[124] Perry, N. B.; Becker, E. G.; Blunt, J. W.; Lake, R. J.; Munro, M. H. G. J. Nat. Prod. 1990, 53, 732-734.

[125] Lee, S.; Zhao, Q.; Choi, K.; Hong, J.; Lee, D. S.; Lee, C.; Jung, J. H. Nat. Prod. Sci. 2003, 9, 232-234.

[126] Pettit, G. R.; Fujii, Y. J. Nat. Prod. 1982, 45, 640-643.

[127] M.D’Ambrosio, F., A.Guerriero Experientia 1996, 52, 624-627.

[128] Seo, Y.; Cho, K. W.; Lee, H. S.; Rho, J. R.; Shin, J. J. Nat. Prod. 1999, 62, 122-126.

[129] Kinashi, N.; Fujiwara, K.; Tsunoda, T.; Katoono, R.; Kawai, H.; Suzuki, T. Tetrahedron Lett. 2013, 54, 4564-4567.

[130] Meimetis, L. G.; Williams, D. E.; Mawji, N. R.; Banuelos, C. A.; Lal, A. A.; Park, J. J.; Tien, A. H.; Fernandez, J. G. J. Med. Chem. 2012, 55, 503-514.

[131] Cardellina, J. H.; Graden, C. J.; Greer, B. J.; Kern, J. R. Lipids 1983, 18, 107-110.

[132] Guella, G.; Mancini, I.; Pietra, F. Helv. Chim. Acta 1989, 72, 1121-1124.

[133] Santos, V. L.; Billett, D. S.; Wolff, G. A. Journal of the Brazilian Chemical Society 2002, 13, 653-657.

[134] Stocker, B. L.; Khan, A. A.; Chee, S. H.; Kamena, F.; Timmer, M. S. ChemBioChem 2014, 15, 382-388.

[135] Matsunaga, I.; Moody, D. B. Journal of Experimental Medicine 2009, 206, 28652868.

[136] Kodar, K.; Eising, S.; Khan, A. A.; Steiger, S.; Harper, J. L.; Timmer, M. S.; Stocker, B. L. ChemBioChem 2015, 16, 683-693.

[137] West, L. M. The Isolation of Secondary Metabolites from New Zealand Marine Sponges, PhD Thesis, 2001.

[138] Blunt, J. W.; Calder, V. L.; Fenwick, G. D.; Lake, R. J.; McCombs, J. D.; Munro, M. H.; Perry, N. B. Journal of natural products 1987, 50, 290-292. 